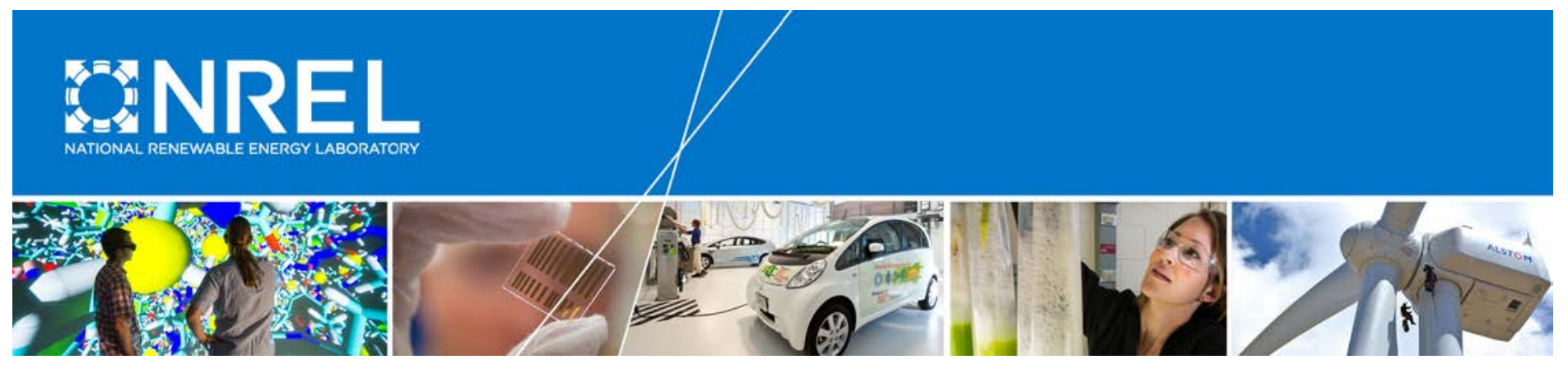

\title{
GeneratorSE: A Sizing Tool for Variable-Speed Wind Turbine Generators
}

Latha Sethuraman and Katherine Dykes National Renewable Energy Laboratory

NREL is a national laboratory of the U.S. Department of Energy Office of Energy Efficiency \& Renewable Energy Operated by the Alliance for Sustainable Energy, LLC

This report is available at no cost from the National Renewable Energy Laboratory (NREL) at www.nrel.gov/publications.

Technical Report

NREL/TP-5000-66462

September 2017

Contract No. DE-AC36-08G028308 


\title{
GeneratorSE: A Sizing Tool for Variable-Speed Wind Turbine Generators
}

\author{
Latha Sethuraman and Katherine Dykes \\ National Renewable Energy Laboratory
}

Prepared under Task No. WE16.3F01

NREL is a national laboratory of the U.S. Department of Energy Office of Energy Efficiency \& Renewable Energy Operated by the Alliance for Sustainable Energy, LLC

This report is available at no cost from the National Renewable Energy Laboratory (NREL) at www.nrel.gov/publications.

National Renewable Energy Laboratory 15013 Denver West Parkway Golden, CO 80401

303-275-3000 • www.nrel.gov

\section{Technical Report}

NREL/TP-5000-66462

September 2017

Contract No. DE-AC36-08GO28308 


\section{NOTICE}

This report was prepared as an account of work sponsored by an agency of the United States government. Neither the United States government nor any agency thereof, nor any of their employees, makes any warranty, express or implied, or assumes any legal liability or responsibility for the accuracy, completeness, or usefulness of any information, apparatus, product, or process disclosed, or represents that its use would not infringe privately owned rights. Reference herein to any specific commercial product, process, or service by trade name, trademark, manufacturer, or otherwise does not necessarily constitute or imply its endorsement, recommendation, or favoring by the United States government or any agency thereof. The views and opinions of authors expressed herein do not necessarily state or reflect those of the United States government or any agency thereof.

This report is available at no cost from the National Renewable Energy Laboratory (NREL) at www.nrel.gov/publications.

Available electronically at SciTech Connect http:/www.osti.gov/scitech

Available for a processing fee to U.S. Department of Energy and its contractors, in paper, from:

U.S. Department of Energy

Office of Scientific and Technical Information

P.O. Box 62

Oak Ridge, TN 37831-0062

OSTI http://www.osti.gov

Phone: 865.576.8401

Fax: 865.576.5728

Email: reports@osti.gov

Available for sale to the public, in paper, from:

U.S. Department of Commerce

National Technical Information Service

5301 Shawnee Road

Alexandria, VA 22312

NTIS http://www.ntis.gov

Phone: 800.553 .6847 or 703.605 .6000

Fax: 703.605.6900

Email: orders@ntis.gov 


\section{Acknowledgements}

This work was supported by the U.S. Department of Energy under contract number DE-UGA-0-41026-00 with the National Renewable Energy Laboratory. Funding for the work was provided by the DOE Office of Energy Efficiency and Renewable Energy, Wind Energy Technologies Office. The authors would like to thank Michael Maness (analyst, National Renewable Energy Laboratory, Strategic Energy Analysis Center) for his inputs on cost modeling, Cameron P. Reagor (principal mechanical engineer, Motorized R\&D, SharkNinja) and Haran Karmaker (principal scientist, Teco Westinghouse) for their expert review on synchronous machines. 


$\begin{array}{ll}\text { List of Acronyms } \\ \text { DFIG } & \text { doubly-fed induction generator } \\ \text { EESG } & \text { electrically excited synchronous generator } \\ \text { MW } & \text { megawatt } \\ \mathrm{m} & \text { meter } \\ \mathrm{mm} & \text { millimeter } \\ \text { MW } & \text { megawatt } \\ \text { NREL } & \text { National Renewable Energy Laboratory } \\ \text { NWTC } & \text { National Wind Technology Center } \\ \text { PMSG } & \text { permanent-magnet synchronous generator } \\ \text { rpm } & \text { revolutions per minute } \\ \text { SCIG } & \text { squirrel-cage induction generator }\end{array}$




\section{Table of Contents}

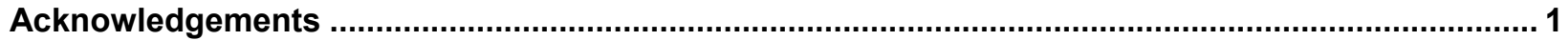

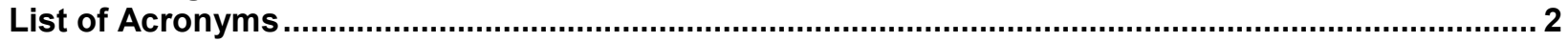

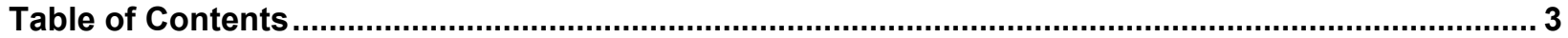

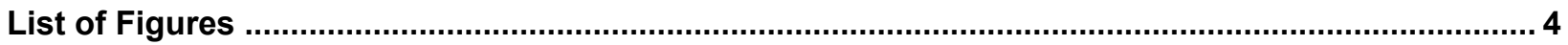

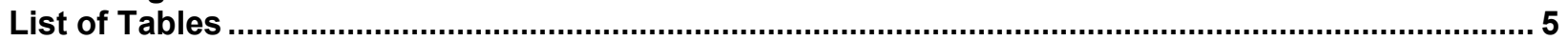

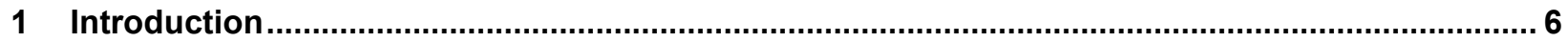

2 Generator Sizing Models and Optimization Algorithm ......................................................... 8

2.1 Optimization Criteria and Objective Function ............................................................ 10

2.2 Synchronous Generator: Permanent-Magnet Machine .................................................... 11

2.3 Electrically Excited Synchronous Generator............................................................... 32

2.4 Asynchronous Generator: Squirrel Cage Rotor Induction Generators (SCIG-3G) ..................45

2.5 Asynchronous Generators: Doubly-Fed Induction Generators(DFIG) ............................... 57

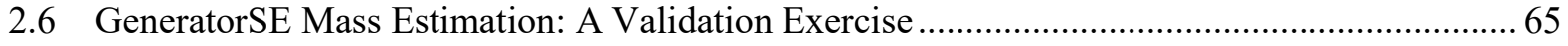

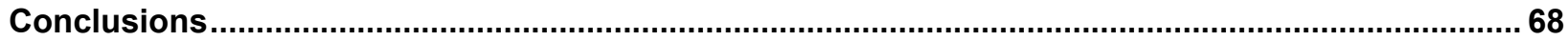

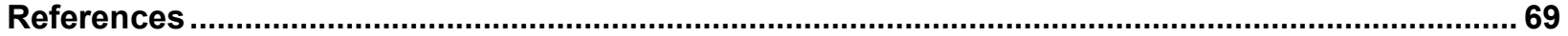

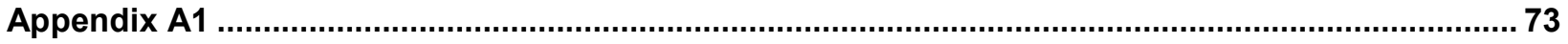

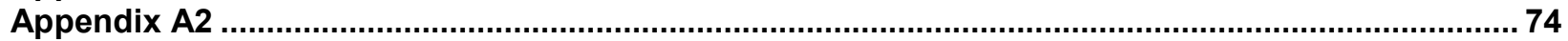

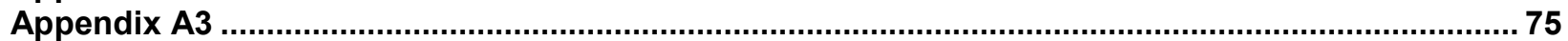

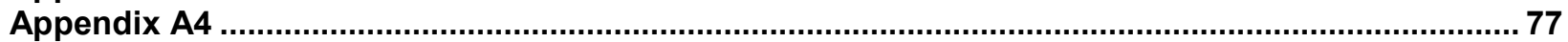

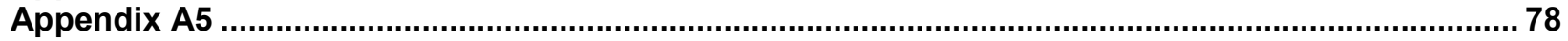

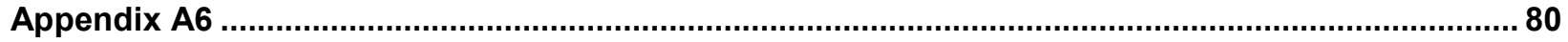

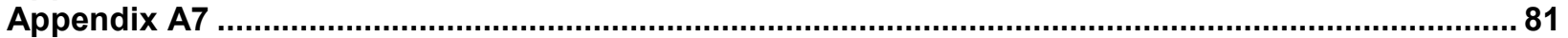

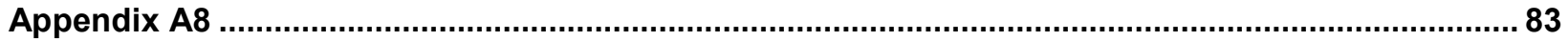

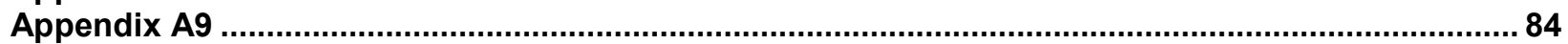

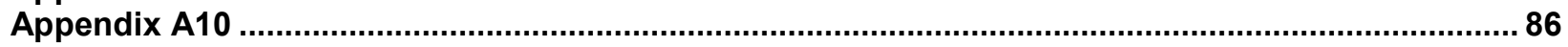

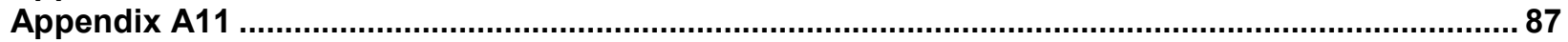




\section{List of Figures}

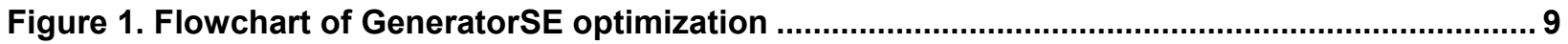

Figure 2. Parts and dimensions of a radial-flux permanent-magnet generator................................. 11

Figure 3. Equivalent circuit model and phasor diagram of a permanent-magnet synchronous

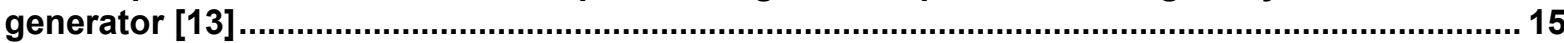

Figure 4. Generator support structures: (a) spoked arms, (b) spoked arm stator and disc rotor, and (c) loads acting on the structural support; reproduced from [21] ...................................... 18

Figure 5. Structural design variables for the (a) spoke arm and (b) disc construction..................... 19

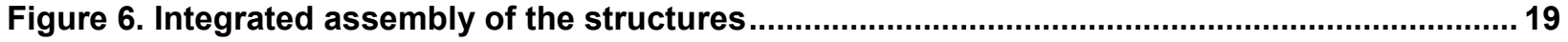

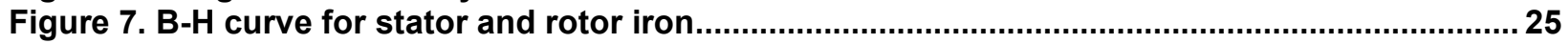

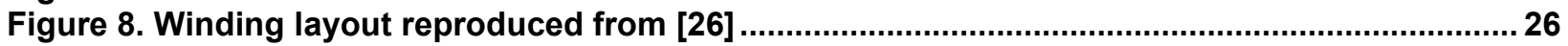

Figure 9. The 5-MW PMSG model in FEMM showing the: (a) finite-element mesh, (b) magnetic flux density contour, and (c) a comparison of air-gap flux density estimated using FEMM

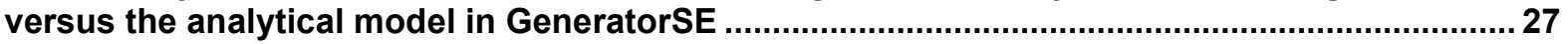

Figure 10. Components of structural deflection computed in ANSYS ............................................ 29

Figure 11. Components of structural deflection computed in ANSYS ............................................. 31

Figure 12. Basic design of an EESG: (a) design dimensions (b) CAD illustration............................ 32

Figure 13. Equivalent circuit model and phasor diagram of an EESG [13]..................................... 33

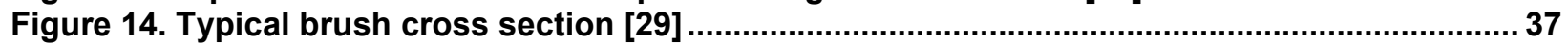

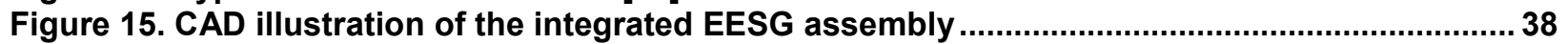

Figure 16. The 5-MW EESG model using FEMM showing (a) the finite-element mesh, (b) magnetic flux density contour, and (c) a comparison of air-gap flux density estimated using FEMM and analytical model in GeneratorSE...

Figure 17. Stator winding layout in EESG reproduced from [26] ............................................... 43

Figure 18. Components of structural deflection for the 5-MW EESG computed in ANSYS .............. 44

Figure 19. Basic design of an SCIG: design dimensions (a), end-ring section (b), and CAD illustration (c)

Figure 20. End winding geometry [33]

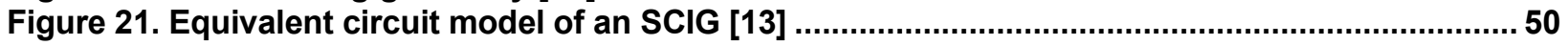

Figure 22. Stator winding layout of the SCIG reproduced from [26] ............................................... 55

Figure 23. The 5-MW SCIG in FEMM showing the finite-element mesh (a), magnetic flux density contour (b), and the comparison of air-gap flux density estimated using FEMM vs. GeneratorSE (c)

Figure 24. Basic design of a DFIG; design dimensions (a) and CAD illustration (b) ......................57

Figure 25. Stator winding layout in the DFIG reproduced from [26]: stator (a) and the rotor (b) ..... 63

Figure 26. The 5-MW DFIG model using FEMM showing the finite-element mesh (a), the magnetic flux density contour (b), and a comparison of the air-gap flux density estimated using FEA and GeneratorSE (c)...

Figure 27. PMSG mass estimates for turbines rated between 0.75 and $10 \mathrm{MW}$; GeneratorSE vs.

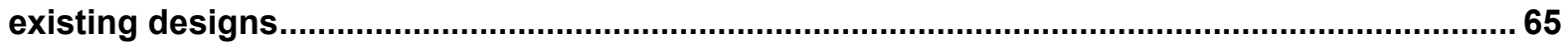

Figure 28. EESG mass estimates for turbines rated between 0.75 and $10 \mathrm{MW}$; GeneratorSE vs. existing designs.................................................................................................................. 66

Figure 29. SCIG mass estimates for turbines rated between 0.75 and $10 \mathrm{MW}$; GeneratorSE vs.

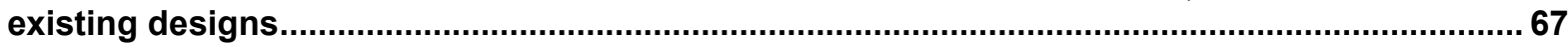

Figure 30. DFIG mass estimates for turbines rated between 0.75 and $10 \mathrm{MW}$; GeneratorSE vs.

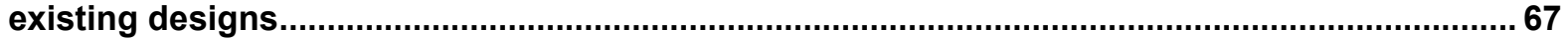




\section{List of Tables}

Table 1. Design Parameters of the Permanent-Magnet Synchronous Generator ............................ 11

Table 2. Specific Costs and Densities for Different Materials ..................................................... 17

Table 3. Design Parameters for the PMSG Structural Model........................................................ 19

Table 4. Structural Deflection Models of the PMSG .................................................................... 20

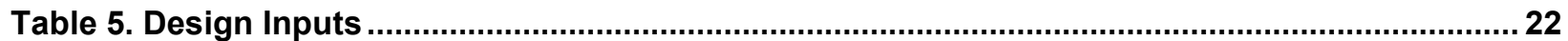

Table 6. Electromagnetic Design and Performance Variables in PMSG ....................................... 22

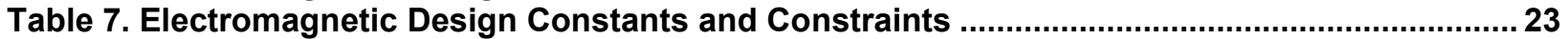

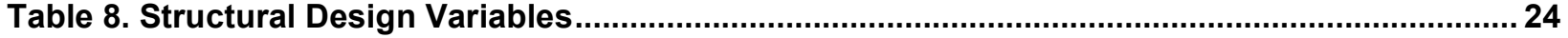

Table 9. Structural Design Constraints, Constants, and Fixed Relations...................................... 24

Table 10. Comparison of Magnetic Loading in a PMSG (FEA vs. GeneratorSE).............................. 28

Table 11. Comparison of Structural Deflections: GeneratorSE vs. ANSYS for Arm-Arm-Type

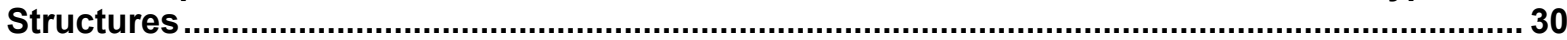

Table 12. Comparison of Structural Deflections: GeneratorSE vs. ANSYS for Arm-Disc-Type

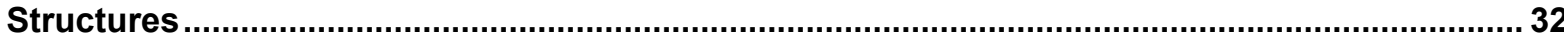

Table 13. Electromagnetic Design and Performance Variables in EESG ........................................40

Table 14. Electromagnetic Design Constants and Constraints for EESG ......................................40

Table 15. Comparison of Magnetic Loading in EESG (FEA vs. GeneratorSE) ................................. 43

Table 16. Comparison of Structural Deflections: GeneratorSE vs. ANSYS for Arm-Type

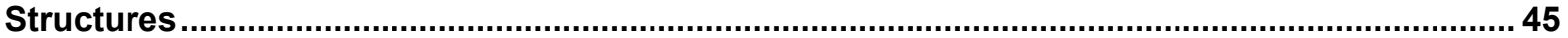

Table 17. Electromagnetic Design and Performance Variables in an SCIG.....................................53

Table 18. Electromagnetic Design Constants and Constraints for an SCIG ...................................5 54

Table 19. Comparison of Magnetic Loading in the SCIG (FEA vs. GeneratorSE) ........................... 57

Table 20. Electromagnetic Design and Performance Variables in the DFIG....................................61

Table 21. Electromagnetic Design Constants and Constraints for the DFIG ................................62

Table 22. Comparison of Magnetic Loading in the DFIG (FEA vs. GeneratorSE) ...........................63

Table A1. Constants and Parameters Used in Deflection Calculations for a Permanent-Magnet excited and Electrically Excited Synchronous Generator (Based on references [21,22]) ..........73

Table A2. Initial Values and Boundary Conditions Used for Generation of Spoked-Arm-Type Permanent Magnet Synchronous Generators

Table A3. Optimized Dimensions for spoked arm-Type Permanent Magnet Synchronous Generators.

Table A4. Initial Values and Boundary Conditions Used for Generation of Disc-Arm-Type Permanent Magnet Synchronous Generators.

Table A5. Optimized Dimensions for Disc-Arm-Type Permanent Magnet Synchronous Generators

Table A6. Initial Values and Boundary Conditions Used for Generation of the Designs for Electrically Excited Synchronous Generators

Table A7. Optimized Designs for Electrically Excited Synchronous Generators ............................. 81

Table A8. Initial Values and Boundary Conditions Used for Generation of the Designs for

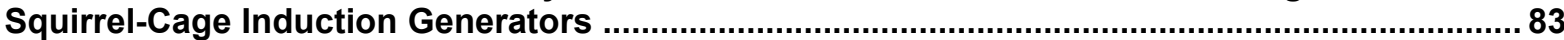

Table A9. Optimized Designs for Squirrel-Cage Induction Generators .......................................... 84

Table A10. Initial Values and Boundary Conditions Used for Generation of the Designs for Doubly-Fed Induction Generators

Table A11. Optimized Designs for Doubly-Fed Induction Generators 87 


\section{Introduction}

In the past decade, the wind industry has witnessed significant levels of innovation, resulting in the development of larger, multimegawatt turbines aimed at achieving lower associated costs of energy. Yet, increasing their competitiveness within the energy sector compared to conventional power sources imposes more requirements on the technology in terms of performance, reliability, and cost. As a result, the industry has been focusing on a variety of goals including trading off installed capital costs for the turbine and plant, costs for operation and maintenance (O\&M), energy production, and negative external impacts such as noise emission or habitat disruption [1].

Wind turbine drivetrains serve the fundamental role of converting the aerodynamic torque from the turbine into useful electrical power that can be fed to the power grid. Within the turbine drivetrain, the electrical generator is an important functional element that enables the conversion of energy and is a key determinant of the overall efficiency, reliability, and costs of energy production. In gear-driven systems, the generator is the third most expensive element (after the gearbox and power converters [2]), whereas in direct-driven systems, the generator is the single biggest cost component that challenges their upscaling potential.

As part of the National Renewable Energy Laboratory's (NREL's) Wind-Plant Integrated System Design and Engineering Model development effort aimed at providing sizing and costing pathways for various subsystems within the wind turbine, GeneratorSE is a new modeling capability developed by NREL specifically intended for optimizing variable-speed wind turbine generators. GeneratorSE provides users with the ability to customize the generator design, thereby satisfying certain design requirements. As a result, users can achieve optimal performance of the entire wind turbine drivetrain by negotiating certain fundamental, interdependent factors such as weight, cost, and efficiency to meet the wind turbine original equipment manufacturer's objectives.

GeneratorSE can be used as an autonomous tool that focuses on generator design or integrated in the system using DriveSE, NREL's drivetrain sizing tool [3]. Thus, the designer has the option to trade magnet, copper, or lamination properties and weights to achieve the optimal generator design that is also optimal for a given drivetrain system. Two types of generator systemssynchronous and induction machines - are currently being handled by GeneratorSE. The tool includes the following subclasses: permanent-magnet synchronous generators (PMSGs) electrically excited synchronous generators (EESGs), squirrel-cage induction generators (SCIGs), and doubly-fed induction generators (DFIGs).

This report documents a set of analytical models employed by the optimization algorithms within the GeneratorSE framework. The initial values and boundary conditions employed for the generation of the various designs and initial estimates for basic design dimensions, masses, and efficiency for the four different models of generators are presented and compared with empirical data collected from previous studies and some existing commercial turbines. These models include designs applicable for variable-speed, high-torque application featuring direct-drive synchronous generators and low-torque application featuring induction generators. In all of the four models presented, the main focus of optimization is electromagnetic design with the exception of permanent-magnet and wire-wound synchronous generators, wherein the structural design is also optimized. Thermal design is accommodated in GeneratorSE as a secondary attribute by limiting the winding current densities to acceptable limits. A preliminary validation 
of electromagnetic design was carried out by comparing the optimized magnetic loading against those predicted by numerical simulation in FEMM4.2 [4], a finite-element software for analyzing electromagnetic and thermal physics problems for electrical machines. For direct-drive synchronous generators, the analytical models for the structural design are validated by static structural analysis in ANSYS [5]. 


\section{Generator Sizing Models and Optimization Algorithm}

GeneratorSE is a sizing tool based on OpenMDAO (an open-source high-performance computing platform [6]) that is comprised of a combination of analytical tools involving electromagnetic, structural, and basic thermal design that are integrated to provide the optimal generator design dimensions using conventional magnetic circuit laws. The sizing tool mainly considers available torque, mechanical power, normal and shear stresses, material properties, and costs to customize designs of variable-speed wind turbine generators by satisfying specific design criteria. Specifically, GeneratorSE:

- Integrates electromagnetic, structural, and basic thermal designs of the generator and provides the optimal design dimensions by trading off active and inactive materials to satisfy certain fundamental and interdependent factors, such as weight, costs, or efficiency

- Contains two modules featuring synchronous machines (PMSG and EESG) and two modules featuring induction machines (squirrel cage and DFIG)

- Provides basic design attributes in addition to key electrical performance parametersincluding, but not limited to, output voltage, current, resistances, inductances, and lossesand also the weights and costs of materials involved in the basic design

- Allows for an integrated design with DriveSE [3] and NREL's Cost and Scaling Model [7], thereby enabling a complete drivetrain optimization of direct-drive, medium-speed, and highspeed geared systems considering the entire turbine system and balance of plant

- Enables drivetrain design coupled with the turbine rotor and tower for a full integrated wind turbine design or even wind plant cost of energy optimization as part of the Wind Plant Integrated Systems Design and Engineering Model[8] (WISDEM ${ }^{\mathrm{TM}}$ ).

The optimization algorithm illustrated in Figure 1 involves the simultaneous treatment of structural design, electromagnetic design, and basic thermal design — to satisfy a certain objective function. The analytical models of each generator module were created in Python [9], which allow for optimal design using various optimization algorithms. The objective function for the optimization may be overall cost, efficiency, mass, or a weighted combination of these three. If only one of the three objective functions (cost, weight, or efficiency) is chosen, then constraints may be applied to ensure minimum performance for the other objectives.

As a first step, the user can choose the type of generator that needs to be optimized along with the optimization goal. Each generator subset is identified by a design space that contains decision variables based on which the design is most sensitive (e.g., the air-gap radius and core length are design variables that determine the air-gap volume required to generate the torque), and the optimal design is searched by mathematical methods (linear and nonlinear programming or evolutionary plans based on genetic algorithms).

The key inputs for each design generation include the power rating, torque, rated speed, shear stress, specific costs (i.e., unit costs per kilogram of material), and properties of materials (e.g., material density, magnetic field strength, resistivity) used in the basic design. The designs are generated in compliance with the user-specified constraints on generator terminal voltage and constraints imposed on the dimensions and electromagnetic performance. This approach provides a reasonable estimate on the excitation requirement (e.g., magnetization current or magnet dimensions) that results in a required voltage at no-load. The magnetically required 
minimum generator dimensions are derived from initial design variables and then used to evaluate design-specific requirements on performance including electrical and magnetic loading.

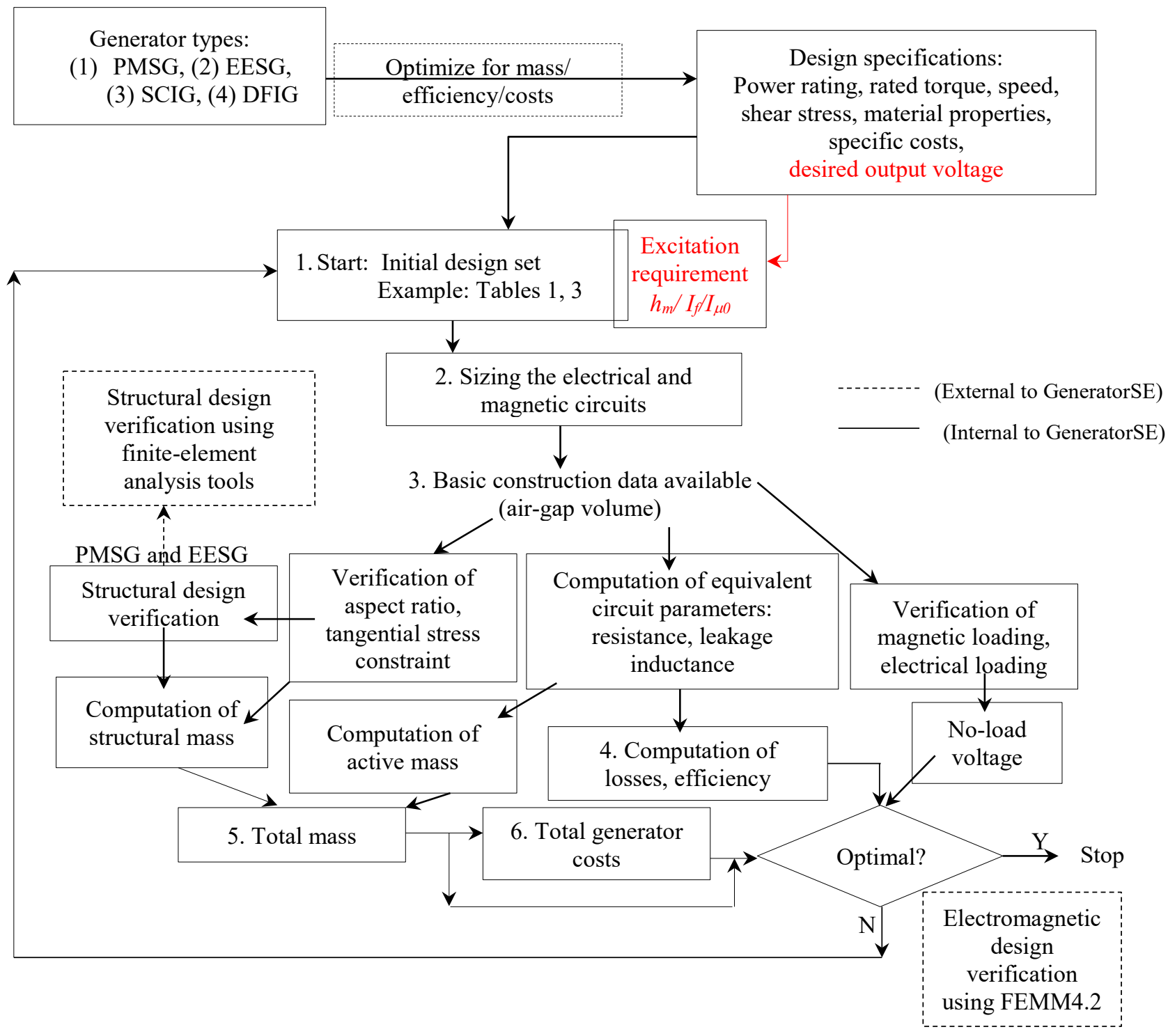

Figure 1. Flowchart of GeneratorSE optimization

At a minimum, verification of the structural design ensures that it overcomes tangential stress and produces the required electromagnetic torque. A more rigorous treatment of the structural design is implemented for direct-drive synchronous generators that ensures that the structural stiffness meets the deflection criteria. When the main dimensions are known, detailed dimensions of conductors and cores are worked out based on the allowed electric and magnetic loading.

The calculation of electrical equivalent circuit parameters (e.g., resistances, inductances) and various loss components constitute the next step. The mass and cost estimates of materials involved in the basic design, together with efficiency, are used to determine the optimal design. Starting with an initial set of variables, the designs are computed analytically and checked against predefined constraints to meet objective functions. The iteration is repeated until all the 
performance objectives are met and the objective function is minimized (cost or mass) or maximized (efficiency). The process may be done with the user in the loop and in that case, requires reinitializing the variables (step [1] or [3]) when the chosen construction data are altered. The optimized design dimensions are available in an output file in a Microsoft Excel format. A supplementary feature of GeneratorSE is the interface with FEMM4.2 [4] (an opensource finite-element program for solving low-frequency electromagnetic problems on twodimensional planar and axisymmetric domains) through MATLAB, which allows the designer to verify the electromagnetic design. The optimized design dimensions can be used to automate a two-dimensional (2-D) finite-element mesh creation and solve for an electromagnetic field solution. In the following sections, each generator design is discussed with relevant analytical models, performance criteria, design constraints, and limits. The designs are validated against commercial tools.

\subsection{Optimization Criteria and Objective Function}

As turbines grow in size, the design requirements tend to become more stringent in terms of the top-head mass that can be accommodated and limitations associated with the assembly and transport of components. Although high efficiency and adequate system performance of wind turbines are prerequisites, high reliability, less weight, and low costs are key to their success. Moreover, wind farm developers aim to retrieve the capital costs through increased energy yields within shorter time spans and decrease the cost of energy by reducing the need for maintenance. GeneratorSE enables the preliminary design of generators, which satisfies these requirements and helps define the design sensitivities to differing objectives.

Like most technical systems, generator design is inherently multiobjective. By this, we mean that there are many goals for the design that we would like to simultaneously meet but trade-offs exist between them. By exploring the design space for the performance of several design objectives (i.e., performance and cost), a set of designs will emerge as Pareto superior to all the others (Pareto superior is a state based on the criteria in which one parameter is improved without causing a negative effect on a different parameter). The solution to the problem is not unique and usually an infinite set of Pareto points (optimal solutions wherein further improvements in a design objective are not possible without compromising another performance metric). For GeneratorSE, a number of choices exist for the objective function and ultimately depend on the user input. Examples include:

- Maximization of the efficiency (or annual energy output in a full turbine model) with costs and mass either constrained or unconstrained

- Minimizing the mass in which the efficiency of the generator is constrained to some lower bound

- Minimizing the costs in which the efficiency of the generator is constrained to be above some lower bound

- Optimizing the aspect ratio while constraining the other design features of efficiency, mass or cost

- Optimizing for cost of energy, within a full wind plant WISDEM model, wherein the efficiency impacts energy production, the mass affects the cost of other turbine components and the installation costs, the aspect ratio affects the installation costs and the overall costs 
affect the turbine capital costs. These cost components combine together into a cost of energy equation as a single objective.

The latter objective is not treated explicitly in this report because it requires the integration of GeneratorSE with the larger set of system models. The analytical models for the different generator types and the optimization objectives are discussed in the following sections.

\subsection{Synchronous Generator: Permanent-Magnet Machine}

Various types of generator design configurations and topologies exist for permanent-magnet synchronous generators depending on the direction of the flux path [10]. A radial-flux, surfacemounted, PMSG of inner-rotor-type construction was assumed for deriving the geometric and electromagnetic properties of the generator. Optimizing the generator design required a simultaneous treatment of structural and electromagnetic models. Figure 2 shows the simplified cross section and the active and structural parts of the generator. Analytical methods based on the magnetic circuit and equivalent circuit models as described in some previous work and generator design handbooks [11-13] were used to evaluate the main design parameters, including the active and inactive material.

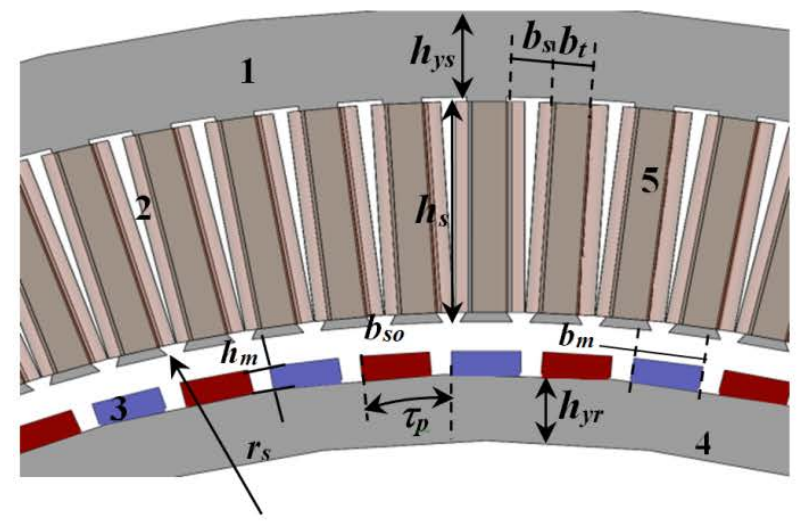

1. Stator yoke

2. Winding

3. Magnet

4. Rotor yoke

5. Stator tooth

6. Rotor wheel spider

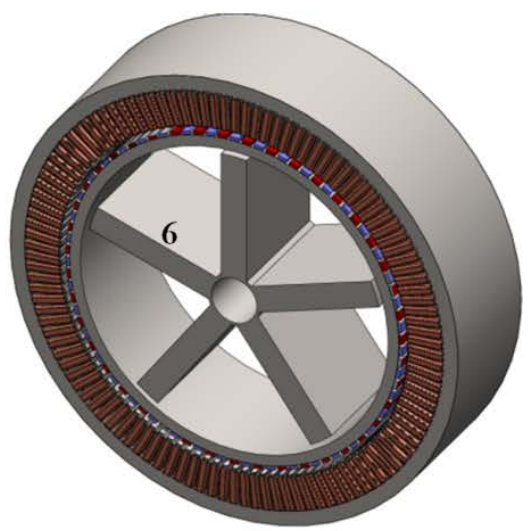

Figure 2. Parts and dimensions of a radial-flux permanent-magnet generator

Table 1. Design Parameters of the Permanent-Magnet Synchronous Generator

\begin{tabular}{llll}
\hline \hline Symbol & Design Dimension & Symbol & Design Dimension \\
\hline \hline$r_{s}$ & Air-gap radius & $g$ & Mechanical air-gap length \\
$h_{s}$ & Slot height & $b_{t}$ & Tooth width \\
$b_{s}$ & Slot width & $h_{y r}$ & Rotor yoke height \\
$h_{y s}$ & Stator yoke height & $\tau_{s}$ & Slot pitch \\
$\tau_{p}$ & Pole pitch & $h_{m}$ & Magnet height \\
$b_{m}$ & Magnet width & & \\
\hline
\end{tabular}

\subsubsection{Sizing Equations}

To determine the main generator parameters for the active part, we used analytical models derived from conventional magnetic circuit laws. In the following section, only the main design equations used for defining the basic dimensions (as illustrated in Figure 1 and Table 1) are presented. The equivalent circuit parameters, power loss, and mass are also determined for use in the optimization routines. For more detailed calculations, refer to models discussed in [11-13]. 


\subsubsection{Electromagnetic Model}

For the interior rotor PMSG, the electromagnetically active material consists of the magnets mounted on the rotor surface, copper windings on the stator, and steel placed on the stator teeth and back. Within the stator, the iron is assumed to be infinitely permeable. The magnet has low permeability, and the majority of magnetic flux is assumed to cross the air gap in a direction that is normal to the stator surface.

The air-gap length, $g$, is chosen to be $(1 / 1,000)$ times the air-gap diameter for turbines rated at 2 megawatts (MW) and below [12]. The air-gap diameter of the generator for a given power rating depends on the force density, $F_{d}$, the rated torque, $T$ and the aspect ratio, $k_{r a d}$, and can be analytically determined as [14]

$$
D_{g}=\sqrt[3]{\frac{2 T}{\pi K_{\text {rad }} F_{d}}}
$$

A force density of 40.16 kilonewton $(\mathrm{kN})$ is assumed for machines at all power ratings. The aspect ratio, $K_{\text {rad }}=\frac{l_{s}}{D_{g}}$, is assumed to be small-in the range of $0.2-0.27$ - to minimize the total mass. The flux density is assumed to remain approximately constant over the length of the core but gradually decreases towards the edge as a result of edge field fringing, which also participates in the torque production. An equivalent core length correction of the stator, $l_{\mathrm{e}}$, is defined to account for fringing from the edge field at the machine end, hence the lengthening of the machine [12]

$$
l_{e}=l_{s}+2 \cdot g
$$

$K_{F e s}$ is the iron-filling factor that accounts for the insulation layer between core laminations, so the useful iron stack length, $l_{u}$, is defined as

$$
l_{u}=K_{\text {Fes }} l_{s}
$$

The magnet height is chosen as a design variable and the magnet width, $b_{m}$, is $70 \%$ of the pole pitch, $\tau_{p}$. A simplified, rectangular stator slot geometry is assumed to accommodate a single layer full pitch winding. Because of the low-magnetic permeance of the magnet itself, the effective air-gap length is longer than the mechanical air gap by

$$
g_{\text {eff }}=K_{c s}\left(g+\frac{h_{m}}{\mu_{r m}}\right)
$$

where $K_{c s}$ is the Carter factor for stator slots [13]

$$
K_{c s}=\frac{\tau_{s}}{\tau_{s}-\left(g+\frac{h_{m}}{\mu_{r m}}\right) \gamma_{s}}
$$

Where 


$$
\gamma_{s}=\frac{4}{\pi} \frac{0.5 b_{s o}}{\left(g+\frac{h_{m}}{\mu_{r m}}\right)} \tan ^{-1}\left(\frac{0.5 b_{s o}}{\left(g+\frac{h_{m}}{\mu_{r m}}\right)}\right)-\ln \sqrt{1+\left(\frac{b_{s o}}{\left(g+\frac{h_{m}}{\mu_{r m}}\right)}\right)^{2}}
$$

where slot wedge width, $b_{s o}$, is equal to the sloth width, $b_{s}$, (for a rectangular slot geometry). The flux density above the magnet and the fundamental component of air-gap flux density are determined from the magnet height on the rotor as

$$
\widehat{B}_{P M}=B_{r} \frac{h_{m}}{\mu_{r} g_{e f f}}
$$

where $B_{r}$ is the remnant flux density of the magnets.

$$
\hat{B}_{g}=B_{r} \frac{h_{m}}{\mu_{r} g_{e f f}}\left(\frac{4}{\pi}\right) \sin \left(\frac{\pi}{2} \frac{b_{m}}{\tau_{p}}\right)
$$

The stator yoke height, $h_{y s}$, is also chosen as a design variable so that the allowable peak stator yoke flux density can be determined using [12]

$$
\hat{B}_{s y}=\frac{\hat{B}_{g} b_{m} l_{e}}{2 l_{u} h_{y s}}
$$

The outer radius of the rotor (including the magnet height) is given by $r_{r}$ and can be deduced from the air gap radius as:

$$
r_{r}=r_{s}-g
$$

where $g=0.002 r_{s}$. The number of pole pairs, $p$, is determined from the circumference of the air gap and pole pitch, $\tau_{p}$

$$
p=\frac{\pi r_{s}}{\tau_{p}}
$$

The number of stator slots, $S$, is calculated as

$$
S=2 p m q
$$

The stator slot pitch $\tau_{s}$ is given by

$$
\tau_{s}=\frac{2 \pi r_{S}}{S}
$$

where the number of slots per pole per phase, $q$, is chosen to be 1 , which allows for a small pole pitch [13]; $h_{s}$ and $b$ s describe the height and width of the stator slot, whereas $b_{t}$ defines the tooth width. The tooth width is determined from the slot pitch as

$$
b_{t}=\tau_{s}-b_{s}
$$

with $b_{s}$ maintained at $0.45 \tau_{s}$. The rotor yoke height, $h_{y r}$, is also chosen as a design variable, hence the rotor back iron flux density is determined using 


$$
\hat{B}_{r y}=\frac{\hat{B}_{g} b_{m} l_{e}}{2 l_{s} h_{y r}}
$$

The outer diameter of the stator, $d_{s e}$, and the overall length of the stator, $L_{t}$, including the end windings, are

$$
\begin{gathered}
d_{s e}=d+2\left(h_{s}+h_{y s}\right) \\
L_{t}=\left(l_{s}+2 \tau_{s}\right)
\end{gathered}
$$

The number of stator turns in series required per phase per current path is given by

$$
N_{s}=\frac{S}{3 \cdot a}
$$

where $a$ is the number of parallel paths. The stator phase resistance, $R_{s}$, is determined from the length of the winding, $L_{c u}$, and the conductor cross section, $A_{c u}$

$$
\begin{gathered}
R_{s}=\frac{\rho_{c u} L_{c u}}{A_{c u}} \\
L_{c u}=2 N_{s}\left(2 \tau_{p}+L_{t}\right) \\
A_{c u}=k_{f i l l s} \frac{p q b_{s}\left(h_{s}-h_{w}\right)}{N_{s}}
\end{gathered}
$$

where $N_{s}$ is the number of turns in the stator winding, $h_{w}$ is the slot wedge height, and $k_{\text {fills }}$ is the stator copper fill factor.

Four components of partial leakage inductance exist in the stator, including leakage from the stator slot $\left(L_{s s l}\right)$, tooth tip $\left(L_{s t}\right)$, and end winding connection $\left(L_{s e l}\right)$, and differential leakage from harmonics [11].

$$
\begin{gathered}
L_{s s l}=\frac{2 \mu_{0} N_{s}^{2} l_{s}}{p q}\left(\frac{\left(h_{s}-h_{w}\right)}{3 b_{s}}+\frac{h_{w}}{b_{s 0}}\right) \\
L_{s t l}=\frac{2 \mu_{0} N_{s}^{2} l_{s}}{p q}\left(\frac{5 g / b_{s 0}}{5+4 g / b_{s 0}}\right) \\
L_{s e l}=\frac{2 \mu_{0} N_{s}^{2}}{p q l s} 0.34 g\left(l_{e}-0.64 \frac{y}{\tau_{p}} \tau_{p}\right)
\end{gathered}
$$

The differential leakage from harmonics is assumed to be small and therefore neglected. The stator leakage inductance is the sum of these partial inductances

$$
L_{s \sigma}=L_{s s l}+L_{s t l}+L_{s e l}
$$

The magnetizing main field inductance $L_{s m}$ is given by

$$
L_{s m}=\frac{6 \mu_{0} k_{w}^{2} N_{s}^{2} L_{t} \tau_{p}}{\pi^{2} g_{e f f} p}
$$

where $k_{w}$ is the total stator winding factor given by [11] 


$$
k_{w}=\frac{\sin (\pi / 6)}{q \cdot \sin (\pi / 6 q)} \sin \left(\frac{y}{\tau_{p}} \frac{\pi}{2}\right)
$$

where $\frac{y}{\tau_{p}}=1$ (coil span/pole pitch) for a full pitch winding. The total excitation inductance is therefore the sum of the main field inductance, $L_{s m}$, and the leakage field inductance, $L_{s} \sigma$,

$$
L_{s}=L_{s m}+L_{s \sigma}
$$

\subsubsection{Generator Equivalent Circuit and Efficiency Calculation}

The loss model in the generator consists of copper loss in the windings, losses in the iron core, magnet losses, and losses from friction and windage. As a first step in the loss calculation, the no-load voltage in the stator winding and phase current are determined using the generator equivalent circuit [13].
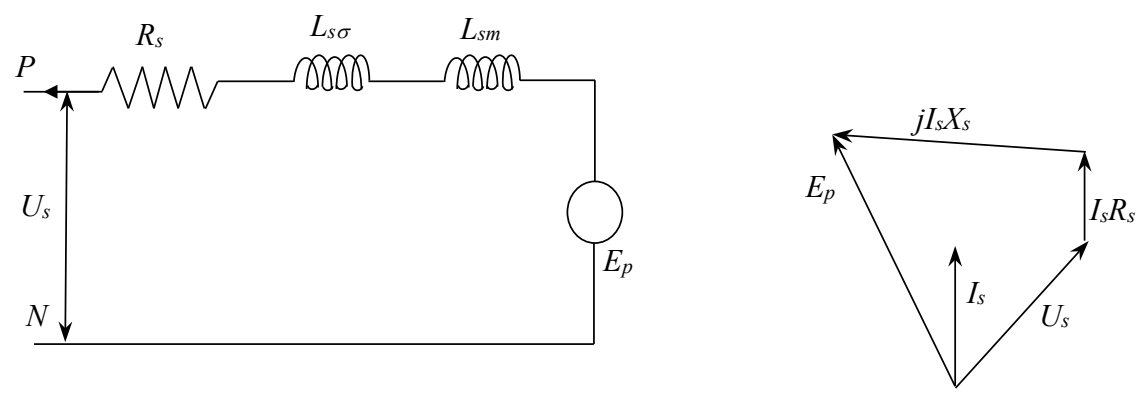

Figure 3. Equivalent circuit model and phasor diagram of a permanent-magnet synchronous generator [13]

$E_{p}$ refers to the no-load voltage induced in the stator caused by the magnets and $U_{s}$ is the terminal voltage in the stator. The stator current, $I_{s}$, lags behind the induced voltage but ensures the lowest power rating requirements on the generator while ensuring the torque produced in the air-gap field is at maximum. The no-load voltage induced in the stator winding is given by

$$
E_{p}=\sqrt{2} k_{w} N_{s} \omega_{m} r_{s} L_{t} \hat{B}_{g}
$$

where the $\omega_{m}\left(=\frac{\pi N}{30}\right)$ is the rotor angular frequency with $N$, the rated speed. The generator operating point is chosen so that the stator current is given by [13]

$$
I_{s}=\sqrt{\left(\frac{P_{g}}{m E_{p}}\right)^{2}+\left(\frac{E_{p}-\sqrt{E_{p}^{2}-\left(\omega_{e} L_{s}\right)^{2}\left(\frac{P_{g}}{m E_{p}}\right)^{2}}}{\left(\omega_{e} L_{s}\right)^{2}}\right)^{2}}
$$

where $\omega_{e}=p . N$ is the electrical frequency. The copper losses at a winding temperature of $\theta_{c u}$ can be calculated from the current in the stator winding, $I_{s}$, and stator phase resistance, $R_{\mathrm{S}}$ as

$$
P_{c u}=m I_{s}^{2} R_{s}\left(\theta_{c u}\right)
$$

The copper losses will be higher if the ambient temperature is high and vice versa. To account for the losses caused by skin effect on the stator resistance, a factor $K_{R}=1.2$ is applied. For the 
purpose of calculation, the generator is assumed to be operating at an ambient temperature. The specific current loading, $A_{1}$, and the current density are determined using

$$
\begin{gathered}
A_{1}=\frac{6 \cdot N_{s} \cdot I_{s}}{\pi D} \\
J_{s}=\frac{I_{s}}{A_{c u} 10^{6}}
\end{gathered}
$$

The iron losses per unit mass are calculated using the Steinmetz formula [11] that accounts for the hysteresis and eddy current components given by

$$
P_{F e}=M_{f e s}\left(P_{F e o h}\left(\frac{\omega_{e}}{2 \pi \cdot 60}\right)\left(\frac{\hat{B}_{F e}}{1.5}\right)^{2}+P_{F e o e}\left(\frac{\omega_{e}}{2 \pi \cdot 60}\right)^{2}\left(\frac{\hat{B}_{F e}}{1.5}\right)^{2}\right)
$$

where $P_{F e o h}$ and $P_{F e o e}$ are the specific hysteresis loss and eddy current loss in the stator core.

The stator iron loss components consist of the teeth as well as the yoke, and the specific mass of iron, $M_{f e s}$, in these parts is included. To compute the losses in the stator yoke, $\hat{B}_{F e}$ is replaced by the peak flux density in the yoke $\left(\widehat{B}_{y s}\right)$ and for iron losses in the teeth $\left(\widehat{B}_{t}\right)$, the peak flux density in the teeth given by [12]

$$
\hat{B}_{t}=\frac{\hat{B}_{g} \tau_{s} l_{e}}{b_{t} l_{u}}
$$

The magnet losses are generally assumed to be minor with small magnets, and assumed to have a constant loss density on the magnet surface [12].

$$
P_{p m}=p_{p m} 2 p b_{m} l_{s}
$$

where the specific losses, $p_{p m}$, are assumed at $300 \mathrm{~W} / \mathrm{m}^{2}$. Additional losses are assumed to be largely a result of stray loads from slot leakage, end-winding leakage, and rotor pole face losses. These stray losses are assumed to be $20 \%$ of iron losses [11].

$$
\begin{gathered}
P_{a d}=0.2 P_{F e} \\
P_{\text {Losses }}=P_{F e}+P_{C u}+P_{p m}+P_{a d}
\end{gathered}
$$

The full-load generator efficiency is approximated as

$$
\eta=\frac{P_{\text {gennom }}}{P_{\text {gennom }}+P_{\text {Losses }}} \times 100
$$

Note: the mechanical losses (bearings and ventilation circuit) have not been modeled.

\subsubsection{Generator Active Mass}

The total mass and cost of active material is determined from [13]

$$
M_{a c t}=M_{C u}+M_{F e}+M_{P M}
$$

where $M_{c u}$ is the mass of copper in the stator given by

$$
M_{c u}=\rho_{c u}\left(m L_{c u} A_{c u}\right)
$$


The amount of copper per unit of air-gap area is assumed to be constant. $M_{\text {Fes }}$ is the mass of the iron in the stator tooth, stator yoke, and rotor yoke

$$
\begin{gathered}
M_{F e}=M_{F e s y}+M_{F e s t}+M_{F e r y} \\
M_{F e s y}=\rho_{F e}\left(\pi L_{t}\left(r_{s}+h_{s}+h_{y s}\right)^{2}-\left(r_{s}+h_{s}\right)^{2}\right) \\
M_{F e r y}=\rho_{F e}\left(\pi L_{t}\left(r_{r}-h_{m}\right)^{2}-\left(r_{r}-h_{m}-h_{y r}\right)^{2}\right) \\
M_{F e s t}=\rho_{F e}\left(2 m p q L_{t} b_{t} h_{s}\right)
\end{gathered}
$$

The mass of the permanent magnet on the rotor is calculated from the volume it occupies on the rotor surface as [15]

$$
M_{P M}=2 \pi R l\left(\frac{b_{m}}{\tau_{p}}\right) h_{m} \cdot \rho_{P M}
$$

where $\rho_{P M}$ is the magnet density. The cost of the generator active material is calculated as

$$
C_{a c t}=C_{C u} M_{C u}+C_{F e} M_{F e}+C_{P M} M_{P M}
$$

where $\mathrm{C}_{\mathrm{cu}}, \mathrm{C}_{\mathrm{Fe}}$, and $\mathrm{C}_{\mathrm{PM}}$ are the specific costs of the copper, iron, and permanent magnet. Table 2 provides the specific costs per metric ton of active and inactive material.

Table 2. Specific Costs and Densities for Different Materials

\begin{tabular}{|l|l|l|}
\hline Material & $\mathbf{\$ / m T}$ & Density $\left(\mathbf{k g} / \mathbf{m}^{\mathbf{3}} \mathbf{)}\right.$ \\
\hline Specific cost of copper, $\mathrm{C}_{\mathrm{cu}}$ & $4,786.24^{\mathrm{a}}$ & 8,900 \\
\hline $\begin{array}{l}\text { Specific cost of Neodymium- } \\
\text { Iron-Boron magnets, } \mathrm{C}_{\mathrm{PM}}\end{array}$ & $95,000^{\mathrm{b}}$ & 7,450 \\
\hline $\begin{array}{l}\text { Specific cost of structural steel, } \\
\mathrm{C}_{\mathrm{Fes}}\end{array}$ & $501.39^{\mathrm{a}}$ & 7,850 \\
\hline $\begin{array}{l}\text { Specific cost of electrical steel, } \\
\mathrm{C}_{\mathrm{Fe}}\end{array}$ & $556^{\mathrm{c}}$ & 7,700 \\
\hline
\end{tabular}

a Based on Bloomberg's March 2016 prices [16]

${ }^{\mathrm{b}}$ Average price based on CEMAC and Bloomberg's March 2016 prices [17]

${ }^{c}$ Average price based on [16] and [18]

\subsubsection{Structural Mass}

In the case of a PMSG, a significant contributor to the generator mass comes from the support structure. It therefore becomes crucial to optimize the support structure by integrating it with the electromagnetic model for overall design optimization. Stator/rotor yoke structures are supported in various ways depending on whether axle, shaft, or spindle bearing support is used. Typical supporting geometries are simple disks, structural profiled spokes/tension rods, ribs, or support arms manufactured as either continuous cast-iron or segmented steel weldment assemblies [19]. The typical construction in commercial machines employs either a spider-wheel or disc-type arrangement for support structures. In determining the optimal dimensions of the support structure, we assumed a double bearing arrangement for the load path [19, 20].

To formulate the generator structural mass and costs, two different structural arrangements covered by McDonald [21] (shown in Figure 3) were considered. These arrangements included a combination of a spoked-arm rotor and stator or a spoked-arm stator and disc rotor, which are 
characteristic approximations of typical constructions in commercial machines. The generator rotor is supported with a shaft resting on two bearings housed in the stator housing. The analytical models presented in [21-23] were used to arrive at the optimal structure that ensures that the air-gap clearance was not compromised. These models account for the most important forces in the electrical machine, which, if not carefully treated, can endanger air-gap clearance that is typically $1 / 1,000^{\text {th }}$ of the air-gap diameter [12]. These forces include the normal component of Maxwell's stress $\left(q=\frac{\widehat{B}_{g}^{2}}{2 \mu_{o}}\right)$ acting along the circumference of the rotor and stator, centripetal force from torque, $T$, and the acceleration caused by gravity, $g$, which acts in the vertical direction. Thermal expansion from heat generated in the windings was not included because adequate cooling of the generator was assumed. The forces and moments from rotor blades were also not included in these models. The structural adequacy of the support structures were determined by verifying the components of structural deflection, namely axial deflection (as a result of gravity ), radial deflection (as a result of the normal component of Maxwell's stress), and torsional deflection (as a result of centripetal force) to be within permissible limits. The equations describing these structural deflections are explained in great detail by McDonald [21].

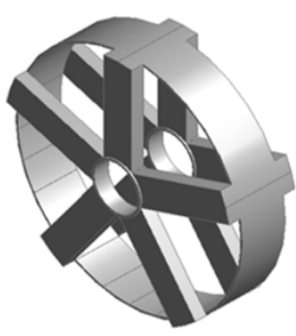

(a)
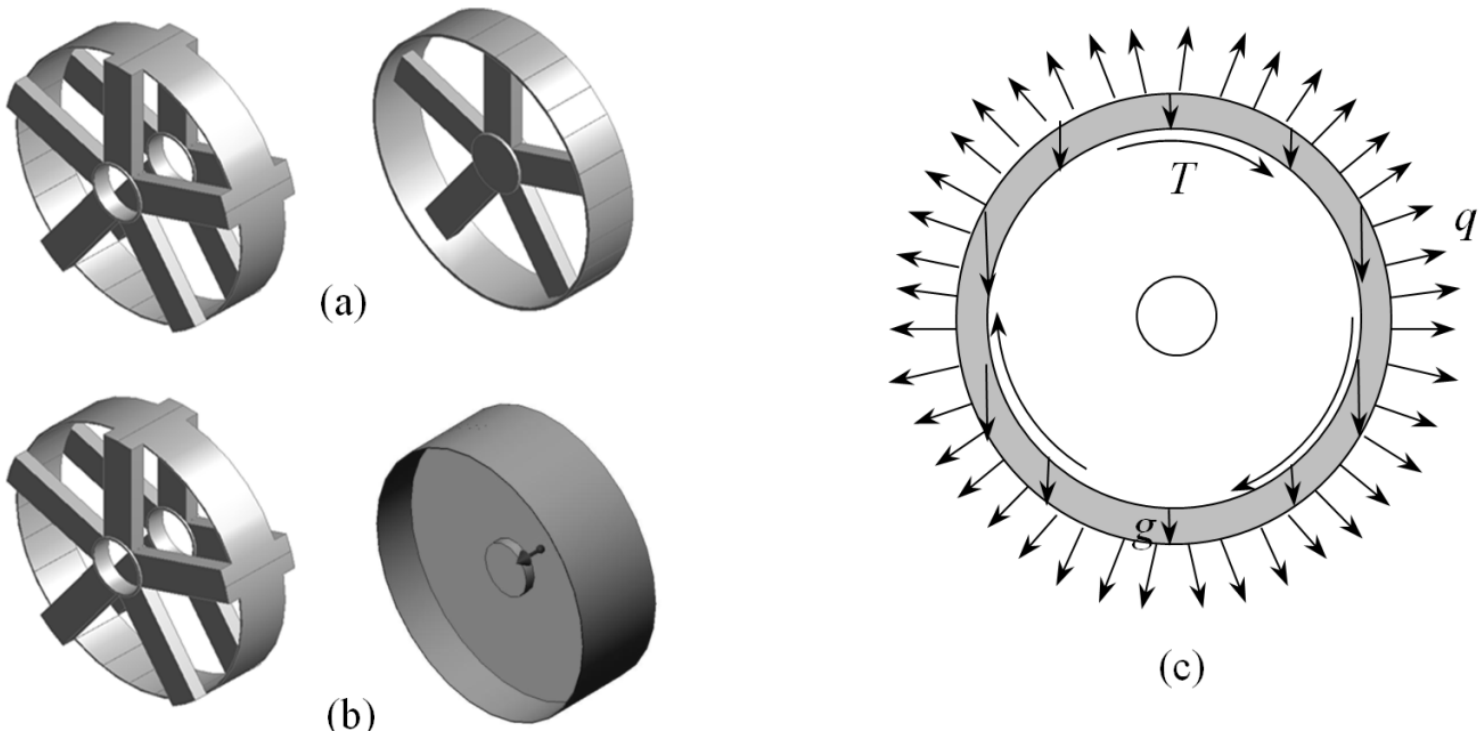

(c)

(b)

Figure 4. Generator support structures: (a) spoked arms, (b) spoked arm stator and disc rotor, and (c) loads acting on the structural support; reproduced from [21] 


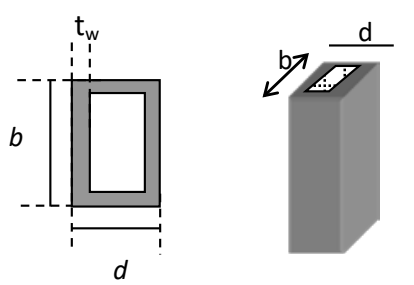

(a)

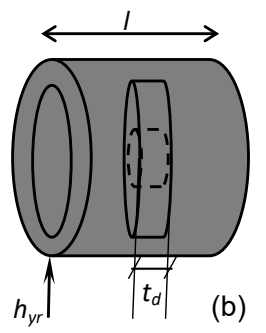

(b)

Figure 5. Structural design variables for the (a) spoke arm and (b) disc construction

The size and mass of the structure are defined by six design variables in the case of spoked arms and two variables in the case of the disc. These variables include the number of arms, rotor and stator yoke thickness, and circumferential and axial arm dimensions. Regarding the disc structure, the thickness and yoke height are used to define its size and mass. These variables for the structural model are listed in Table 3. Figures 4(a) and (b) illustrate the integrated structural and magnetic assembly.

Table 3. Design Parameters for the PMSG Structural Model

\begin{tabular}{|c|c|c|c|c|c|}
\hline Symbol & Description & Symbol & Description & Symbol & Description \\
\hline$n_{r}$ & $\begin{array}{l}\text { Number of rotor } \\
\text { arms }\end{array}$ & $n_{s}$ & Number of stator arms & $t_{d}$ & $\begin{array}{l}\text { Rotor disc } \\
\text { thickness }\end{array}$ \\
\hline$t_{r}=h_{y r}$ & $\begin{array}{l}\text { Thickness of rotor } \\
\text { cylinder back }\end{array}$ & $t_{s}=h_{y s}$ & $\begin{array}{l}\text { Thickness of stator } \\
\text { cylinder back }\end{array}$ & & \\
\hline$b_{r}$ & $\begin{array}{l}\text { Circumferential rotor } \\
\text { arm dimension }\end{array}$ & $b_{s t}$ & $\begin{array}{l}\text { Circumferential stator arm } \\
\text { dimension }\end{array}$ & & \\
\hline$d_{r}$ & $\begin{array}{l}\text { Rotor axial arm } \\
\text { dimension }\end{array}$ & $d_{s}$ & $\begin{array}{l}\text { Stator axial arm } \\
\text { dimension }\end{array}$ & & \\
\hline$t_{w r}$ & $\begin{array}{l}\text { Rotor arm wall } \\
\text { thickness }\end{array}$ & $t_{w s}$ & Stator arm wall thickness & & \\
\hline
\end{tabular}
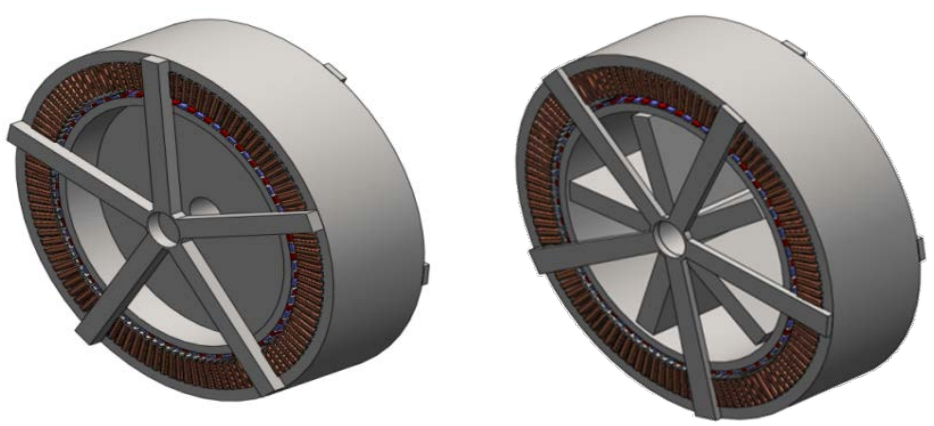

Figure 6. Integrated assembly of the structures 
For each type of support structure, the radial, axial, and tangential components of structural deflections denoted by $U_{a r, s}, Y_{a r, s}$, and $Z_{a r, s}$ are computed analytically using reference [21] (as listed in Table 4) and compared against certain allowable deflection constraints. For the disc structure, tangential deflection criterion was not modeled, but was verified using the finiteelement-analysis tool.

Table 4. Structural Deflection Models of the PMSG

\begin{tabular}{|c|c|c|}
\hline$\delta$ & Spoked Arm Structure & Disc-Type Structure \\
\hline $\mathrm{U}_{\mathrm{ar}, \mathrm{s}}$ & $\begin{array}{l}\frac{q R^{2}}{E t}(1 \\
+\frac{R^{3}\left[\frac{(\sin \theta-\theta \cos \theta)}{4 \sin ^{2} \theta}-\frac{1}{2 \sin \theta}+\frac{1}{2 \theta}\right]}{\left.I\left[\left(\frac{\theta}{\sin ^{2} \theta}+\frac{1}{\tan \theta}\right)\left(\frac{R}{4 A}+\frac{R^{3}}{4 I}\right)-\frac{R^{3}}{2 I \theta}\left(\frac{1}{m+1}\right)+\frac{R_{1}-R_{o}}{a}\right]\right)} \\
\text { For the stator with the double-sided spoke arm arrangement, } \\
\text { the arm area is doubled }(\mathrm{a} \rightarrow 2 \mathrm{a}), R \rightarrow R_{s t}, R_{l} \rightarrow R_{I s}, \mathrm{~m} \rightarrow m_{s}\end{array}$ & $\begin{array}{l}\mathrm{U}_{a r} \\
=\frac{q R^{2}}{E\left(R_{a}-R\right)} \\
+\frac{f}{2 D_{r a} \lambda^{3}}\left[\frac{-F_{1}(x=0)\left(C_{3} C_{a 2}-C_{4} C_{a 1}\right)}{C_{11}}\right. \\
\left.+\frac{F_{2}(x=0)\left(C_{2} C_{a 2}-2 C_{3} C_{a 1}\right)}{2 C_{11}}-\frac{F_{a 4}(x=0)}{2}\right]\end{array}$ \\
\hline$Y_{\text {ar }}$ & $\frac{W R^{3}}{12 E I_{\text {arm, axi }}}+\frac{w R_{1}^{4}}{24 E I_{\text {arm, axi }}}$ & $\begin{aligned}-\frac{w R^{4}}{R_{o} D_{a x}}\left[\frac{C_{2 p} C_{6}}{C_{5}}-C_{3 p}\right] & +M_{r b} \frac{R_{a}^{2}}{D_{a x}} C_{2 p}+Q_{b} \frac{R_{a}^{3}}{D_{a x}} C_{3 p} \\
& -w \frac{R_{a}^{4}}{D_{a x}} L_{11}\end{aligned}$ \\
\hline $\mathrm{Y}_{\mathrm{as}}$ & $\frac{W_{i s} l_{\text {is }}^{3}}{12 E I_{\text {arm,axi }}}+\frac{W_{\text {iis }} l_{\text {iis }}^{4}}{24 E I_{\text {arm,axi }}}+\frac{w_{s} l_{\text {iiis }}^{4}}{24 E I_{\text {arm,axi }}}$ & $\frac{W_{i s} l_{i s}^{3}}{12 E I_{\text {arm,axi }}}+\frac{W_{i i s} l_{i i s}^{4}}{24 E I_{\text {arm, axi }}}+\frac{w_{s} l_{\text {iiis }}^{4}}{24 E I_{\text {arm,axi }}}$ \\
\hline $\mathrm{Z}_{\mathrm{ar}}$ & $\frac{2 \pi\left(\mathrm{R}-0.5 \mathrm{~h}_{y r}\right) \sigma\left(\mathrm{l}_{i r}-0.5 \mathrm{~h}_{y r}\right)^{3}}{\mathrm{n}_{r} 3 E I_{\text {arm,tor }}}$ & - \\
\hline $\mathrm{Z}_{\mathrm{as}}$ & $\frac{2 \pi\left(\mathrm{R}_{s t}+0.5 \mathrm{~h}_{y s}\right) \sigma\left(\mathrm{l}_{i s}+0.5 \mathrm{~h}_{y s}\right)^{3}}{2 \mathrm{n}_{s t} 3 E I_{\text {arm tor }}}$ & $\frac{2 \pi\left(\mathrm{R}_{s t}+0.5 \mathrm{~h}_{y s}\right) \sigma\left(\mathrm{l}_{i s}+0.5 \mathrm{~h}_{y s}\right)^{3}}{2 \mathrm{n}_{s t} 3 E I_{\text {arm tor }}}$ \\
\hline
\end{tabular}

Appendix A1 provides a detailed list of parameters used in the deflection calculations.

\subsubsection{Inactive Mass}

The mass of steel in the stator yoke and rotor yoke are already accounted for by Eqs. (42) and (43). The mass of the support structures are estimated for both types as follows

$$
\begin{gathered}
M_{\text {Inactive_arms }}=2 n_{s}\left(R_{1 s}-R_{o}\right) a_{s} \rho+n_{r}\left(R_{1}-R_{o}\right) a_{r} \rho \\
M_{\text {Inactive_discrotor }}=2 n_{s}\left(R_{1 s}-R_{o}\right) a_{s} \rho+\pi t_{d} \rho\left(R^{2}-R_{o}^{2}\right)
\end{gathered}
$$

The total mass of the generator is given by

$$
M_{\text {Gen }}=M_{\text {act }}+M_{\text {inactive }}
$$

\subsubsection{Design Optimization}

The analytical models presented so far are useful to calculate the parameters and performance for a given geometry and various design parameters, and even serve as good starting points for a few initial dimensions that can fulfill the given specifications. With the computation of resistances and losses limited by desired efficiency margins, the mass and costs of active materials may be computed. The most demanding design task for a permanent-magnet synchronous generator especially for a low-speed, high-torque application is keeping the physical air-gap length as 
small as possible, saving the amount of material in the permanent magnet [24] while ensuring adequate structural stiffness to avoid closure. GeneratorSE mechanizes this design optimization process allowing initialization of both electromagnetic and structural design variables and verifying performance parameters against constraints. A mathematical method searches for the optimal design satisfying one of the following objectives.

\subsubsection{Mass Optimization}

The first optimization problem seeks to find a lightweight design. The objective criterion that is minimized is

$$
\text { Mass }=M_{\text {Gen }}
$$

The key performance variables, including specific current loading, current density, output voltage, and efficiency, determine the optimal active mass required for the generator, whereas deflection criteria are used to determine the optimal structural mass.

\subsubsection{Cost Optimization}

The second optimization problem attempts to provide the most economic design assuming certain specific costs of materials that were used to build the generator. The objective criterion that is minimized is given by

$$
\text { Costs }=M_{P M} \cdot C_{P M}+C_{C U} \cdot M_{C U}+C_{\text {steel,struc }} \cdot M_{\text {steel,struc }}+C_{\text {steel,mag }} \cdot M_{\text {steel,mag }}
$$

The $C_{P M}, C_{C U}, C_{\text {steel,struc }}$, and $C_{\text {steel,mag }}$ are the specific costs of the magnet, copper, structural steel, and steel used in the magnetic circuit as shown in Table 2. Because magnets and copper are the most expensive among the constituent elements, the optimizer attempts to minimize the respective masses that result in the most economic design.

\subsubsection{Efficiency Optimization}

The third optimization problem attempts to provide the most efficient design by minimizing the losses in the systems. The objective criterion that is minimized is given by

$$
\text { Losses }=P_{\text {Losses }}
$$

It may also be possible to attribute a certain cost to losses as lost revenue as a result of drivetrain inefficiency. This designation leads to a biobjective optimization problem wherein the costs and losses are minimized. The new objective function would be

$$
M_{P M} \cdot C_{P M}+C_{C U} \cdot M_{c u}+C_{\text {steel,struc }} \cdot M_{\text {steel,struc }}+C_{\text {steel,mag }} \cdot M_{\text {steel,mag }}+C_{k W h} P_{\text {Losses }} * N
$$

where $C_{k W h}$ is the cost of electricity per kilowatt-hour and $N$ is the number of hours.

\subsubsection{Optimization of Aspect Ratio}

The final optimization problem attempts to locate a design that ensures an optimal aspect ratio This objective ensures a light weight with a small design envelope defined by its air gap diameter and stack length

$$
k_{\text {rad }}=\mathrm{l} / \mathrm{D}
$$




\subsubsection{Decision Variables}

To optimize the generator design for the proposed objectives, some parameters were chosen as the key decision variables before the optimization process. The optimization problem had approximately 15 free parameters in the case of spoked arm structures, 12 free parameters in the case of disc rotor and some constant parameters. It must be noted that the main shaft design is not included in the present model; the shaft radius, generator speed, rated power, generator torque and target design efficiency are user inputs besides material costs and properties (Table 5); the other dimensions were calculated from the given parameters:

- Magnetic circuit. Seven parameters of the generator, namely the air-gap radius, stator length, slot height, pole pitch, rotor yoke height, stator yoke height, and magnet height were allowed to vary within a certain range. The air-gap length, stator tooth, and slot dimensions were defined as geometrical variables with respect to the air-gap radius and pole pitch. Pole pitch was chosen as a free variable because it has no restrictions and the number of pole pairs is not usually an integer in design calculations. These variables are summarized in Table 6. The stator length and air-gap radius are adjusted to get the correct air-gap volume required to overcome the shear stress, $\sigma$. The magnet height and pole pitch determine the number of pole pairs required to generate a certain air-gap flux density while also limiting the terminal voltage to within 5 kilovolts $(\mathrm{kV})$. The corresponding performance variables are also included Table 6.

Table 5. Design Inputs

\begin{tabular}{cc}
\hline \hline Symbol & Description \\
\hline \hline$R_{0}$ & Shaft radius \\
$T$ & Rated Torque \\
$P_{\text {rated }}$ & Rated power \\
$N$ & Rated speed \\
$\eta_{\text {target }}$ & Target efficiency \\
\hline
\end{tabular}

Table 6. Electromagnetic Design and Performance Variables in PMSG

\begin{tabular}{clcl}
\hline Symbol & Design Variables & Symbol & Performance Variables \\
\hline \hline$r_{s}$ & Air-gap radius & $\hat{B}_{g}$ & Peak air-gap flux density \\
$l_{s}$ & Stator core length & $\hat{B}_{s y}$ & Peak stator yoke flux density \\
$h_{s}$ & Slot height & $\hat{B}_{r y}$ & Peak rotor yoke flux density \\
$\tau_{p}$ & Pole pitch & $\widehat{B}_{t}$ & Peak tooth flux density \\
$h_{m}$ & Magnet height & $E_{p}$ & Terminal voltage \\
$h_{y r}$ & Rotor yoke height & $A_{1}$ & Specific current loading \\
$h_{y s}$ & Stator yoke height & $J_{s}$ & Stator current density \\
\hline
\end{tabular}


The key design constants and constraints imposed on the electromagnetic design and performance indices are listed in Table 7.

Table 7. Electromagnetic Design Constants and Constraints

\begin{tabular}{lll}
\hline Description & Symbol & Value \\
\hline \hline Remnant flux density & $B_{r}$ & $1.2 \mathrm{Tesla}(\mathrm{T})$ \\
\hline Permeability of free space & $\mu_{o}$ & $4 \pi 10^{-7}$ \\
\hline Relative permeability & $\mu_{r}$ & 1.06 \\
\hline Stator slot opening & $b_{s o}$ & $4 \mathrm{~mm}$ \\
\hline Slot wedge thickness & $h_{w}$ & $5 \mathrm{~mm}$ \\
\hline Shear stress & $\sigma$ & $40 \mathrm{kN} / \mathrm{m}^{2}$ \\
\hline Slot fill factor & $k_{\text {sfill }}$ & 0.65 \\
\hline Iron fill factor & $k_{\text {fes }}$ & 0.9 \\
\hline Specific hysteresis losses & $P_{\text {FeOh }}$ & $4 \mathrm{~W} / \mathrm{kg}$ \\
\hline Specific eddy current & $P_{\text {FeOe }}$ & $1 \mathrm{~W} / \mathrm{kg}$ \\
\hline Copper resistivity & $\rho_{c u}$ & $2.52 \mathrm{e}-08 \Omega \mathrm{m}$ \\
\hline & & $A_{1}<60 \mathrm{kA} / \mathrm{m}$ \\
\hline $0.7 T(T e s l a) \leq \hat{B}_{g} \leq 1.2 T$ & & $J_{s} \leq 6 \mathrm{~A} / \mathrm{mm}^{2}$ \\
\hline$\hat{B}_{s y}<2 T$ & & $A_{c u} \geq 5 \mathrm{~mm}^{2}$ \\
\hline$\hat{B}_{r y}<2 T$ & & $10 \mathrm{~Hz}<f<60 \mathrm{~Hz}$ \\
\hline$\widehat{B}_{s}<\hat{B}_{g}$ & & $500 \mathrm{~V} \leq E_{p} \leq 5,000 \mathrm{~V}$ \\
\hline$\widehat{B}_{t}<2 T$ & & $\eta \geq \eta_{\text {target }}$ \\
\hline $0.2<K_{\text {rad }} \leq 0.27$ &
\end{tabular}

- Structural design. For the spoked-arm construction, the number of arms for the rotor and stator, arm dimensions, and arm thicknesses (as described in Section 2.1.4) were varied to create the different generations of structures. In the case of the disc type rotor, the disc thickness and rotor yoke height were also chosen to vary within a certain range. The adequacy of the structural design was verified by constraining the deflections to acceptable levels; the permissible values were $10 \%$ of the air-gap clearance for the total radial deflection in the air gap caused by Maxwell stress, $2 \%$ of the axial length for the gravitational deflection, and a relative twist of $0.05^{\circ}$ for torsional deflection. Whenever the radial deflection in the air gap exceeded the limits, the yoke thickness was increased. When deflection caused by gravity or torque exceeded the limits, the disc thickness or the arms' width or depth were increased. The combination of all of the variables at the end of each optimization run led to a different design. If the circumferential arm dimension $b>2 \pi R_{o} / n$, then the rotor shaft circumference is considered insufficient to accommodate $n$ arms. When $\frac{T}{2 \pi \sigma}>R^{2} l$, the generator air-gap dimensions are insufficient to produce the required torque. The optimal solution was selected from a range of results based on the relative merits and demerits of the designs. The key design constants and constraints imposed on the structural design are listed in Table 9. Note the mechanical design of the shaft and the bearing supports were not part of the present study, a rough estimate for the shaft radius was derived by extrapolating different power levels from DriveSE [3] and used as design inputs. 
Table 8. Structural Design Variables

\begin{tabular}{ll}
\hline \hline Symbol & Design Variables \\
\hline \hline$n_{r}$ & Number of rotor arms \\
\hline$b_{r}$ & Rotor circumferential arm dimension $(\mathrm{mm})$ \\
\hline$d_{r}$ & Rotor axial arm dimension $(\mathrm{mm})$ \\
\hline$t_{w r}$ & Rotor arm wall thickness $(\mathrm{mm})$ \\
\hline$n_{s}$ & Number of stator arms \\
\hline$b_{s t}$ & Stator circumferential arm dimension $(\mathrm{mm})$ \\
\hline$d_{s}$ & Stator axial arm dimension $(\mathrm{mm})$ \\
\hline$t_{w s}$ & Stator arm wall thickness $(\mathrm{mm})$ \\
\hline$t_{d}$ & Disc thickness $(\mathrm{mm})$ \\
\hline
\end{tabular}

Table 9. Structural Design Constraints, Constants, and Fixed Relations

\begin{tabular}{|c|c|}
\hline$U_{a s}<0.05 \mathrm{~g}$ & $b_{s}<2 \pi \frac{R_{o}}{n_{s}}$ \\
\hline$U_{a r}<0.05 g$ & $b_{r}<2 \pi \frac{R_{o}}{n_{r}}$ \\
\hline$Y_{a r}<0.02 I$ & $\frac{T}{2 \pi \sigma}<R_{s t}^{2} l$ \\
\hline$Y_{\text {as }}<0.02 I$ & $\frac{T}{2 \pi \sigma}<R^{2} l$ \\
\hline $\mathrm{Z}_{\mathrm{ar}}<0.05 \pi \frac{2 R}{360}$ & \\
\hline $\mathrm{Z}_{\mathrm{as}}<0.05 \pi \frac{2 R_{s t}}{360}$ & \\
\hline Young's Modulus, E & 200 gigapascals (GPa) \\
\hline Shaft Radius, $\mathrm{R}_{\circ}{ }^{*}$ & $0.139 \ln \left(P_{\text {rated }}\right)-1.6179$ \\
\hline
\end{tabular}

\subsubsection{Optimization Assumptions, Results, and Validation}

Some of the key assumptions in the optimization process include the following:

- The temperature of the winding is assumed to be $120^{\circ}$

- The slot width, $b_{s}$, is $45 \%$ of the pole pitch, $\tau_{p}$.

Five different representative turbines with power ratings of $0.75 \mathrm{MW}, 1.5 \mathrm{MW}, 3 \mathrm{MW}, 5 \mathrm{MW}$, and $10 \mathrm{MW}$ were chosen to demonstrate the different design sensitivities and opportunities in design optimization. The torque and speed ratings for these turbines were based on [25]. Appendix A2 presents the boundary conditions and the initialization problem for each case, Appendices A3 and A4 present the results of the detailed design dimensions and some key performance parameters of the generators obtained with lowest costs as the objective while ensuring a prerequisite efficiency of $93 \%$.

The optimization was carried out using the constraint minimization framework, ConMIN. Note that the GeneratorSE models do not account for thermal design optimization. The stator current density was limited to 3-6 kilo Ampere $/$ millimeter ${ }^{2}\left(\mathrm{kA} / \mathrm{mm}^{2}\right)$ and the specific current loading to $60 \mathrm{kA} / \mathrm{m}$. These limits are subject to change depending on the type of cooling and heat dissipation design and are expected to influence the generator design and overall mass. For the present designs, indirect air cooling was assumed with permissible values chosen based on 
recommendations in [24] so that the temperature rise was within the appropriate limit. This assumption circumvented the need to model deflection that is caused by thermal expansion. It is expected that the type of cooling influences the size of the windings, and hence the size of the machine. However, the effects of these influences on the mass and overall costs were not included. Therefore, the results presented are based on preliminary optimization.

\subsubsection{Electromagnetic Design Validation}

To validate the electromagnetic design given by GeneratorSE, a 2-D finite-element analysis was carried out using FEMM 4.2, an open-source 2-D finite element software for magneto-static simulation [4]. The purpose of this model was to verify magnetic loading at various parts predicted by GeneratorSE for the no-load condition. The optimized design dimensions for a 5MW arm-type design (Appendix A3) from GeneratorSE available in Microsoft Excel format were passed on to a MATLAB-scripting interface that was used to automate the population of the 2-D geometry. A magnetostatic analysis was performed to examine the magnetic loading at no load. The various parts were drawn as planar 2-D components defined using nodes connected by line and arc segments. The stator and rotor iron were modeled using a nonlinear B-H relationship as shown in figure 7.

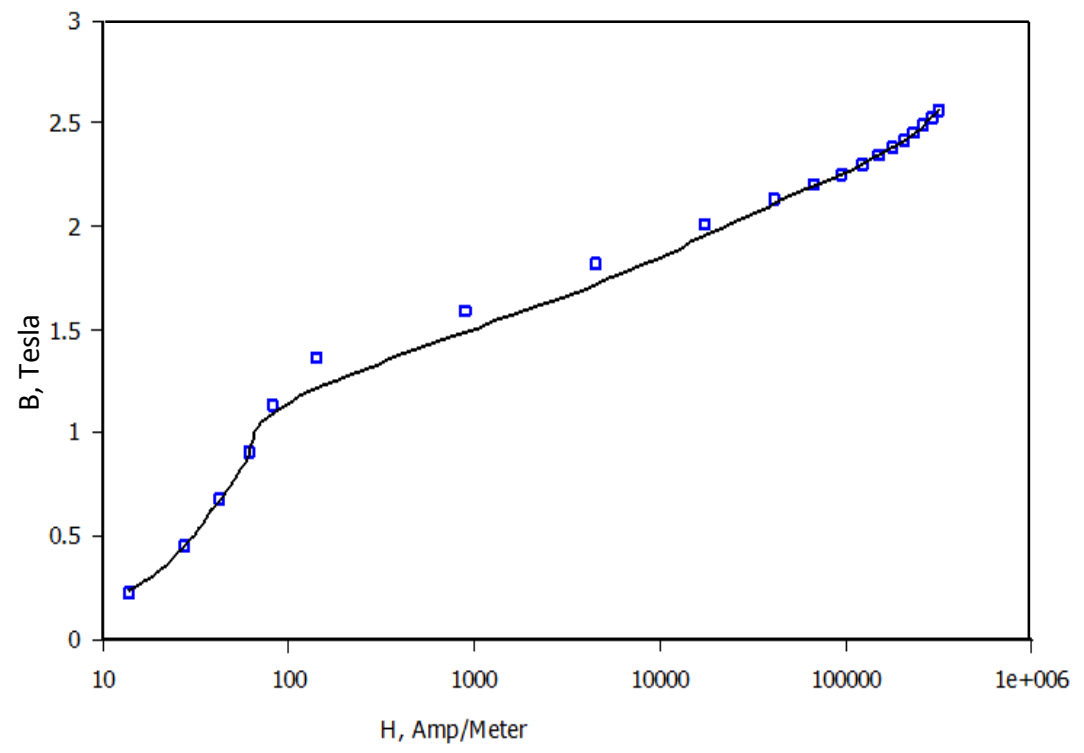

Figure 7. B-H curve for stator and rotor iron

They were assumed to have zero electrical conductivity, so that stray currents are neglected. The magnet material was assumed to have been of type neodymium iron boron $(\mathrm{NdFeB})$ with a nominal energy product of 40 megaGauss Oersteds. The magnetic field is assumed to be linear and mainly driven by the magnets with a relative permeability of 1.2 Tesla.

To ensure a unique solution for the magnetic field, a dirichlet boundary condition was enforced (i.e., magnetic vector potential, $\mathrm{A}=0$ ) at the stator outer radius and rotor inner radius. The stator winding with 234 turns per phase is of a single-layer type with the coil pitch equal to the pole pitch. An integral slot winding resulting in one slot per pole per phase $(\mathrm{q}=1)$ was used to model the stator winding. The winding pattern shown in Figure 8 is typically repeated 117 times to represent the stator winding. 


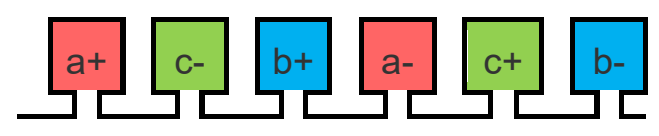

Figure 8. Winding layout reproduced from [26]

The FEMM program discretizes the solution space using a triangular mesh with nodes refined towards the air gap, wherein most of the magnetic energy of the machine is concentrated (Figure 9) and utilizes a set of Maxwell's equations to solve the magnetostatic problem. Additionally, field solutions are available in the form of contour and density plots rendered by different colors (see Figure 9). A circular path between the magnet and stator teeth was created to extract the normal component of flux density in the air gap from the plots of field quantities produced along these contours. 


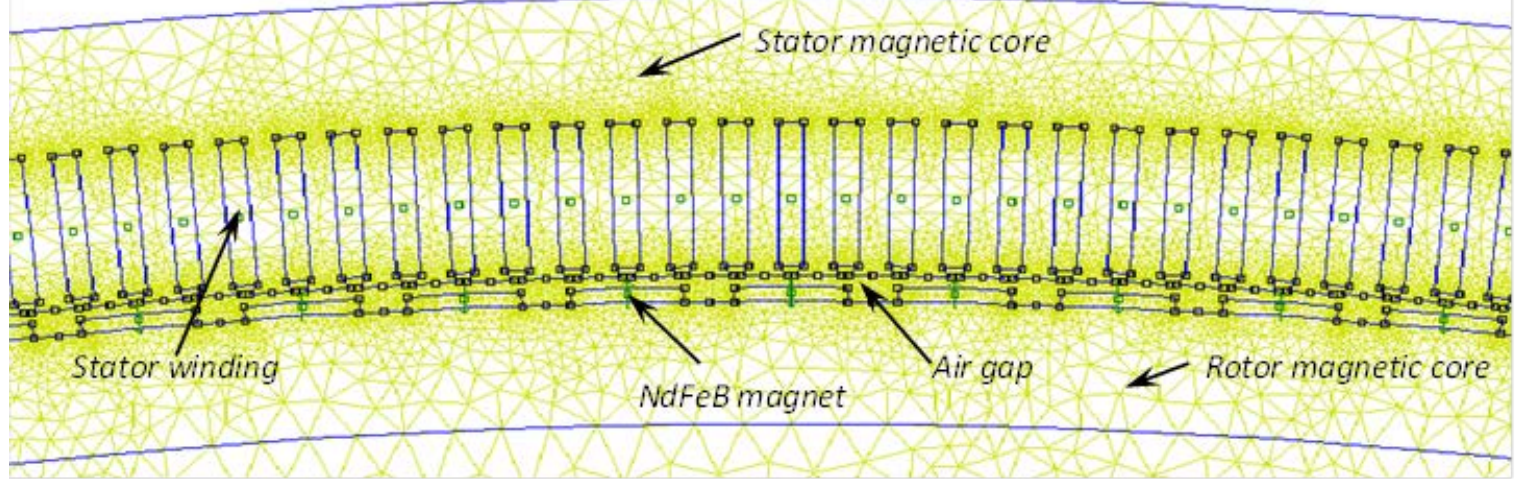

(a)

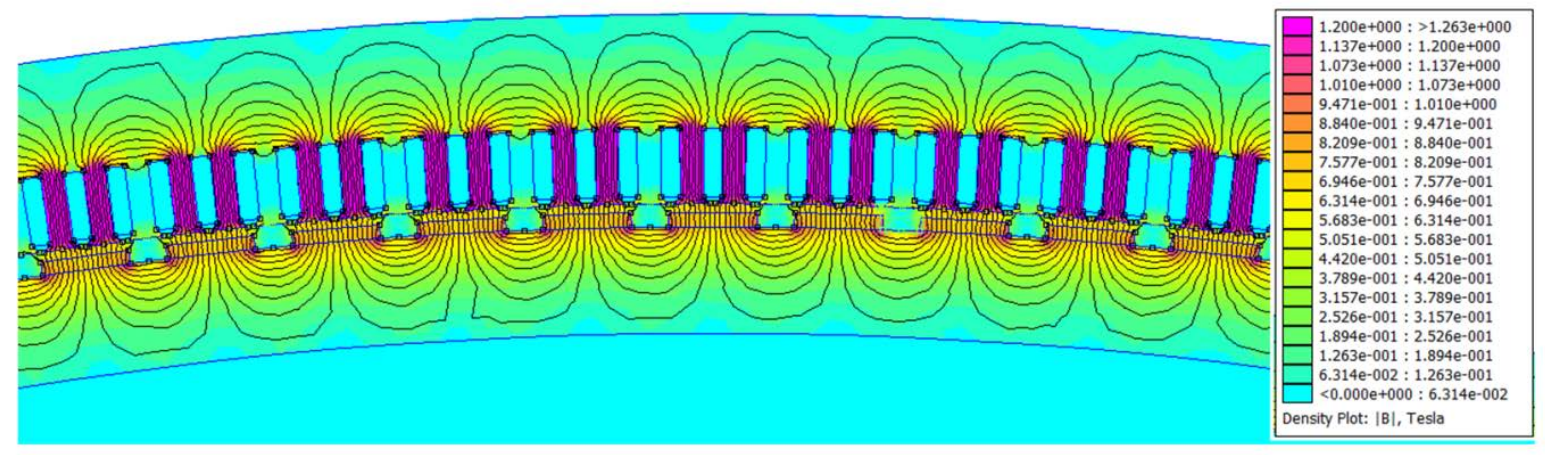

(b)

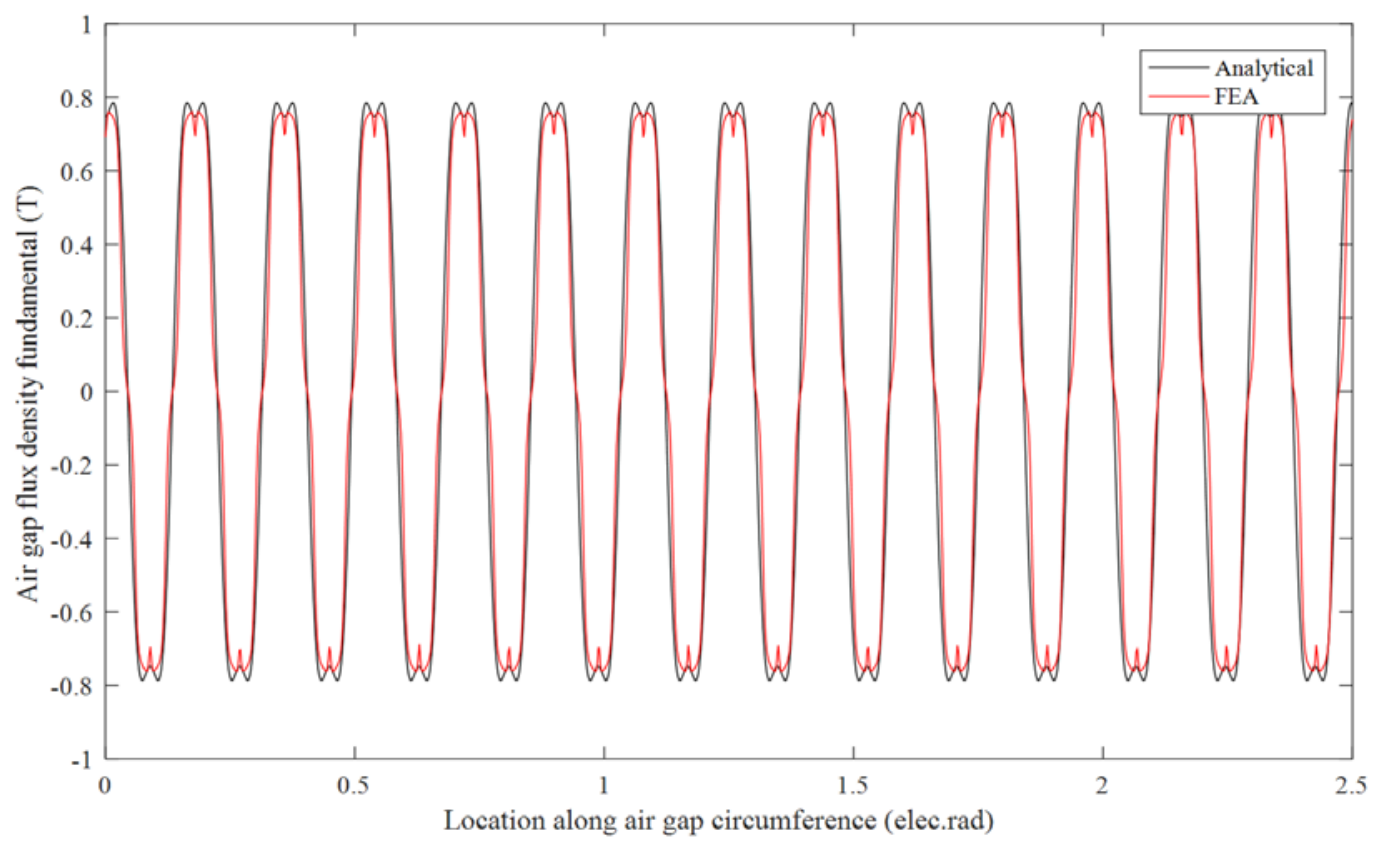

(c)

Figure 9. The 5-MW PMSG model in FEMM showing the: (a) finite-element mesh, (b) magnetic flux density contour, and (c) a comparison of air-gap flux density estimated using FEMM versus the analytical model in GeneratorSE 
In Figure 9 the spatial distribution of air-gap flux densities predicted by FEMM is compared against analytically computed values using GeneratorSE. Note that only the fundamental component of the stator slot harmonics (order represented by $\mu$ ) was included in the air-gap flux density predicted along the air-gap circumference by GeneratorSE given by eq. (56) and (57):

$$
\begin{gathered}
\hat{B}_{\mathrm{g}}(\theta)=\sum_{\mu .} K_{f v} B_{p m} \cos \left(\frac{\pi}{\tau_{p}} \mu \theta\right) \\
K_{f v}=\frac{4}{\pi} \sin \left(\frac{\pi b_{m}}{2 \tau_{p}} \mu\right)
\end{gathered}
$$

Because this validation deals with simulating the no-load peak air-gap flux density due to permanent magnets, no attempt was made to model the armature reaction. The plot shows that the stator slot opening of the machine reduces flux density just before the air gap as it increases the reluctance of the magnet circuit. Table 10 compares the average of the peak values of flux densities in the various parts of the machine predicted by finite-element analysis (FEA) against the peak values given by GeneratorSE at the no-load condition. The results were between 95\% and $110 \%$ of the FEA predictions.

Table 10. Comparison of Magnetic Loading in a PMSG (FEA vs. GeneratorSE)

\begin{tabular}{|l|c|c|c|}
\hline $\begin{array}{l}\text { Peak Value of Flux } \\
\text { Density } \\
\text { (Tesla) }\end{array}$ & GeneratorSE & FEA & $\Delta=\frac{X_{S E}-X_{F E A}}{X_{F E A}} \times 100 \%$ \\
\hline Stator yoke & 0.31 & 0.283 & 9.54 \\
\hline Rotor yoke & 0.28 & 0.293 & -4.44 \\
\hline Stator teeth & 1.45 & 1.32 & 9.85 \\
\hline
\end{tabular}

\subsubsection{Structural Design Verification}

To validate the structural models and the deflections predicted by GeneratorSE, we created computer-aided design (CAD) models of the stator and rotor for the arm-disc combination for the 5MW generator and evaluated them using static structural analysis in ANSYS (see Figure 10 for arm-type structures). The z-axis represents the axial component; whereas the $\mathrm{x}$ and $\mathrm{y}$ axes represent the radial and torsional components of the deflections defined in the cylindrical coordinate system. Note that only the support structure arms and cylinder back thickness are modeled. However, the analytical model for axial deflection includes the weight of magnets, steel in stator tooth, and copper windings. These components contribute to the axial component of deflection and were included as a lumped load acting at the center of mass in the FEA model. The remaining loads applied to the models include acceleration caused by gravity (the gravity component was applied in the $-\mathrm{ve} \mathrm{Z}$ direction to represent the extreme case involving transportation), a normal stress of 0.255 megapascals (MPa) (normal to the rotor exterior and stator interior surfaces), and a shear stress of 40 kilopascals (kPa). Figure 10 shows the components of structural deflections computed in ANSYS for the stator and rotor models. The highest of the maximum values along the $\mathrm{X}, \mathrm{Y}, \mathrm{Z}$ coordinates is compared against analytically computed values in GeneratorSE in Table 11 . The results are between $80 \%$ and $103 \%$ of FEA predictions. 


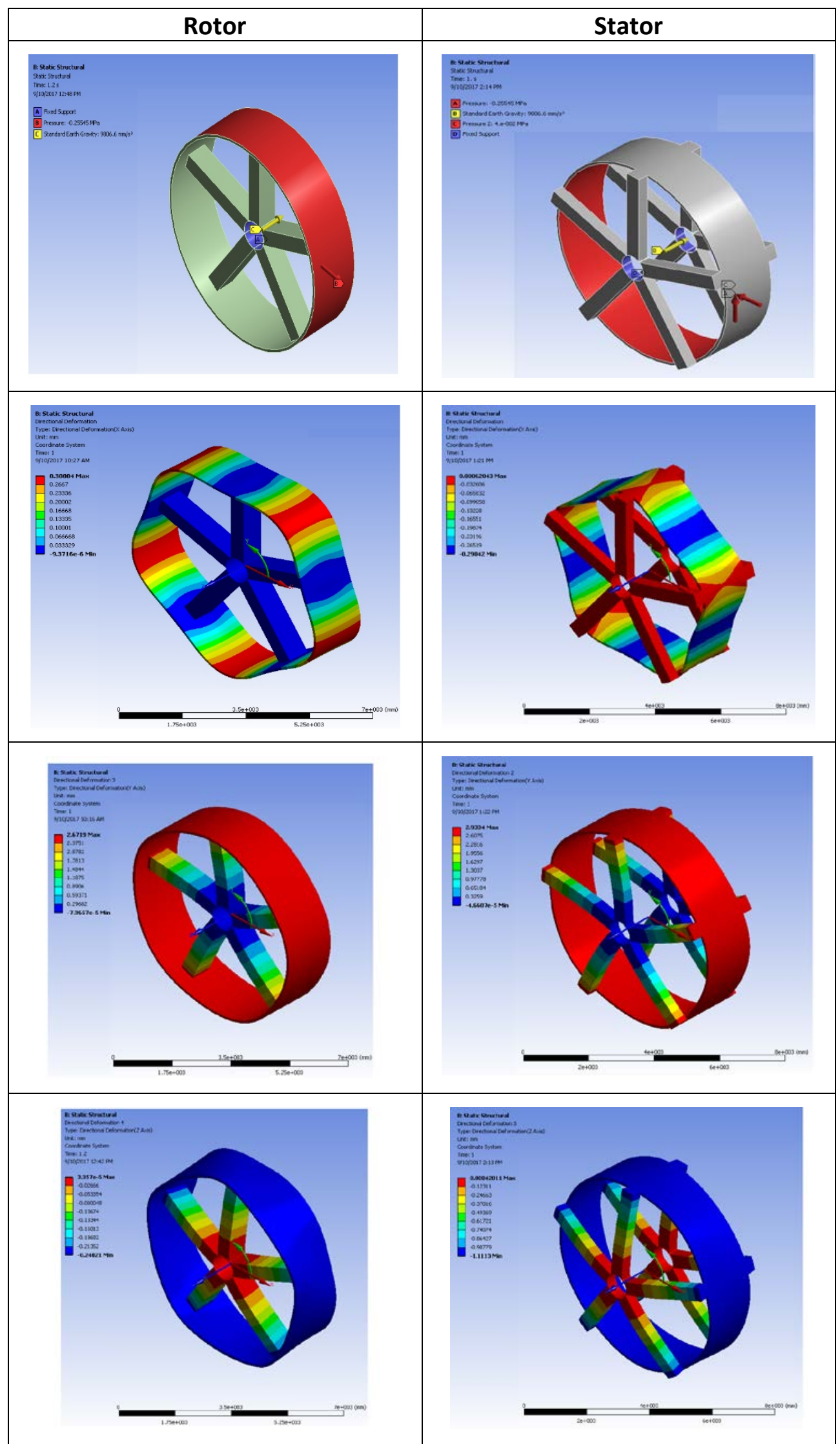

Figure 10. Components of structural deflection computed in ANSYS 
Table 11. Comparison of Structural Deflections: GeneratorSE vs. ANSYS for Arm-Arm-Type Structures

\begin{tabular}{|c|c|c|c|c|}
\hline $\begin{array}{c}\text { Deflection } \\
(\mathbf{m m})\end{array}$ & GeneratorSE & ANSYS & $\Delta=\frac{X_{S E}-X_{F E A}}{X_{F E A}} \times 100 \%$ & $\delta_{\text {Allowable }}$ \\
\hline$U_{a r}$ & 0.273 & 0.3 & -9 & 0.320 \\
\hline$U_{a s}$ & 0.303 & 0.2984 & 1.54 & 0.336 \\
\hline$Y_{a r}$ & 0.207 & 0.24 & -13.75 & 35.54 \\
\hline$Y_{a s}$ & 0.889 & 1.11 & -19.90 & 35.54 \\
\hline$Z_{a r}$ & 2.73 & 2.671 & 2.21 & 2.79 \\
\hline$Z_{a s}$ & 2.81 & 2.93 & -4.09 & 2.94 \\
\hline
\end{tabular}

The exercise was repeated for the disc-type structure with a normal stress of $0.219 \mathrm{MPa}$ and a shear stress of $40 \mathrm{kPa}$. The analytically computed deflections (Figure 11 and Table 12) were found to be $96 \%$ to $106 \%$ of FEA results. 


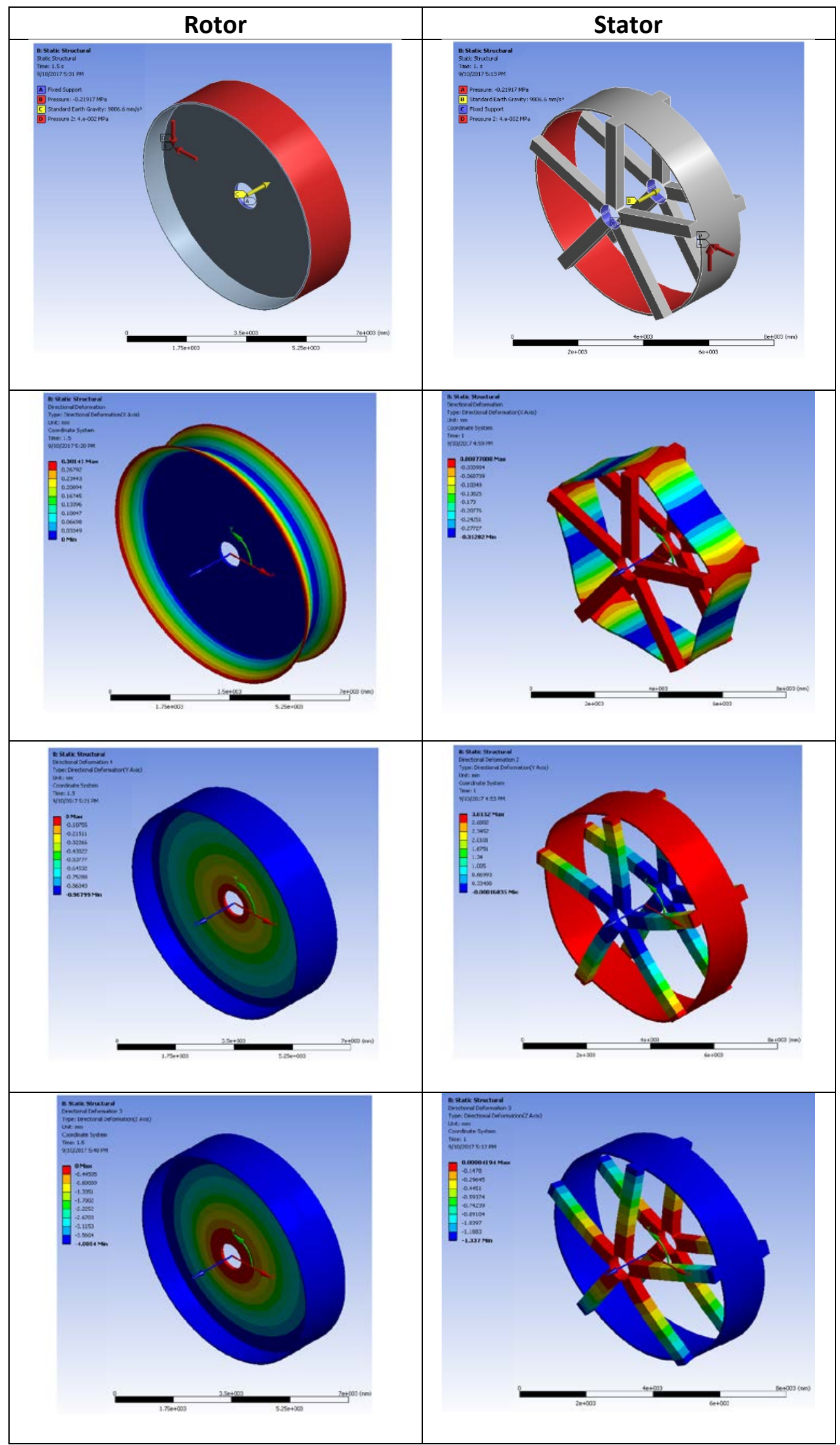

Figure 11. Components of structural deflection computed in ANSYS 
Table 12. Comparison of Structural Deflections: GeneratorSE vs. ANSYS for Arm-Disc-Type Structures

\begin{tabular}{|c|c|c|c|c|}
\hline $\begin{array}{c}\text { Deflection } \\
(\mathbf{m m})\end{array}$ & GeneratorSE & FEA & $\Delta=\frac{X_{S E}-X_{F E A}}{X_{F E A}} \times 100 \%$ & $\delta_{\text {Allowable }}$ \\
\hline$U_{a r}$ & 0.319 & 0.301 & 5.98 & 0.345 \\
\hline$U_{a s}$ & 0.312 & 0.312 & 0 & 0.359 \\
\hline$Y_{a r}$ & 3.864 & 4.0 & -3.4 & 33.14 \\
\hline$Y_{a s}$ & 1.29 & 1.34 & -3.73 & 33.14 \\
\hline$Z_{a r}$ & - & 0.97 & $\mathrm{NA}^{*}$ & $3.01^{\#}$ \\
\hline$Z_{a s}$ & 2.89 & 3.01 & -3.98 & 3.14 \\
\hline
\end{tabular}

*NA- Not applicable, ${ }^{*}$ computed considering $0.05^{\circ}$ as maximum allowable twist

\subsection{Electrically Excited Synchronous Generator}

This section presents the analytical expressions for dimensioning wire-wound synchronous generators that satisfy certain design requirements. The design equations are generally consistent with conventional equivalent circuit models presented in the generator handbook [11] with references to previous studies [27]. The stator is assumed to have rectangular geometry with coils connected to form a three-phase winding. The rotor has a salient pole design with a DC rotor field winding excited by slip rings and brushes. The output of the generator is processed and assumed to be coupled to the utility grid through a full-rated power electronic converter system. The main parts and basic design dimensions with the winding arrangement are shown in Figure $12 \mathrm{a}$ and $\mathrm{b}$. The core of rotors is made of a solid iron pole wheel spider with $2 p$ salient poles usually made of laminations. The poles are attached to the pole wheel spider through a hammer or dove-tail key bars or bolts and screws with end plates [11].

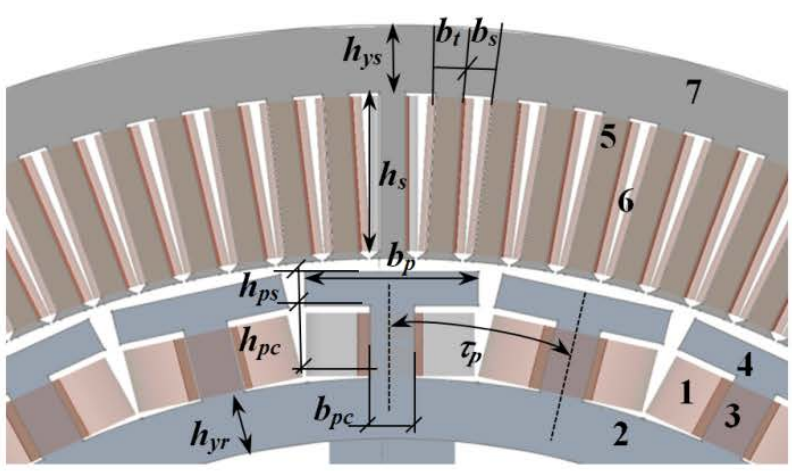

(a)
1. Field coil
2. Rotor back iron
3. Pole core
4. Pole shoe
5. Stator tooth
6. Stator slot(winding)
7. Stator back iron
8. Pole wheel(spider)

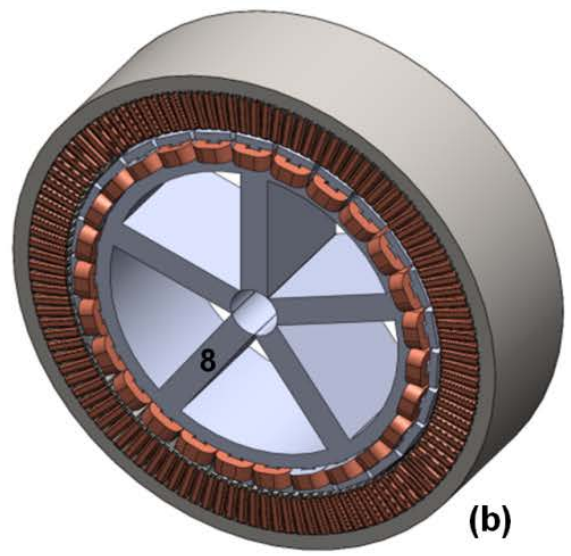

Figure 12. Basic design of an EESG: (a) design dimensions (b) CAD illustration 
The salient pole rotors are designed for a variable air gap under the pole to render the air-gap flux density to be more sinusoidal. The air gap under the rotor pole grows larger towards the pole shoe ends as shown in Figure 12a. However, a simplified geometry with rectangular pole dimensions was assumed so the average air gap under the pole shoe is $g_{a} \sim g$.

The equations for the pole pairs and main dimensions of the stator, namely the slot pitch, slot width, and tooth width are the same as stated for the PMSG (Eqs. [11] through [14]) and therefore not repeated here. The stator slots and stator winding turns in series are calculated using Eq. (12) and (18). Two slots per pole per phase (i.e., $q=2$ ) were considered to arrive at integer slot winding. The stator yoke height and rotor yoke height are treated as design variables with values to ensure that the peak yoke flux densities are below 2 Tesla. The rotor pole shoe width, $b_{p}$, is assumed to be $70 \%$ of the pole pitch. The pole height, $h_{p}$, is assumed to be the same as the pole width. The pole shoe height, $h_{p s}$, is assumed to be $10 \%$ of the pole pitch; the pole core height, $h_{p c}$, and width, $b_{p c}$, are $40 \%$ and $60 \%$ of the pole pitch, respectively [13].

The stator winding phase resistance is calculated using Eq. (19). The length of the conductor in winding is determined by assuming full pitch winding (Eq. [20]). The core length, $L_{t}$, is considered to be the same as the stator, $l_{s}$. The cross-sectional area of the stator winding is given in Eq. 21, assuming a 5-mm wedge thickness, $h_{w}$. The steady-state equivalent circuit and phasor diagram of the wire-wound synchronous machine is shown in Figure 13.
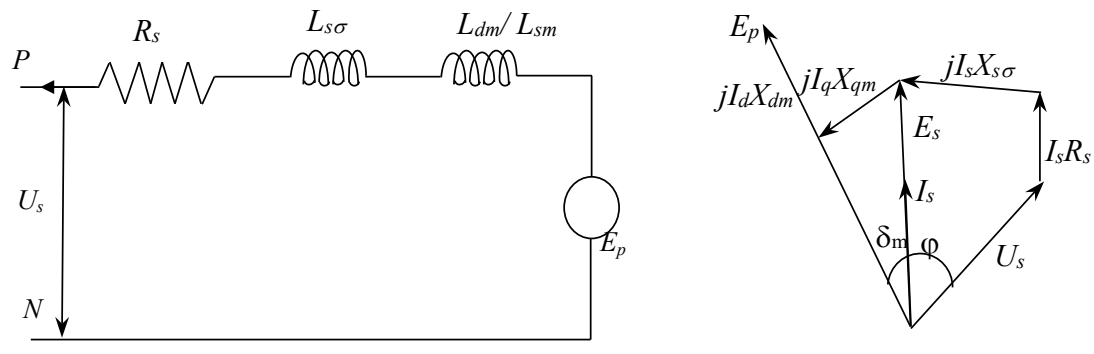

Figure 13. Equivalent circuit model and phasor diagram of an EESG [13]

$L_{s} \sigma, L_{d m}$, and $L_{q m}$ refer to the stator leakage inductance and d-q magnetizing inductances. The stator leakage inductance is made of the typical components from slot leakage, tip-tooth leakage, and end winding leakage as described in Section 2.1 and the magnetizing inductance is calculated. The direct and quadrature axis inductances are estimated as

$$
\begin{gathered}
L_{d m}=\left(\frac{b_{p}}{\tau_{p}}+\frac{1}{\pi} \sin \left(\pi \frac{b_{p}}{\tau_{p}}\right)\right) L_{m} \cong 0.95 L_{m} \\
L_{q m}=\left(\frac{b_{p}}{\tau_{p}}-\frac{1}{\pi} \sin \left(\pi \frac{b_{p}}{\tau_{p}}\right)\right)+\frac{2}{3 \pi} \cos \left(\frac{\pi b_{p}}{2 \tau_{p}}\right) L_{m} \cong 0.5 L_{m}
\end{gathered}
$$

The synchronous magnetizing inductance is given by

$$
L_{d, q}=L_{d m, q m}+L_{s \sigma}
$$

The mutual inductance between the stator and rotor is calculated from the fundamental harmonic of the rotor-field flux density. The main inductances depend on the saturation in iron, which is interpreted as an increase in the effective air gap, $g_{\text {eff. }}$ Stator slotting and the finite permeability 
of iron are the main reasons for the flux path to be longer than the air gap, which is modeled using [27]

$$
g^{\prime}=K_{c} g
$$

where $K_{c}$ is the Carter factor for slots given by

$$
K_{c}=\frac{\left(\tau_{s}+10 g_{a}\right)}{\left(\tau_{s}-b_{s}+10 g_{a}\right)}
$$

where the average air gap under the salient rotor pole shoe is

$$
\mathrm{g}_{\mathrm{a}} \sim \mathrm{g}
$$

The effective air-gap length is determined from the total ampere turns required for magnetizing the air gap, which involves the flux densities caused by the poles $\left(B_{g}\right)$, stator teeth $\left(\widehat{B}_{t}\right)$, stator yoke $\left(\hat{B}_{s y}\right)$, rotor pole core $\left(\hat{B}_{p c}\right)$, and rotor yoke $\left(\hat{B}_{r y}\right)[27]$

$$
g_{\text {eff }}=\frac{A t_{\text {total }}}{A t_{g}} g^{\prime}=\frac{A t_{t}+A t_{s y}+A t_{p c}+A t_{r y}}{A t_{g}} g^{\prime}
$$

with the respective ampere turns computed from the flux densities as

$$
\begin{gathered}
A t_{g}=\frac{\hat{B}_{g}}{\mu_{0}} g^{\prime} \\
A t_{t}=h_{s}\left(400 \hat{B}_{t}+7 \hat{B}_{t}^{13}\right) \\
A t_{s y}=0.5 \tau_{p}\left(400 \hat{B}_{s y}+7 \hat{B}_{s y}^{13}\right) \\
A t_{p c}=\left(h_{p c}+h_{p s}\right)\left(400 \hat{B}_{p c}+7 \hat{B}_{p c}^{13}\right) \\
A t_{r y}=0.5 \tau_{p}\left(400 \hat{B}_{r y}+7 \hat{B}_{r y}^{13}\right)
\end{gathered}
$$

The fundamental component of air-gap flux density obtained from Ampere's law is given by [11]

$$
\hat{B}_{g 1}=\frac{\mu_{o} N_{f} \cdot I_{f}}{K_{c} g\left(1+\mathrm{K}_{s}\right)}
$$

where $N_{f}$ and $I_{f}$ are field winding turns and current, respectively. $K_{s}$, the magnetic saturation factor for iron, is assumed at 0.2. The peak air-gap flux density is estimated using

$$
\begin{gathered}
\hat{B}_{g}=\hat{B}_{g 1} \cdot \frac{4}{\pi} \sin \left(0.5 \frac{b_{p} \pi}{\tau_{p}}\right) \\
\hat{B}_{t}=\left(\hat{B}_{g}+\hat{B}_{g 1}\right) \frac{\tau_{s}}{2 b_{t}} \\
\hat{B}_{s y}=\frac{\tau_{p}}{\pi h_{y s}} \hat{B}_{g} \\
\hat{B}_{r y}=\frac{0.5 b_{p c} B_{p c}}{h_{y r}} \\
\hat{B}_{p c}=\frac{1}{b_{p c}}\left(\frac{2 \tau_{p}}{\pi} \hat{B}_{g} \cos \left(\delta_{m}\right)+2 \mu_{o} N_{f} I_{f}\left(\frac{2 h_{p s}}{\tau_{p}-b_{s}}+\frac{h_{p c}}{\tau_{p}-b_{p c}}\right)\right)
\end{gathered}
$$


where $\delta_{\mathrm{m}}$ is the load angle (Figure 13), given by

$$
\delta_{m}=\tan ^{-1}\left(\omega_{e} L_{q m} \frac{I_{s}}{E_{s}}\right)
$$

Because the load angle is not known at the beginning of optimization, it is initialized at $\delta_{\mathrm{m}}=$ zero [27] and iterated to appropriate values after the flux densities are calculated. The phase current, $I_{s}$, is [13]

$$
I_{S}=\frac{1}{2 R_{S}}\left(E_{s}-\sqrt{E_{S}^{2}-\frac{4 R_{s} P_{\text {rated }}}{3}}\right)
$$

Eq. (32) and (33) are applied to determine the stator winding current density and specific electric loading.

The no-load voltage induced by a flux density with amplitude $\widehat{B}_{g 1}$ in the stator winding is given by

$$
E_{s}=\sqrt{2} N_{s} I_{s} r_{s} k_{w} \omega_{m} \hat{B}_{g}
$$

where $\omega_{m}$ is the angular frequency of the rotor and $k_{w}$ is the stator winding factor given by Eq. (27). The voltage induced by the rotor poles is given by

$$
\begin{gathered}
E_{p}=\omega_{e} L_{d m} I_{s d}+\sqrt{E_{s}^{2}-\left(\omega_{e} L_{q m} I_{s q}\right)^{2}} \\
\text { where } I_{s d}=I_{s} \sin \left(\delta_{m}\right) \text { and } \\
I_{s q}=I_{s} \cos \left(\delta_{m}\right)
\end{gathered}
$$

\subsubsection{Field Winding Design}

The field winding is made of a number of single-circuit coils that are energized with DC power fed via the shaft from the slip rings riding on the shaft and positioned outside the main generator bearings. It is typical for the rotor field to be fed from a relatively low-power, low-voltage circuit rated between 120 and 500 volts (V) (moving high currents and high power through the slip rings and brushes would represent a technical challenge, making the machine that much more complex and expensive). The resistance of the field winding in the rotor is calculated using

$$
R_{r}=\frac{\rho_{c u} L_{c u r}}{A_{c u r}}
$$

the length of field winding is determined using [13]

$$
L_{c u r}=4 p N_{f}\left(L_{p f e}+b_{p c}+\frac{\pi}{4}\left(\frac{\pi\left(r_{r}-h_{p c}-h_{p s}\right)}{p}-b_{p c}\right)\right)
$$

Where the length of the pole core, $L_{p f e}$ is assumed to be $50 \mathrm{~mm}$ than the stator core length and $120 \mathrm{~mm}$ longer to accommodate end stack. Considering iron fill factor for rotor, $K_{f e}=0.95, L_{p f e}=0.95(l-0.05+0.120)$

$$
A_{\text {cur }}=k_{\text {fillr }} \frac{h_{p c}}{2 N_{f}}\left(\frac{\pi\left(r_{r}-h_{p c}-h_{p s}\right)}{p}-b_{p c}\right)
$$


where $r_{r}$ is the rotor outer radius and $k_{f i l l}$ is the rotor fill factor assumed at 0.7 .

For constant speed operations, conventional salient pole generators that are directly coupled to the grid are equipped with damper windings to attenuate synchronous field feedback when asynchronous loads occur. They also help minimize rotor vibrations caused by grid perturbance, voltage rise during short circuits, and stator slot harmonic components in the voltage [24]. For wind turbine application, variable-speed operation for large synchronous machines has a major influence on the rotor design and the ability to operate in unbalanced load conditions. A variable frequency power electronic converter can provide the necessary attenuation when asynchronous loads occur thereby precluding the need to include a damper cage in the rotor design.

The rotor field excitation is generally determined in response to changing wind speeds. The rotor excitation required on load at rated wind speed is determined by the peak air-gap flux density required to generate the required terminal voltage. The excitation power is estimated assuming a rated DC supply voltage $V_{f}$ as

$$
P_{\text {excitation }}=2 \cdot V_{f} \cdot I_{f}
$$

The field current density $\left(\mathrm{A} / \mathrm{mm}^{2}\right)$ is determined using

$$
J_{f}=\frac{I_{f}}{A_{\text {cur }} 10^{6}}
$$

\subsubsection{Generator Losses and Efficiency}

Four main types of losses are typical in EESGs: copper losses, iron losses, mechanical losses (bearing and ventilation), and losses in the brushes-slip ring/exciter system, if any. Additional losses may exist, such as the end-stack core losses and extra losses in stator teeth from magnetic saturation. However, no additional correction factors have been modeled in the present tool. The copper losses in an EESG are greater than the PMSG because of the additional DC losses from the field winding in the rotor. The total contribution from the stator and rotor winding is calculated from

$$
P_{c u}=\left(I_{f}^{2} R_{f}+m I_{s}^{2} R_{s} K_{R}\right)
$$

A correction factor $K_{R}$ of 1.2 was used to adjust the losses in the stator winding due to skin effects. The losses in the brushes and slip rings are approximated using [11]

$$
P_{b}=2 \cdot \Delta V \cdot I_{f} \text { with contact voltage drop, } \Delta V<1 \text { by design }
$$

\section{Brushes}

The number of brushes per polarity is chosen by assuming a standard brush current density of 12 Ampere/centimeter ${ }^{2}\left(\mathrm{~A} / \mathrm{cm}^{2}\right)$ or 0.12 Ampere/millimeter ${ }^{2}\left(\mathrm{~A} / \mathrm{mm}^{2}\right)$ [28]. The brush is assumed to be made of electrographitic material applicable for synchronous machines used in low humidity or difficult filming conditions. The standard brush cross section ( $t \times{ } a)$ (as shown in Figure 14) was assumed to be $25 \mathrm{~mm}$ by $40 \mathrm{~mm}$. The maximum current each brush carries is $120 \mathrm{~A}$. The field current is divided by the brush current to determine the number of brushes, $N_{b}$. 


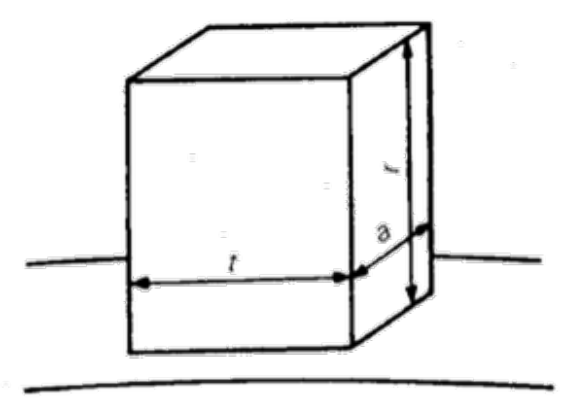

Figure 14. Typical brush cross section [29]

The specific iron losses $\left(P_{\mathrm{fe}}\right)$ in teeth and yoke are determined in the same manner as described in Section 2, using the Steinmetz formula. The losses are approximated using

$$
P_{\text {Losses }}=P_{c u}+P_{b}+P_{f e}
$$

The efficiency of the generator is approximated using

$$
\eta=\frac{P_{g e n}-P_{\text {Losses }}}{P_{\text {gen }}} \times 100
$$

The efficiency model may be further refined to include losses from ventilation circuit, short circuit, and bearing losses [11].

\subsubsection{Generator Mass}

The total active material mass is made up of the winding weight from the stator and rotor and iron in the rotor (pole and yoke) and stator (teeth and yoke)

$$
M_{a c t}=M_{C u}+M_{F e}
$$

where $M_{c u}$ is the mass of copper in the stator and rotor given by

$$
\begin{gathered}
M_{c u}=\rho_{c u}\left(m L_{c u s} A_{c u s}\right)+M_{c u r} \\
\text { where } M_{c u r}=\rho_{c u}\left(L_{c u r} A_{c u r}\right)
\end{gathered}
$$

The mass of the iron is calculated as [13]

$$
\begin{gathered}
M_{F e}=M_{F e s y}+M_{F e s t}+M_{F e r y}+M_{F e r t} \\
M_{F e s t}=\rho_{F e}\left(\pi L_{t}\left(\left(r_{s}+h_{s}\right)^{2}-r_{s}^{2}\right)-2 m q p b_{s} h_{s} L_{t}\right) \\
M_{F e s y}=\rho_{F e}\left(\pi L_{t}\left(r_{s}+h_{s}+h_{y s}\right)^{2}-\left(r_{s}+h_{s}\right)^{2}\right) \\
M_{F e r t}=\rho_{F e}\left(2 p L_{t}\left(b_{p c} h_{p c}+b_{p s} h_{p s}\right)\right. \\
M_{F e r y}=\rho_{F e}\left(\pi L_{t}\left(r_{r}-h_{p s}-h_{p c}\right)^{2}-\left(r_{r}-h_{p s}-h_{p c}-h_{r y}\right)^{2}\right)
\end{gathered}
$$

\subsubsection{Structural Mass}

Estimates for structural mass for some commercially available EESGs are not known. However, to arrive at practical estimates, the spoked-arm structure (Figure 3a), which is similar to the PMSG, was considered as this closely represented the pole wheel spider shown in Figure 12(b). 
The cross section of the integrated structural and magnetic rotor-stator assembly is illustrated in Figure 15. The analytical treatment for the structural deflections for the stator is fundamentally similar to the PMSG, based on the models discussed by McDonald [15, 21]. Yet, the main difference between the two exists in the treatment of the rotor cylinder support structure, wherein the weight of the magnets is replaced with the rotor pole core and copper windings. To determine the weight of the rotor cylinder support structure, the weight of the magnets was replaced by that of rotor pole core, pole shoe, and field winding. The weight acting on the $\mathrm{n}^{\text {th }}$ section of the rotor cylinder is calculated as

$$
W_{\mathrm{r}}=\frac{g \sin \varphi}{N_{r}}\left(\rho_{f e} 2 \pi\left(R+0.5 h_{y r}\right) l h_{y r}+M_{F e r t}+M_{C u r}\right)
$$

For the purpose of verifying the structural stiffness of the design, the three main components of structural deflection were calculated using the same formulations listed in [15]. For the purpose of calculations, the generators were assumed to be operating at an ambient temperature with adequate cooling so that the temperature rise is within limits, therefore eliminating the need to model deflection caused by thermal expansion.

Figure 15 shows the integrated assembly of electromagnetic and structural parts.

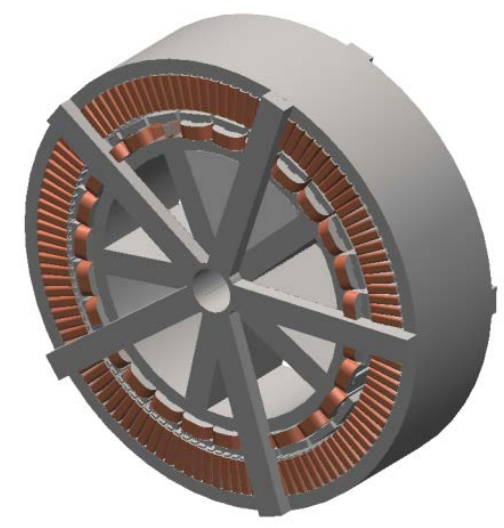

Figure 15. CAD illustration of the integrated EESG assembly

\subsubsection{Design Optimization}

Similar to the permanent-magnet synchronous machine, the physical air-gap length is kept small for electrical excitation in the case of high-torque application. However, the design trade-off is in the determination of the rotor field excitation (copper winding requirement and field current), while also ensuring adequate structural stiffness to avoid air-gap closure. GeneratorSE searches for the optimal electromagnetic and structural design satisfying one of the following objectives.

\subsubsection{Mass Optimization}

The objective function that seeks to find a lightweight design is given by

$$
\text { Mass }=M_{\text {act }}+M_{\text {inactive }}
$$

The inactive mass is calculated using the same equation as that of spoked-arm construction for PMSG (i.e., Eq. [48]). The design dimensions are optimized without compromising structural strength and generator performance. 


\subsubsection{Cost and Efficiency Optimization}

Costs are minimized with an objective

$$
\text { Costs }=C_{C U} \cdot M_{c u}+C_{\text {steel,struc }} \cdot M_{\text {steel,struc }}+C_{\text {steel,mag }} \cdot M_{\text {steel,mag }}
$$

$C_{C U}, C_{\text {steel,struc }}, C_{\text {steel,mag }}$ are the specific costs of the copper, structural steel, and steel/iron used in the magnetic circuit. In terms of optimization, copper applies the highest penalty owing to its relatively higher cost as compared to structural steel, or iron/magnetic steel; hence a costoptimized design is bound to have less copper content.

The most efficient design is obtained by forcing an objective that minimizes the losses given by

$$
\text { Losses }=P_{c u}+P_{b}+P_{f e}
$$

This implies that the stator core dimensions, together with the stator currents and the field currents, are minimized.

\subsubsection{Optimization of Aspect Ratio}

The final optimization problem attempts to locate a design that ensures an optimal aspect ratio $\left(k_{\mathrm{rad}}\right)$. Equation (55) applies for a light weight with a small design envelope of diameter and stack length.

\subsubsection{Decision Variables}

To optimize the generator design for the proposed objectives, we chose 16 free parameters. The other dimensions were calculated from the given parameters. The key design inputs for the EESG include main shaft radius, generator torque, rated speed, power and target efficiency as previously defined in Table 5.

\subsubsection{Magnetic Circuit}

Eight parameters of the generator (Table 13), namely the air-gap radius, stator length, slot height, pole pitch, and rotor ampere-turns (field turns $\left(N_{f}\right)$ and field current $\left(I_{f}\right)$ ), stator, and rotor yoke heights are allowed to vary within a certain range. Rotor turns and field current were chosen as design variables to allow users to examine the sensitivities of the generator performance and weight to conductor usage. The air-gap length $(g)$ and rotor pole dimensions were defined as geometrical variables. Detailed thermal modeling, ventilation circuit, and temperature rise constraints were not included but will be a part of future work. The three design constraints that limit the size and life of generator rotors are temperature, mechanical force, and electrical insulation. A few important mechanical design considerations include [30]:

- The winding and associated components must withstand centrifugal loading at speed and possible over speed

- The winding and its insulation system must fit within the space available for the rotor slot. The amount of space available for the rotor slot is dependent on the stresses in the rotor teeth; the more area used for the slot, the higher the tooth stresses.

The rotor winding magneto-motive force (mmf) or ampere-turns (field winding turns, $N_{f}$, and field current, $I_{f}$ ) determine the conductor cross section and hence the resistance of the field winding. These values are chosen to achieve a certain required peak air-gap flux density without exceeding the generator terminal voltage by $5 \mathrm{kV}$. The minimum conductor cross section is selected to be 
greater than $10 \mathrm{~mm}^{2}$ to withstand centrifugal loading. The field current is limited such that the total excitation power is less than $2 \%$ of the power rating.

Table 13 lists the main design and performance variables.

Table 13. Electromagnetic Design and Performance Variables in EESG

\begin{tabular}{clcl}
\hline \hline Symbol & Design Variables & Symbol & Performance Variables \\
\hline \hline$r_{s}$ & Air-gap radius & $\hat{B}_{g}$ & Peak air-gap flux density \\
$I_{s}$ & Stator core length & $\hat{B}_{s y}$ & Peak stator yoke flux density \\
$h_{s}$ & Slot height & $\hat{B}_{t}$ & Peak stator tooth flux density \\
$\tau_{p}$ & Pole pitch & $\hat{B}_{r y}$ & Peak rotor yoke flux density \\
$N_{f}$ & Field turns & $\hat{B}_{p c}$ & Peak pole core flux density \\
$I_{f}$ & Field current & $E_{p}$ & Generator output voltage \\
$h_{y s}$ & Stator yoke height & $A_{1}$ & Specific stator current loading \\
$h_{y r}$ & Rotor yoke height & $J_{s}$ & Stator current density \\
& & $J_{f}$ & Rotor current density \\
& & $P_{e x c i t a t i o n}$ & Excitation power \\
& & $f$ & Frequency \\
\hline
\end{tabular}

The key design constants and constraints imposed on the electromagnetic design and performance indices are listed in Table 14.

Table 14. Electromagnetic Design Constants and Constraints for EESG

\begin{tabular}{lll}
\hline \hline Parameter & Symbol & Value \\
\hline Permeability of free space & $\mu_{o}$ & $4 \pi 10^{-7}$ \\
\hline Relative permeability & $\mu_{r}$ & 1.06 \\
\hline Slot wedge thickness & $h_{w}$ & $5 \mathrm{~mm}$ \\
\hline Shear stress & $\sigma$ & $48.373 \mathrm{kN} / \mathrm{m}^{2}$ \\
\hline Stator Slot fill factor & $k_{\text {sfill }}$ & 0.65 \\
\hline Rotor Slot fill factor & $k_{\text {fillr }}$ & 0.7 \\
\hline Specific hysteresis losses & $P_{\text {FeOh }}$ & $4 \mathrm{~W} / \mathrm{kg}$ \\
\hline Specific eddy current & $P_{\text {FeOe }}$ & $1 \mathrm{~W} / \mathrm{kg}$ \\
\hline Copper resistivity & $\rho_{\text {cu }}$ & $2.52 \mathrm{e}-08 \Omega \mathrm{m}$ \\
\hline Stator slot opening & $b_{s o}$ & $4 \mathrm{~mm}$ \\
\hline $0.7 T \leq \hat{B}_{g} \leq 1.2 T$ & & $A_{1}<60 \mathrm{kA} / \mathrm{m}$ \\
$0.61 T \leq \hat{B}_{g 1} \leq 1.05 T$ & & \\
\hline$\widehat{B}_{s y}<2 T$ & & $J_{s} \leq 6 \mathrm{~A} / \mathrm{mm}^{2}$ \\
\hline$\widehat{B}_{r y}<2 T$ & & $0.2<k_{\text {rad }} \leq 0.27$ \\
\hline$\widehat{B}_{p c}<2 T$ & & $\eta \geq \eta_{\text {target }}$ \\
\hline$\widehat{B}_{t}<2 T$ & $N_{b}<6$ \\
\hline $500 \mathrm{~V} \leq E_{s} \leq 5000 \mathrm{~V}$ & $4 \leq \mathrm{h}_{s} / \mathrm{b}_{\mathrm{s}} \leq 10$ \\
\hline $10 \mathrm{~Hz}<f<60 \mathrm{~Hz}$ & $P_{\text {excitation }} / P_{\text {nom }}<0.02$ \\
\hline $300 \mathrm{~mm}^{2} \leq A_{c u s} \leq 5 \mathrm{~mm}^{2}$ & & \\
\hline $300 \mathrm{~mm}^{2} \leq A_{c u r} \leq 10 \mathrm{~mm}^{2}$ & & \\
\hline
\end{tabular}




\subsubsection{Structural Design}

A total of eight design variables that apply to the spoked-arm construction previously listed in Table 8 are valid for the EESG. The absence of permanent magnets does not warrant a rigorous support structure design. However, analogous to the PMSG, the air-gap length, $g$, was retained at $1 / 1,00{ }^{\text {th }}$ of the air-gap diameter. Hence, the structural deflection constraints as listed in [15] are still applicable (i.e., $10 \%$ of the air-gap clearance for the total radial deflection, $2 \%$ of the axial length for the gravitational deflection, and a relative twist of $0.05^{\circ}$ for torsional deflection). The presence of rotor windings and pole core material entails a heavier rotor structure for the EESG as compared to PMSG. A more lenient constraint was considered by allowing the structures to deflect by up to $20 \%$ so that the resulting structures are not excessively heavy. This still lies within tolerance margin permissible for these designs [23].

\subsubsection{Optimization Assumptions, Results, and Validation}

Appendix A6 presents the boundary conditions and initialization problem for each case. Some of the key assumptions in the optimization process include:

- The number of slots per pole per phase $(\mathrm{q}=2)$

- Stator winding is fully pitched; single layer to arrive at integer slot winding

- The temperature of the winding is assumed at $120^{\circ}$

- The current density in the stator and field windings is limited to $6 \mathrm{~A} / \mathrm{mm}^{2}$.

Appendix A7 presents the initial dimensions of the cost optimized designs for turbines rated between 0.75 and $10 \mathrm{MW}$. The results also indicate the trends in mass. We emphasize that GeneratorSE models do not account for thermal design optimization. However, limiting the rotor current density and stator current densities to below $6 \mathrm{~A} / \mathrm{mm}^{2}$ helps avoid excessive temperature rise. 


\subsubsection{Electromagnetic Design Validation}

\section{Stator magnetic core}

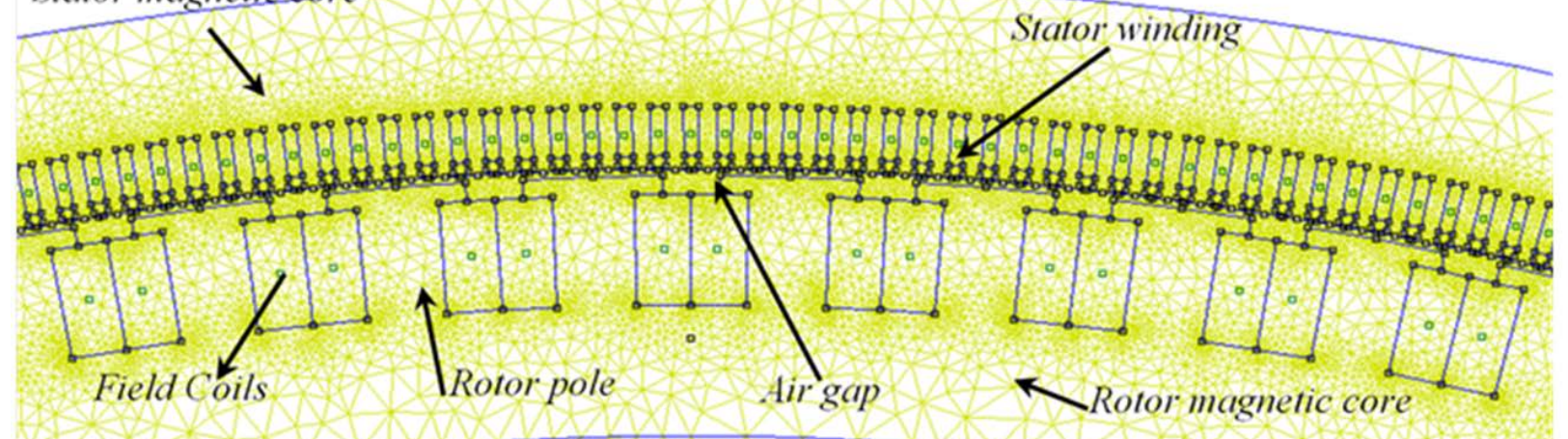

(a)
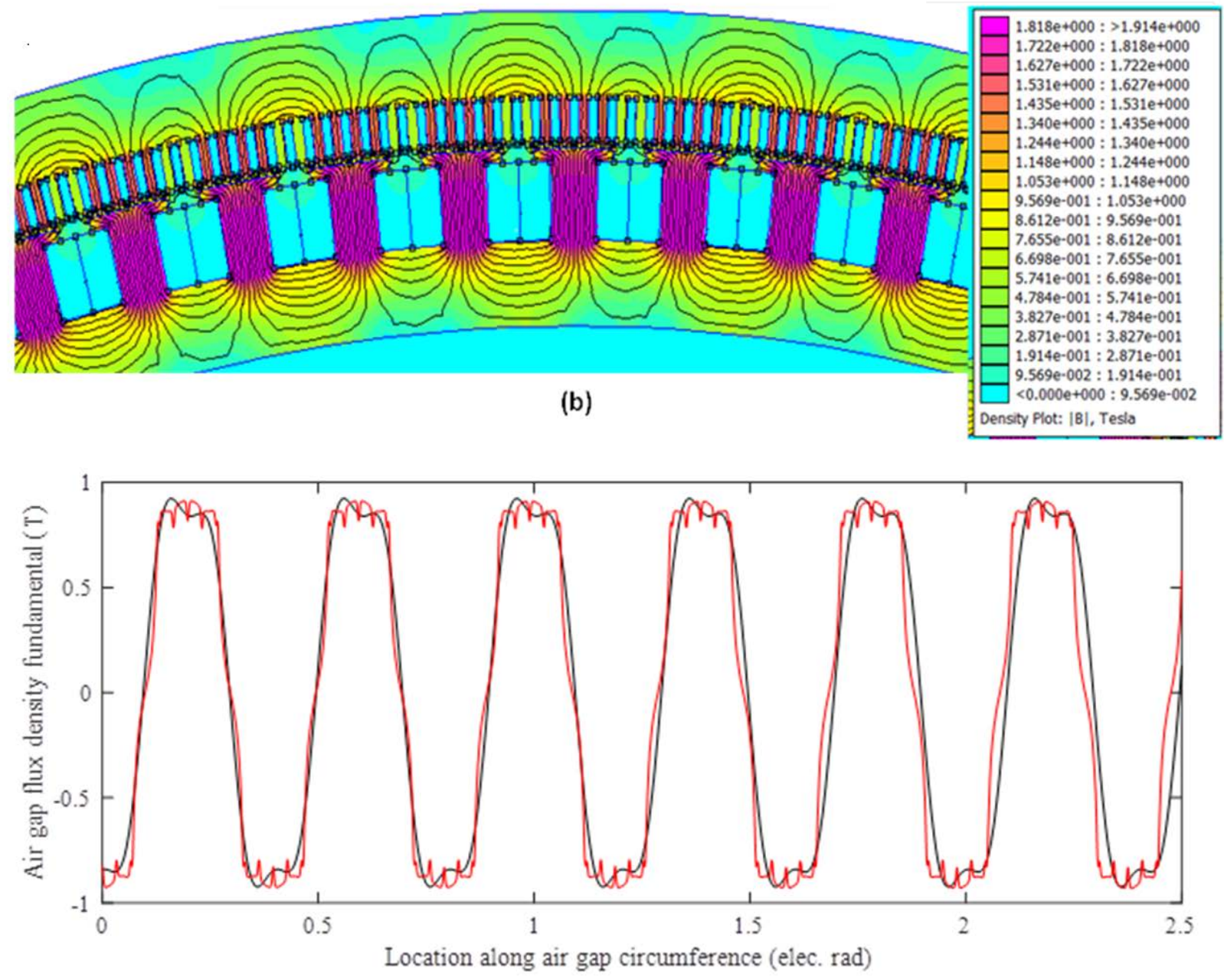

(c)

Figure 16. The 5-MW EESG model using FEMM showing (a) the finite-element mesh, (b) magnetic flux density contour, and (c) a comparison of air-gap flux density estimated using FEMM and analytical model in GeneratorSE. 
Figure 16 shows a segment of a finite-element mesh of the 5-MW salient pole EESG modeled using the MATLAB interface for FEMM with the optimized dimensions for the poles, slots, and teeth from GeneratorSE (Appendix A7). We used a single layer winding with 216 turns per phase with the pattern (as shown in Figure 17) to obtain the entire stator winding layout.

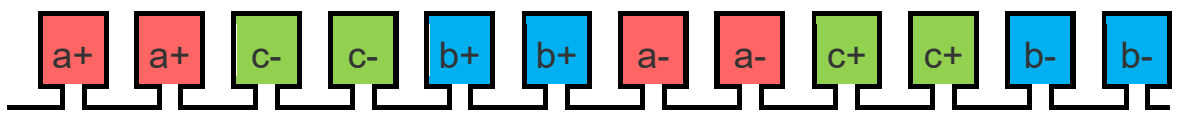

Figure 17. Stator winding layout in EESG reproduced from [26]

The rotor coils were made up of 100 turns of copper (plain stranded wire with electrical conductivity [58 Mega Siemens/meter $(\mathrm{MS} / \mathrm{m})$ ]) that were wound forward, then backwards, then forward, creating a succession of north and south poles in the pole pieces of the rotor. These coils were supplied with a no-load magnetization current of 68.95 A with circuits each assigned a positive and negative polarity. Stator and rotor magnetic cores were modeled using iron with same nonlinear B-H characteristics as shown in Figure 7. The boundary conditions consist of zero magnetic flux conditions on the outer surface of the stator magnetic core and inner surface of the rotor magnetic core in contact with the rotor shaft. Figure 16 (b) shows the magnetic flux distribution contour of the examined salient pole synchronous generator at the no-load steady state with an initial rotor position of $\theta=0^{\circ}$. The computed spatial distribution of air-gap flux density using GeneratorSE (Eq. [56] and [57] shows a very good correlation with those obtained from FEA. Table 15 compares the peak values of flux densities in the various parts of the machine predicted by FEA against GeneratorSE at the no-load condition. The results are between $102 \%$ and $108 \%$ of the FEA predictions.

Table 15. Comparison of Magnetic Loading in EESG (FEA vs. GeneratorSE)

\begin{tabular}{|l|c|c|c|}
\hline $\begin{array}{l}\text { Peak value of flux density } \\
\text { (Tesla) }\end{array}$ & GeneratorSE & FEA & $\Delta=\frac{X_{S_{E}-X_{F E A}}}{X_{F E A}} \times 100$ \\
\hline Stator yoke & 0.468 & 0.443 & 5.64 \\
\hline Rotor yoke & 0.606 & 0.565 & 7.26 \\
\hline Stator teeth & 1.75 & 1.63 & 7.36 \\
\hline Rotor pole core & 1.99 & 1.94 & 2.58 \\
\hline
\end{tabular}

\subsubsection{Structural Design Validation}

CAD models of the stator and rotor for the spoked-arm combination for the 5-MW EESG were created using the structural design dimensions predicted by GeneratorSE (Appendix A7). The designs were then evaluated by static structural analysis in ANSYS. Defined using a cylindrical coordinate system (as shown in Figure 18), the main loads applied to the models include acceleration caused by gravity (the gravity component was applied in the -ve $\mathrm{Z}$ direction to represent the extreme case involving transportation), a normal stress of $0.413 \mathrm{MPa}$ (normal to the rotor exterior and stator interior surfaces), and a shear stress of $48.303 \mathrm{kPa}$ along the $\mathrm{y}$-axis. Similar to the PMSG, only the support structure arms and cylinder back thickness are modeled. The weight components of stator tooth, rotor pole core and shoes, and copper windings in both the stator and rotor were included as lumped load acting at the center of mass in the FEA model and were assumed to act in the -ve $\mathrm{Z}$ direction. Figure 18 shows the components of structural deflections computed in ANSYS for the stator and rotor models. 


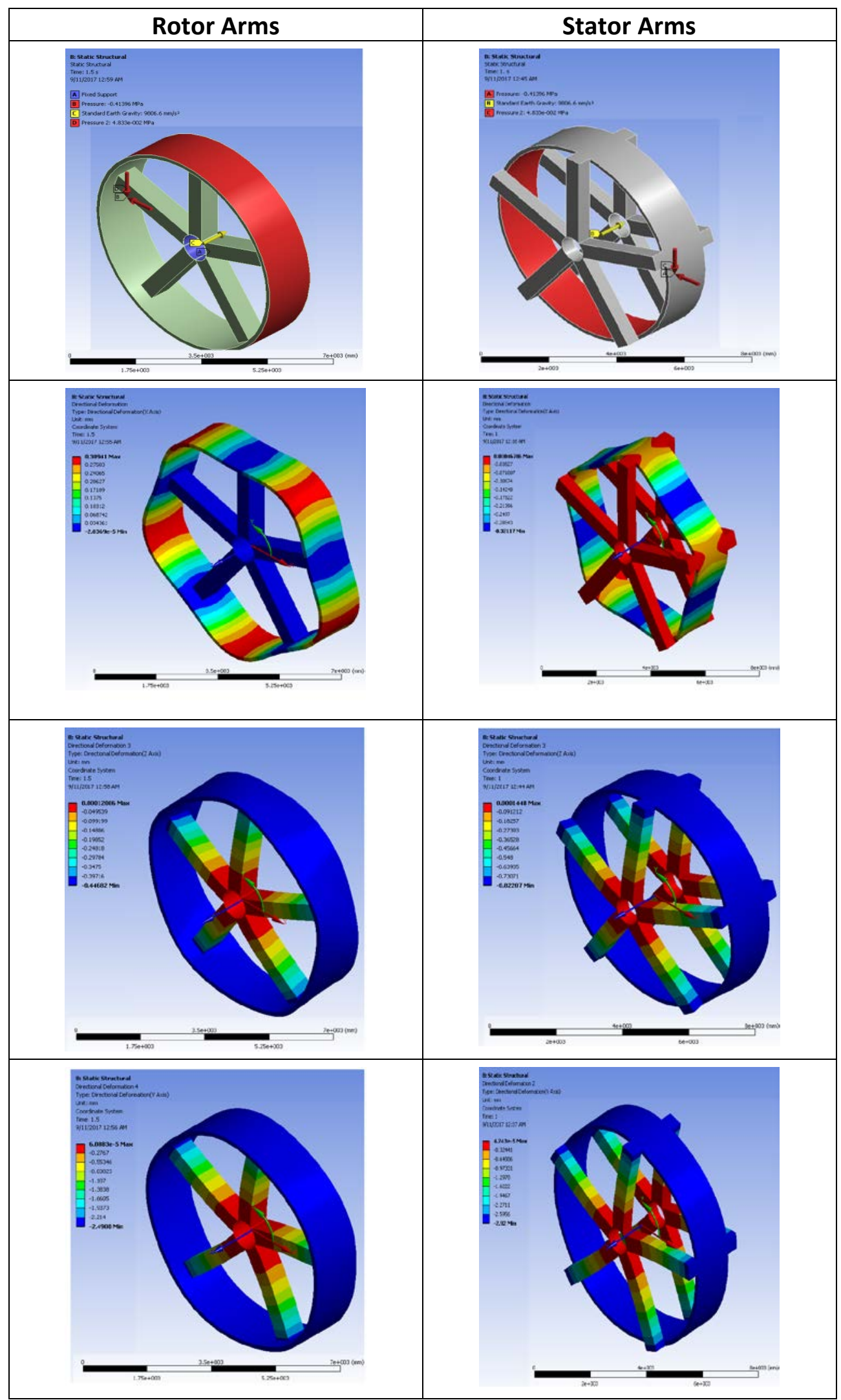

Figure 18. Components of structural deflection for the 5-MW EESG computed in ANSYS 
Table 16 compares the results of deflections against the computed values in GeneratorSE. The highest of the maximum values along the $\mathrm{X}, \mathrm{Y}$, and $\mathrm{Z}$ coordinates is compared against those predicted by GeneratorSE. The results are between $86 \%$ and $105 \%$ of FEA predictions.

Table 16. Comparison of Structural Deflections: GeneratorSE vs. ANSYS for Arm-Type Structures

\begin{tabular}{|c|c|c|c|c|}
\hline $\begin{array}{c}\text { Deflection } \\
(\mathbf{m m})\end{array}$ & GeneratorSE & FEA & $\Delta=\frac{X_{S E}-X_{F E A}}{X_{F E A}} \times 100$ & $\delta_{\text {Allowable }}$ \\
\hline$U_{a r}$ & 0.29 & 0.309 & -6.15 & 0.319 \\
\hline$U_{a s}$ & 0.335 & 0.3211 & 4.33 & 0.354 \\
\hline$Y_{a r}$ & 0.385 & 0.446 & -13.68 & 30.47 \\
\hline$Y_{a s}$ & 0.784 & 0.822 & -4.62 & 30.47 \\
\hline$Z_{a r}$ & 2.58 & 2.49 & 3.61 & 2.788 \\
\hline$Z_{a s}$ & 3.03 & 2.92 & 3.77 & 3.09 \\
\hline
\end{tabular}

\subsection{Asynchronous Generator: Squirrel Cage Rotor Induction Generators (SCIG-3G)}

Asynchronous generators are more popular with gear-driven wind turbines as they enable connection of high-speed machines to the grid. These machines are characterized by cylindrical stator and rotor cores with uniform slots separated by a small air gap (0.3 to $2 \mathrm{~mm}$ in general). The stator slots carry a three-phase winding similar to synchronous generators. The cage rotor contains aluminum or copper bars that are short-circuited by end rings. Figure 18 shows the main design dimensions and parts of a squirrel cage rotor induction generator.

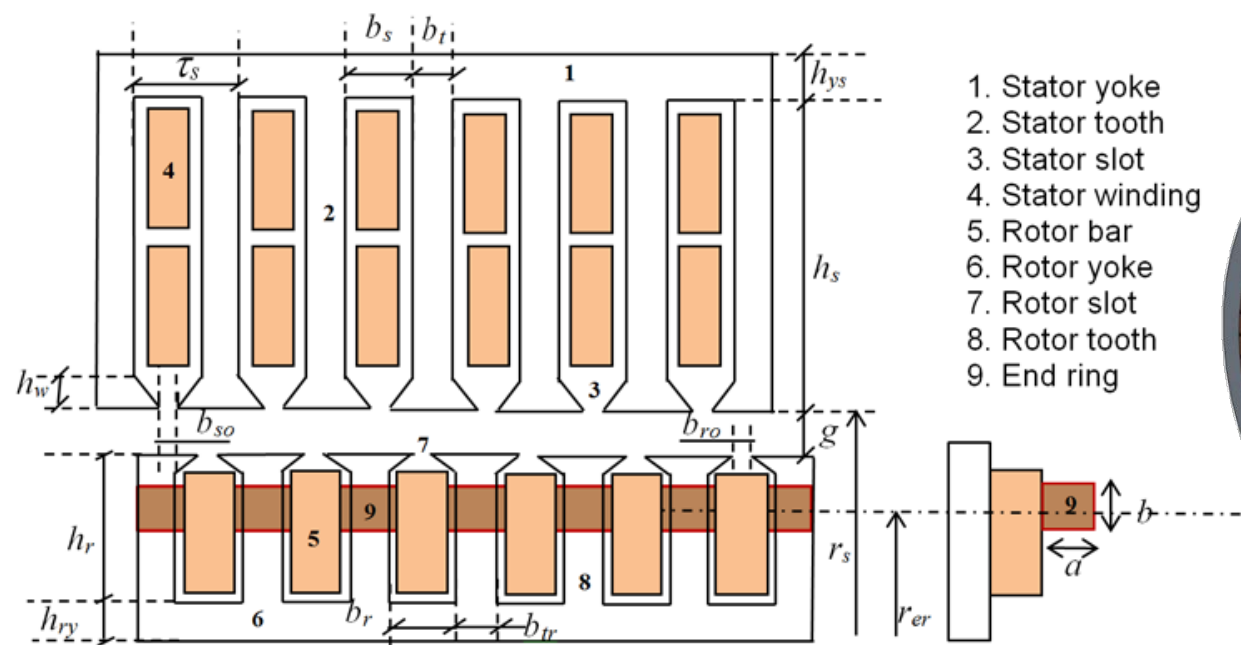

(a) (b)

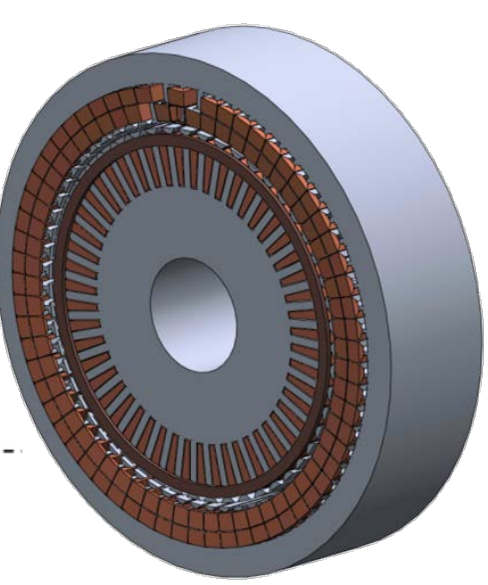

(c)

Figure 19. Basic design of an SCIG: design dimensions (a), end-ring section (b), and CAD illustration (c)

The cage rotor induction generator was widely used in the fixed-speed wind turbine concept. Variable-speed operation with SCIGs has been possible with full-scale power electronic converters [25]. For example, Siemens' generator portfolio for wind turbines with a capacity of up to $6 \mathrm{MW}$ are squirrel-cage machines [31]. There are two main design concepts used when calculating the stator interior diameter, $D_{s}$ : the output coefficient design concept $(C e$ Esson 
coefficient) and the tangential rotor stress as described in the generator design handbooks [32-34]. The basic machine diameter is determined using the tangential stress design concept [32]. The air-gap diameter of the generator stator for a given power rating, $P_{\text {rated }}$, depends on the tangential stress, $\sigma_{\tan }$, and the aspect ratio, $\lambda=\frac{2 p L}{\pi D_{S}}$, and can be analytically determined as [32]

$$
D_{s}=\sqrt[3]{\frac{4 p^{2} P_{\text {rated }}}{\pi \lambda \sigma_{\text {tan }} \cdot f\left(1-s_{N}\right)}}
$$

The rotor tangential stress, $\sigma$, is determined from the electromagnetic torque as

$$
\sigma_{\text {tan }}=\frac{T_{e} \cdot 2}{\pi D_{s}^{2} L}
$$

The electromagnetic torque, $T_{e}$, is approximated as

$$
T_{e}=p \frac{P_{\text {rated }} \cdot 1.01}{2 \pi f\left(1-S_{N}\right)}
$$

The range of tangential stress is usually between 20 and $25 \mathrm{kPa}$ [24]. To minimize the losses, the slip (i.e., the difference between the stator synchronous speed and the actual operating speed) is set to be within $1 \%$, and the number of stator slots per pole per phase $\left(q_{1}\right)$ is set at 6 . The expressions for the number of stator slots, slot pitch, slot, and tooth width (Eq. [12]-[14]) are valid for the SCIG.

The stator winding is modeled using two layers with two symmetrical current paths in parallel $\left(a_{1}=2\right)$ and a coil span/pole pitch ratio, $\beta_{s}=12 / 15$. The winding factor, $k_{w}$, is computed according to Eq. (27). The number of stator turns per current path is calculated with two conductors per coil, $n_{c l}=2$ and $q_{1}=6$

$$
N_{s}=\frac{2 p}{a} q_{1} n_{c 1}
$$

The pole pitch, $\tau_{p}$, is computed using

$$
\tau_{p}=\frac{\pi \cdot D_{s}}{2 p}
$$

The stator winding resistance and winding cross section are calculated using Eq. (19) and (21). The winding length including end connection is calculated using [33]

$$
L_{c u}=\frac{2 N_{s}\left(l_{s}+l_{f s}\right)}{a_{1}}
$$

where the end connection length on one side of the machine, $l_{f s}$, is approximated using geometry as shown in Figure 20 reproduced from [33] 

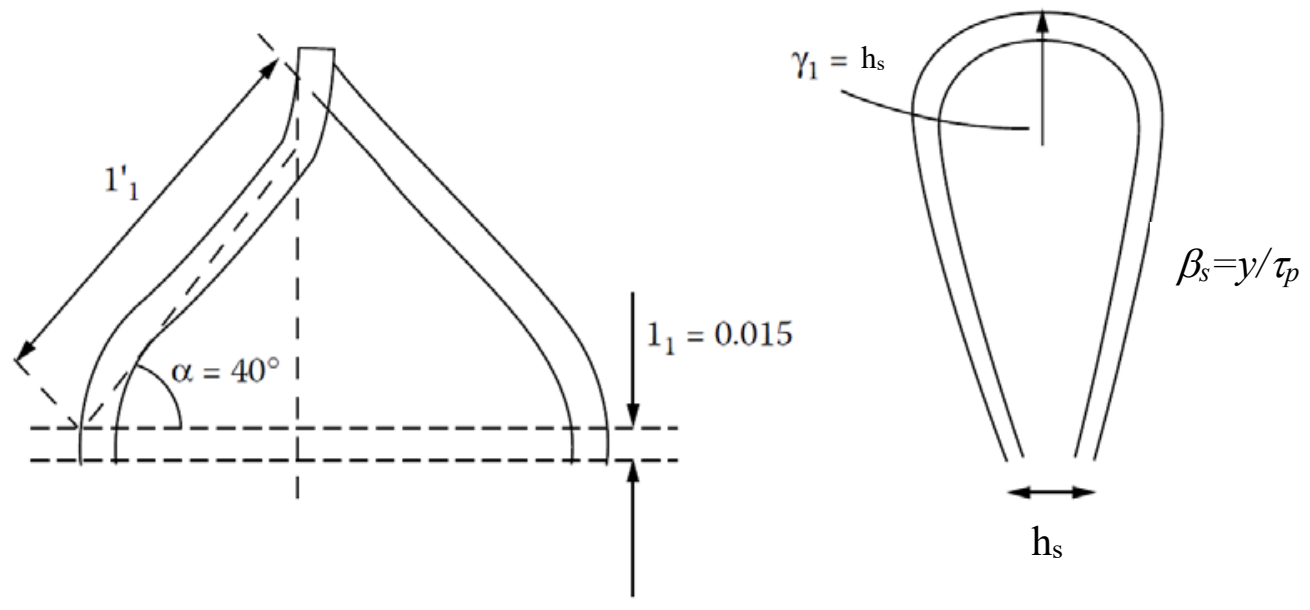

Figure 20. End winding geometry [33]

$$
\begin{gathered}
L_{f s}=2\left(l_{1}+l_{1}^{\prime}\right)+\pi h_{s} \\
L_{f s}=2\left(0.015+\frac{\beta_{s} \tau_{p}}{\cos \alpha}\right)+\pi h_{s}
\end{gathered}
$$

The air-gap length (in meter) is calculated using[33]

$$
g=\left(0.1+0.012 \sqrt[3]{P_{\text {rated }}}\right) 10^{-3}
$$

The stator slot and tooth leakage inductances are calculated using

$$
\begin{gathered}
L_{s s l}=\frac{2 \mu_{0} n_{c 1}^{2} S}{m a_{1}^{2}}\left(\frac{\left(h_{s}-h_{w}\right)}{3 b_{s}}+\frac{h_{w}}{b_{s 0}}\right) \\
L_{s t l}=\frac{2 \mu_{0} n_{c 1}^{2} S}{m a_{1}^{2}}\left(\frac{5 g / b_{s 0}}{5+4 g / b_{s 0}}\right)
\end{gathered}
$$

The end winding leakage inductance is calculated using

$$
L_{s e l}=\frac{2 \mu_{0} n_{c 1}^{2} S}{m a_{1}^{2}} 0.34 g\left(l_{f s}-0.64 y\right)
$$

The magnetizing inductance is calculated using

$$
L_{s m}=\frac{6 \mu_{o} l_{s} \tau_{p}\left(k_{w d} N_{s}\right)^{2}}{\pi^{2} p g_{\text {eff }}\left(1+K_{s}\right)}
$$

where the effective air gap is computed considering the slotting effect in both the rotor and the stator as [33]

$$
g_{e f f}=K_{c} \cdot g
$$


Where

$$
\begin{gathered}
K_{c}=K_{c s} \cdot K_{c r} \\
K_{c s, r}=\frac{\tau_{s, r}}{\tau_{s, r}-0.5 g \gamma_{s, r}} \\
\gamma_{s, r}=\frac{\left(2 W_{s^{\prime}, r^{\prime}} / g\right)^{2}}{5+2 W_{s^{\prime}, r^{\prime}} / g}
\end{gathered}
$$

where $W_{s}$, and $W_{r}$, are the equivalent slot openings, with magnetic wedges given by $\left(b_{s} / 0.005\right) 10^{-3} \mathrm{~m}$ and $\left(b_{r} / 0.005\right) 10^{-3} \mathrm{~m}$, respectively. The rotor-slot dimensions are calculated based on the assumption that the rotor-slot width, $b_{r}$, is $0.45 \tau_{r}$. The slot height, $h_{r}$, is a design variable.

The rotor-slot pitch is calculated as

$$
\tau_{r}=\frac{\pi\left(2 \cdot r_{s}-2 g\right)}{Q_{r}}
$$

where $Q_{r}$ is the number of rotor slots. Care must be taken when choosing the correspondence between the stator and rotor numbers of slots to reduce parasitic torque, additional losses, radial forces, noise, and vibration. $q_{2}$ (rotor slots/pole/phase) was chosen to be smaller than $q_{1}=6$ with $q_{2}=4$. The rotor slots are calculated using

$$
Q_{r}=2 p q_{2} m
$$

The resistance of the rotor conductor is computed as the sum of the resistances of the bar and the end ring as

$$
R_{r}=R_{b a r}+R_{r e}
$$

The rotor bar resistance is calculated using

$$
R_{b a r}=\frac{\rho_{c u} k_{r m} L_{c u}}{A_{b a r}}
$$

$k_{r m}$ is the equivalent winding coefficient for the skin effect correction given by [33]

$$
\begin{aligned}
& k_{r m}=\beta_{\text {skin }} h_{r} \\
& \beta_{\text {skin }} \approx \sqrt{\frac{\mu_{o} \pi f}{\rho_{c u}}}
\end{aligned}
$$

and the rotor bar cross section is approximated using

$$
A_{\text {bar }}=b_{r}\left(h_{r}-h_{w}\right)
$$

The end-ring resistance is calculated using

$$
R_{r e}=\frac{\rho_{c u} L_{e r}}{2 A_{e r} \sin ^{2}\left(\frac{\pi p}{Q_{r}}\right)}
$$

The end-ring segment length, $L_{e r}$, is calculated using 


$$
L_{e r}=\frac{\pi\left(D_{e r}-b\right)}{Q_{r}}
$$

where the ring dimension, $b$, is approximated to be equal to slot height, $h_{r}$ and the end-ring diameter is assumed to be $3 \mathrm{~mm}$ smaller than the rotor diameter and calculated using [32]

$$
D_{e r}=\left(D_{s}-2 g\right)-0.003
$$

The end-ring cross section is calculated from the bar current density. We assumed $6 \mathrm{kA} / \mathrm{mm}^{2}$ for the bar $\left(J_{\text {bar }}\right)$, and the current density in the end ring is assumed to be $J_{e r}=0.8 J_{b a r}$. The end-ring cross section is also calculated using [32]

$$
\begin{gathered}
A_{e r}=\frac{I_{e r}}{J_{e r}} \\
I_{e r}=\frac{I_{b}}{2 \sin \left(\frac{\pi p}{Q_{r}}\right)} \\
I_{b}=\frac{N_{s} 2 m k_{w}}{Q_{r}} I_{1 n}
\end{gathered}
$$

The current density and specific current loading in stator are determined using equations (32) and (33). The rated current, $I_{1 n}$, is computed at rated power, voltage and power factor

$$
I_{1 n}=\frac{P_{\text {rated }}}{\sqrt{3} E_{p} \cos \varphi}
$$

The rotor resistance (Eq. [122]) when reduced to the stator is

$$
R_{r}^{\prime}=R_{r} \frac{4 m\left(k_{w} N_{s}\right)^{2}}{Q_{r}}
$$

The rotor leakage inductance is determined from the sum of the slot, tooth, and end leakage inductances given by

$$
\begin{gathered}
L_{r s l}=\mu_{0} l_{s}\left(\frac{\left(h_{r}-h_{w}\right)}{3 b_{r}}+\frac{h_{w}}{b_{r 0}}\right) \\
L_{r t l}=\mu_{0} l_{s} \frac{0.081 \tau_{r}}{g_{e f f}} \\
L_{r e l}=\mu_{0}\left(l \lambda_{b}+2 \lambda_{e i} L_{i}\right) \\
\lambda_{b}=\frac{h_{r}}{3 b_{r}}+\frac{h_{w}}{b_{r o}} \\
\lambda_{e i}=\frac{2.3 D_{e r}}{\left(4 Q_{r} l_{s}\left(\sin ^{2}\left(\frac{\pi p}{Q_{r}}\right)\right)\right)} \log \frac{4.7 \cdot D_{s}}{(a+2 b)}
\end{gathered}
$$

with the ring dimension $\mathrm{a}=\mathrm{A}_{\mathrm{er}} / \mathrm{b}$ and 


$$
\begin{gathered}
L_{i}=\frac{\pi D_{s}}{Q_{r}} \\
L_{r}=L_{r s l}+L_{r t l}+L_{r e l}
\end{gathered}
$$

The rotor leakage inductance reduced to stator is given by

$$
L_{r}^{\prime}=L_{r} \frac{4 m\left(k_{w} N_{s}\right)^{2}}{Q_{r}}
$$

\subsubsection{Losses and Efficiency}

The electrical losses in a SCIG are made of fundamental winding losses in the stator and rotor, core losses, and rotor-slip ring/brush losses. If $\omega_{s}$ represents the synchronous speed, the no-load voltage induced in the stator winding is determined using

$$
E_{p}=\sqrt{2} k_{w} N_{s} \omega_{s} r_{s} L_{t} \hat{B}_{g 1}
$$

The stator winding factor, $k_{w}$, is determined using Eq. (27) with a coil span/pole pitch ratio, $y / \tau_{p}$ $=12 / 15$. The fundamental component of no-load peak air-gap flux density obtained from Ampere's law is given by [32]

$$
\widehat{B}_{g 1}=\frac{3 \mu_{o} N_{s} \cdot I_{o} K_{w} \sqrt{2}}{\pi p K_{c} g\left(1+\mathrm{K}_{s}\right)}
$$

where $I_{o}$ is the magnetization current at no load and the magnetic saturation factor for iron $K_{s}=0.3$. The peak air-gap flux density is estimated using

$$
\hat{B}_{g}=\hat{B}_{g 1} \cdot K_{c}
$$

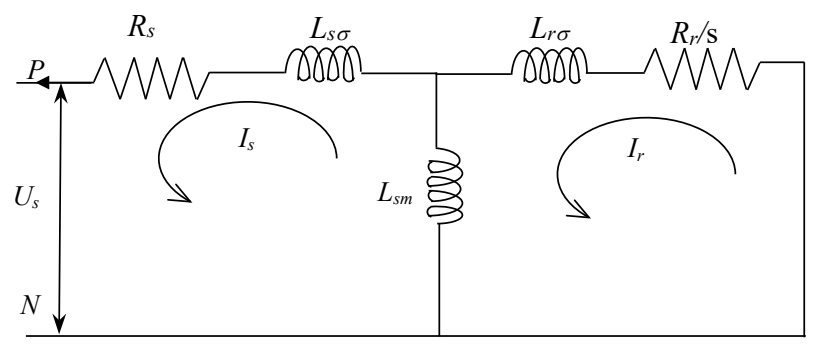

Figure 21. Equivalent circuit model of an SCIG [13]

Using the equivalent circuit in Figure 21, the rotor active current, $I_{r}$, and the stator phase current, $I_{s}$, are determined using

$$
I_{r}=\sqrt{\frac{S_{N} P_{e}}{m R_{r}^{\prime}}}
$$

where the gap power is calculated from the slip and shaft power, $P_{e}=\frac{P_{\text {rated }}}{1-S_{N}}$, and the stator phase current, $I_{s}$, is computed using

$$
\begin{aligned}
& I_{s}=\sqrt{I_{r}^{2}+I_{s m}^{2}} \\
& I_{s m}=\frac{E_{p}}{2 \pi f L_{s m}}
\end{aligned}
$$


The winding current density and specific current loading in the stator are determined using Eqs.(32) and (33). The copper losses in stator and rotor are quantified using

$$
P_{c u}=m\left(I_{s}^{2} R_{s} K_{r}+I_{r}^{2} R_{r}\right)
$$

This equation accounts for the losses in the end rings and bars and a correction factor for skin effect $\left(K_{r}=1.2\right)$. The specific iron losses, $P_{\mathrm{fe}}$, in stator teeth and yoke are determined in the same manner as described in Section 2.1, using the Steinmetz formula (Eq. 34). The iron losses in the rotor are determined using

$$
P_{\text {Fer }}=M_{f e r}\left(P_{\text {Feoh }}\left(\frac{S_{N} \omega_{e}}{2 \pi \cdot 60}\right)\left(\frac{\hat{B}_{F e r}}{1.5}\right)^{2}+P_{F e o e}\left(\frac{S_{N} \omega_{e}}{2 \pi \cdot 60}\right)^{2}\left(\frac{\hat{B}_{F e r}}{1.5}\right)^{2}\right)
$$

The rotor iron loss components consist of the teeth as well as the yoke, and the specific mass of iron, $M_{f e r}$, in these parts is included. To compute the losses in the rotor yoke, $\widehat{B}_{F e r}$, is replaced by the peak flux density in the yoke $\left(\widehat{B}_{y r}\right)$ and for iron losses in the teeth $\left(\widehat{B}_{t r}\right)$.

$$
h_{r, s y}=\frac{\tau_{p}}{\pi \hat{B}_{r, s y}} \hat{B}_{g}
$$

The peak flux densities in stator and rotor teeth are determined using

$$
\begin{gathered}
\hat{B}_{t s}=\frac{\tau_{s}}{b_{t}} \hat{B}_{g} \\
\hat{B}_{t r}=\frac{\tau_{r}}{b_{t r m i n}} \hat{B}_{g}
\end{gathered}
$$

where the maximum flux density is found closest to the bottom of the rotor teeth whose minimum width is given by

$$
b_{\text {trmin }}=0.55 \frac{\pi\left(D_{s}-2\left(g+h_{r}\right)\right.}{Q_{r}}
$$

In addition, the flux-pulsation core losses account for $0.5 \%$ of the total power [33]. The efficiency of the generator is approximated using

$$
\eta=\frac{P_{\text {gennom }}}{P_{\text {gennom }}+\left(P_{c u}+P_{F e}+0.005 * P_{\text {gennom }}\right)} \times 100
$$

\subsubsection{Generator Mass}

The various masses of active material are computed using [13]

$$
\begin{gathered}
M_{c u}=\rho_{C u}\left(m L_{c u s} A_{c u s}+\left(Q_{r} l_{s} A_{b a r}+\pi\left(D_{e r} A_{e r}-A_{e r} b\right)\right)\right. \\
M_{F e s y}=\rho_{F e}\left(\pi l_{s}\left(\left(r_{s}+h_{s}+h_{s y}\right)^{2}-r_{s}^{2}\right)-\left(r_{s}+h_{s}\right)^{2}\right) \\
M_{F e s t}=\rho_{F e}\left(\pi l_{s}\left(\left(r_{s}+h_{s}\right)^{2}-r_{s}^{2}\right)-2 m q_{1} p b_{s} h_{s} l_{s}\right) \\
M_{F e r y}=\rho_{F e}\left(\pi l_{s}\left(\left(r_{r}-h_{r}\right)^{2}-\left(r_{r}-h_{r}-h_{r y}\right)^{2}\right)\right) \\
M_{F e r t}=\rho_{F e}\left(\pi l_{s}\left(r_{r}^{2}-\left(r_{r}-h_{r}\right)^{2}\right)-2 m q_{2} p b_{r} h_{r} l_{s}\right)
\end{gathered}
$$


with the rotor radius $r_{r}$ given by $r_{r}=r_{s}-g$.

The total mass of active material is computed using

$$
M_{\text {act }}=M_{C u}+M_{F e}
$$

\subsubsection{Structural Mass}

Because these machines are designed to operate at a relatively lower torque, the structural support requirements are not as demanding as those of the direct-drive generators. Nevertheless, an empirical estimate for structural mass was derived from the Upwind study [25] that allowed extrapolating the relationships among generator active mass, inactive mass, and power rating, given by

$$
M_{\text {Structure-SCIG }}=0.0001 M_{\text {active }}^{2}+0.8841 M_{\text {active }}-132.5
$$

The total generator mass is calculated as

$$
M_{\text {gen }}=M_{\text {act }}+M_{\text {Structure-SCIG }}
$$

\subsubsection{Design Optimization}

An induction machine is a mature technology with the relationship between performance constraints and the physical aspects that has been well validated in the industry [32]. GeneratorSE determines the design dimensions based on the nonlinear analytical equations presented earlier and optimizes the design geometry, thereby satisfying a vector of performance parameters. The final design solution and performance may be validated using finite-element methods. Also, because detailed structural design is not a part of the analytical models, the structural mass is obtained via extrapolation using active mass in Eq. (162), GeneratorSE searches for optimal total mass by reducing active material.

\subsubsection{Mass Optimization}

The objective function that seeks to find a lightweight design is given by

$$
\text { Mass }=M_{\text {gen }}
$$

The above objective is achieved by also ensuring that the length and radius are sufficient to generate the required torque by using the principle of tangential stress: $\sigma$ (i.e., $T<2 \pi \sigma r_{s}^{2} l_{s}$ ).

\subsubsection{Cost and Efficiency Optimization}

Costs are minimized with an objective

$$
\text { Costs }=C_{C U} \cdot M_{C U}+C_{\text {steel,struc }} \cdot M_{\text {Structure-SCIG }}+C_{\text {steel,mag }} \cdot M_{\text {steel,mag }}
$$

The $\mathrm{C}_{\mathrm{CU}}, \mathrm{C}_{\text {steel,struc, and }} \mathrm{C}_{\text {steel,mag }}$ are the specific costs of copper, structural steel, and steel(iron) used in the magnetic circuit as listed in Table 2. The most efficient design is obtained by forcing an objective that minimizes the losses given by

$$
\text { Losses }=P_{c u}+P_{f e}+0.005 * P_{\text {rated }}
$$




\subsubsection{Optimization of Aspect Ratio}

A design that ensures an optimal aspect ratio (L/D) also ensures a light weight with a small design envelope of diameter and stack length, so the objective function is given by:

$$
k_{\text {rad }}=l / D
$$

The aspect ratio for these machines is assumed to be in the range of 0.2-1.5 [33].

\subsubsection{Decision Variables}

To optimize the generator design for the proposed objectives, we chose six free parameters. The key design inputs include rated power, speed, efficiency of the gearbox and a target overall drivetrain efficiency. The other dimensions were calculated from the given parameters. Future work will include detailed structural model for the machine including designs for the generator shaft, stator casing and rotor support structure.

\subsubsection{Magnetic Circuit}

Six parameters of the generator, namely the air-gap radius, $r_{s}$, stator length, $l_{s}$, stator slot height, $h_{s}$, rotor slot height, $h_{r}$, stator yoke flux density, $\hat{B}_{s y}$, and no-load magnetization current, $I_{o}$, were allowed to vary within a certain range. The value of magnetization current is determined by the peak air-gap flux density required to generate the required terminal voltage. The air-gap length, $g$, is defined as a function of rated power. Detailed thermal modeling, ventilation circuit, and temperature constraints have not been included but will be in future work. Table 17 lists the main design and performance variables for the SCIG. Structural design has not been accounted for in the design; however, the adequacy was confirmed by ensuring that the air-gap volume was sufficient to overcome the shear stress, $\sigma$. For the purpose of optimal lamination, the magnetically required stator outer diameter was limited to be 1.37-1.4 times the air-gap diameter.

Table 17. Electromagnetic Design and Performance Variables in an SCIG

\begin{tabular}{cccc}
\hline \hline Symbol & Design Variables & Symbol & Performance Variables \\
\hline \hline$r_{s}(\mathrm{~m})$ & Air-gap radius & $\hat{B}_{g}$ & Peak air-gap flux density \\
$I_{s}(m)$ & Stator length & $\hat{B}_{t s}$ & Peak stator tooth flux density \\
$h_{s}(m)$ & Stator slot height & $\hat{B}_{r y}$ & Peak rotor yoke flux density \\
$h_{r}(m)$ & Rotor-slot height & $\hat{B}_{r t}$ & Peak rotor tooth flux density \\
$\hat{B}_{s y}(T)$ & Peak stator yoke flux density & $E_{p}$ & Generator output voltage \\
$I_{0}(A)$ & No-load magnetization current & $A_{1}$ & Specific current loading \\
& & $J_{s}$ & Stator winding current density \\
& & $J_{f}$ & Rotor current density \\
& & $f$ & Frequency \\
\hline
\end{tabular}

The key design constants and constraints imposed on the electromagnetic design and performance indices are listed in Table 18. 
Table 18. Electromagnetic Design Constants and Constraints for an SCIG

\begin{tabular}{lll}
\hline Description & Symbol & Value \\
\hline \hline Slot wedge thickness & $h_{w}$ & $5 \mathrm{~mm}$ \\
\hline Stator slot opening & $b_{s o}$ & $4 \mathrm{~mm}$ \\
\hline Rotor-slot opening & $b_{r o}$ & $4 \mathrm{~mm}$ \\
\hline Shear stress & $\sigma_{S C I G}$ & $21.5 \mathrm{kN} / \mathrm{m}^{2}$ \\
\hline Slot fill factor & $k_{\text {fills }}$ & 0.65 \\
\hline Specific hysteresis losses & $P_{\text {FeOh }}$ & $4 \mathrm{~W} / \mathrm{kg}$ \\
\hline Specific eddy current losses & $P_{\text {FeOe }}$ & $1 \mathrm{~W} / \mathrm{kg}$ \\
\hline Copper resistivity & $\rho_{c u}$ & $2.52 \mathrm{e}-08 \Omega \mathrm{m}$ \\
\hline Slip & $S_{N}$ & -0.002 \\
\hline Coil span/pole pitch & $y / \tau_{p}$ & $12 / 15$ \\
\hline $0.7 T \leq \hat{B}_{g} \leq 1.2 T$ & & $A_{1}<60 \mathrm{kA} / \mathrm{m}^{2}$ \\
\hline$\hat{B}_{r y}<2 T$ & & $J_{s} \leq 6 \mathrm{~A} / \mathrm{mm}^{2}$ \\
\hline$\hat{B}_{s t}<2 T$ & & $J_{r} \leq 6 \mathrm{~A} / \mathrm{mm}^{2}$ \\
\hline$\hat{B}_{r t}<2 T$ & & $\eta \geq \eta_{\text {target }}$ \\
\hline $500 \mathrm{~V}<E_{p}<5,000 \mathrm{~V}$ & & $4 \leq h_{s} / b_{s} \leq 10$ \\
\hline $0.2 \leq k_{\text {rad }} \leq 1.5$ & & $r_{s}^{2} l_{s}>\frac{T}{2 \pi \sigma_{S C I G}}$ \\
\hline $1.37 \leq D_{\text {out }} / D_{s} \leq 1.4$ & \\
\hline
\end{tabular}

\subsubsection{Optimization Assumptions, Results, and Validation}

Appendix A8 provides a table for initial values and boundary conditions imposed for obtaining the cost-optimized designs , considering $95.5 \%$ efficiency for the gearbox driving the generator and a target overall drivetrain efficiency of $93 \%$. A double layer winding with $q_{1}=6$ was used for the stator to obtain an integer slot winding. The rotor slots per pole per phase were fixed at $q_{2}=4$. The stator slot fill factor was $k_{\text {fills }}=0.65$ for $D>2 \mathrm{~m}$ and $k_{\text {fills }}=0.4$ for $D<2 \mathrm{~m}$. The stator and rotor winding current densities were limited to $6 \mathrm{~A} / \mathrm{mm}^{2}$ and specific current loading of the stator was limited to $60 \mathrm{kA} / \mathrm{m}$.

Appendix A9 provides the optimized design dimensions, performance, mass, and cost estimates for the five different turbines rated between 0.75 and $10 \mathrm{MW}$. The rated speed of the generator was assumed to be $1,200 \mathrm{rpm}$ with a slip of $-0.2 \%$ [25] to reduce the rotor copper losses and improve the generator efficiency. Hence, all machines were designed for a total pole count of six.

\subsubsection{Electromagnetic Design Validation}

The optimized design dimensions for the stator and rotor obtained from GeneratorSE (Appendix A9) were used to model the main parts of a 5MW SCIG using the MATLAB interface for FEMM4.2. The nonlinear magnetic cores are characterized by using the same material properties defined in Figure 7. The squirrel cage in the rotor is made of 72 solid copper bars, whereas the winding in the stator was realized using a double-layer integer slot layout with stranded coil conductors injected with a no-load magnetization current of 139.9A distributed in two parallel current paths in three phases each displaced by $120^{\circ}$. The stator winding layout is shown in Figure 22. A dirichlet boundary condition was imposed on the rotor inner radius and stator outer radius, respectively, and magnetostatic simulation was carried out to analyze the magnetic 
loading in the various parts of the machine at the no-load condition. The finite-element mesh and flux density contours of the optimized 5-MW SCIG are shown in Figure 23(a) and (b).

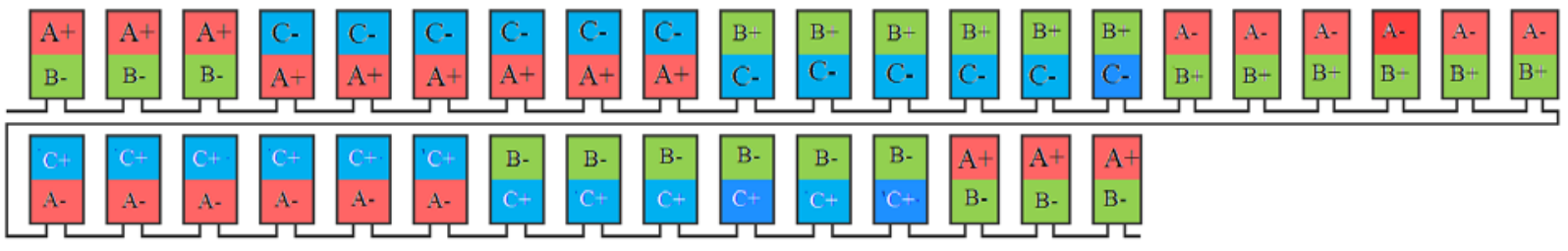

Figure 22. Stator winding layout of the SCIG reproduced from [26] 

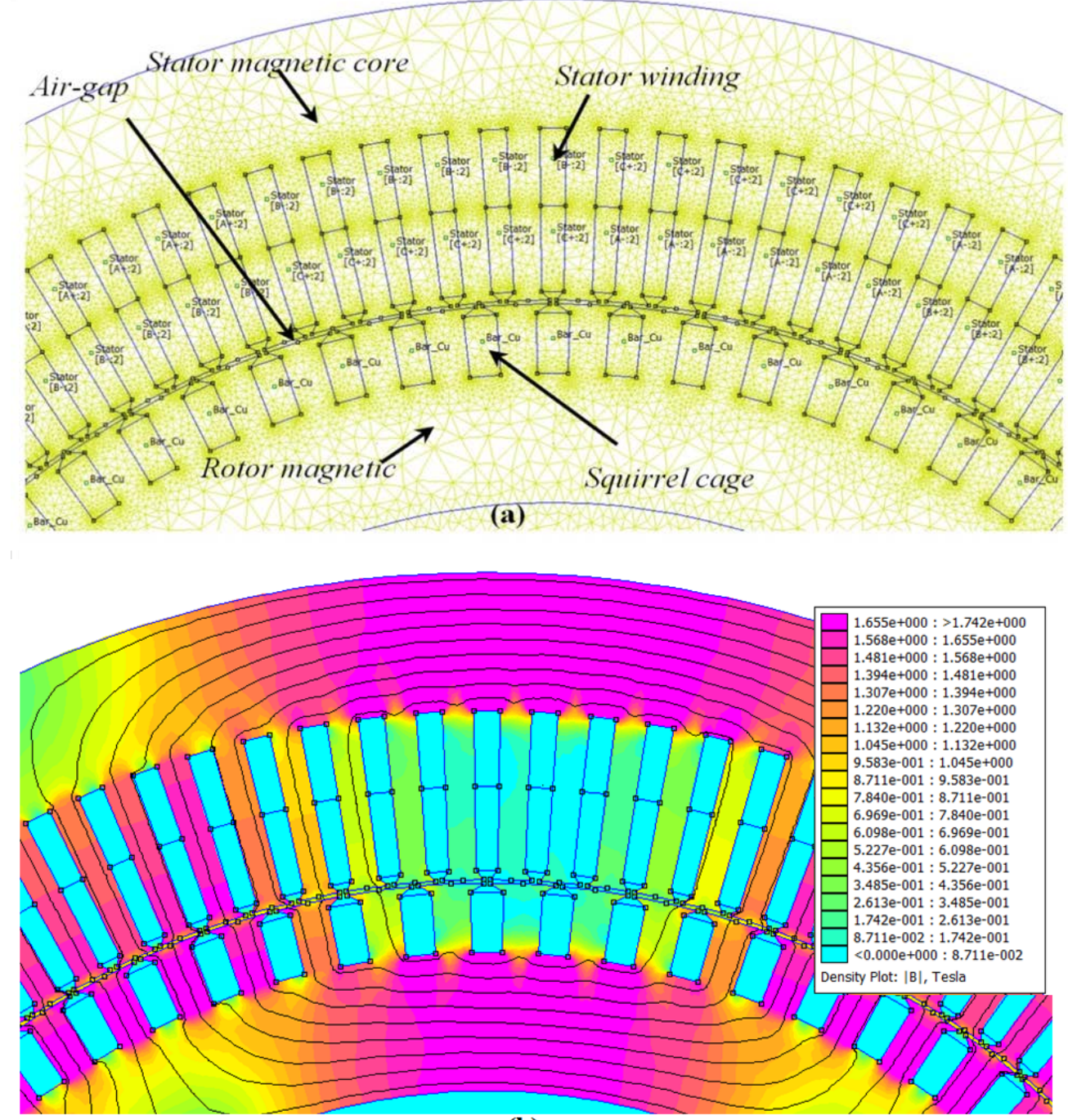

(b)

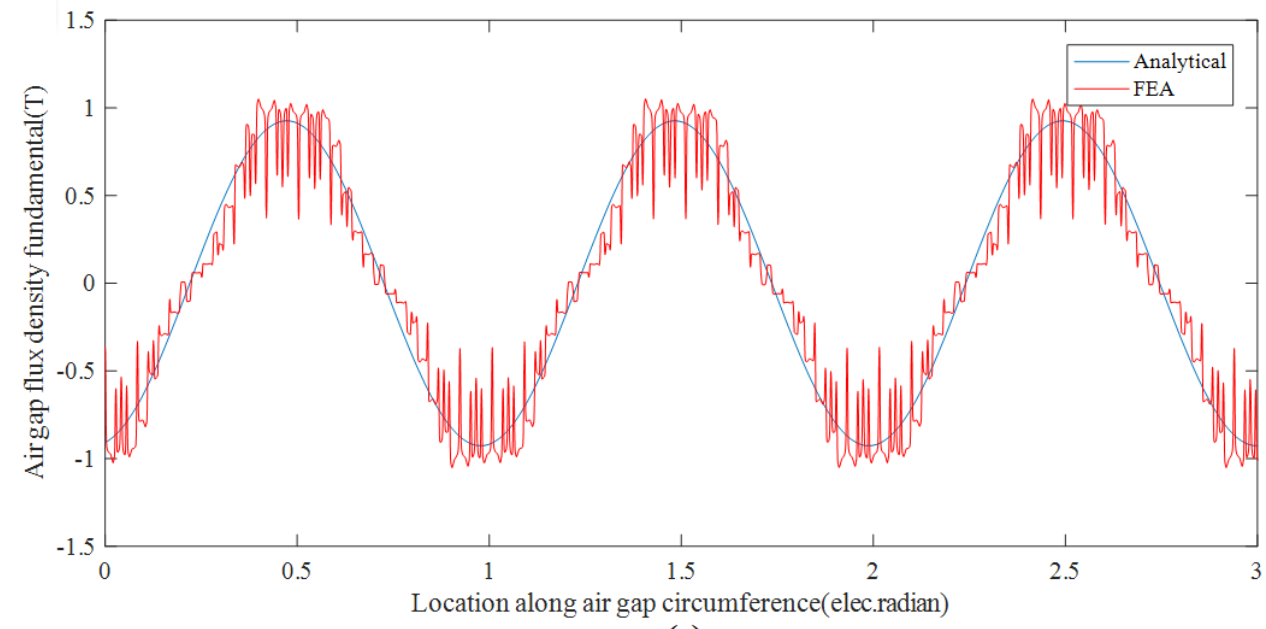

(c)

Figure 23. The 5-MW SCIG in FEMM showing the finite-element mesh (a), magnetic flux density contour (b), and the comparison of air-gap flux density estimated using FEMM vs. GeneratorSE (c) 


$$
\widehat{B}_{\mathrm{g}}(\theta)=\hat{B}_{\mathrm{g}} \cos \left(\frac{\pi}{\tau_{p}} \theta\right)
$$

The results from FEA include the slotting harmonics from both rotor and stator, yet the shape of the flux density distribution has good correlation with the analytical model. Table 19 compares the peak values of flux densities in the various parts of the machine predicted by FEA against GeneratorSE for the no-load condition. The results are found to be between $98 \%-105 \%$ of the FEA predictions.

Table 19. Comparison of Magnetic Loading in the SCIG (FEA vs. GeneratorSE)

\begin{tabular}{|l|c|c|c|}
\hline $\begin{array}{l}\text { Peak Value of Flux Density } \\
\text { (Tesla) }\end{array}$ & GeneratorSE & FEA & $\Delta=\frac{X_{S E}-X_{F E A}}{X_{F E A}} \times 100$ \\
\hline Stator Yoke & 1.86 & 1.86 & 0.00 \\
\hline Rotor Yoke & 1.86 & 1.79 & 3.91 \\
\hline Stator Teeth & 1.68 & 1.607 & 4.54 \\
\hline Rotor Teeth & 1.83 & 1.85 & -1.08 \\
\hline
\end{tabular}

\subsection{Asynchronous Generators: Doubly-Fed Induction Generators(DFIG)}

DFIGs are commonly found in most modern wind turbines. In these generators, both the armature and field windings are realized by a set of three-phase windings. The stator slot and geometry are semienclosed and similar to the cage-type machine. The rotor slots are also semienclosed with access to the rotor windings by means of a slip-ring assembly with brushes. Figure 23. shows the main design dimensions and parts of a DFIG.
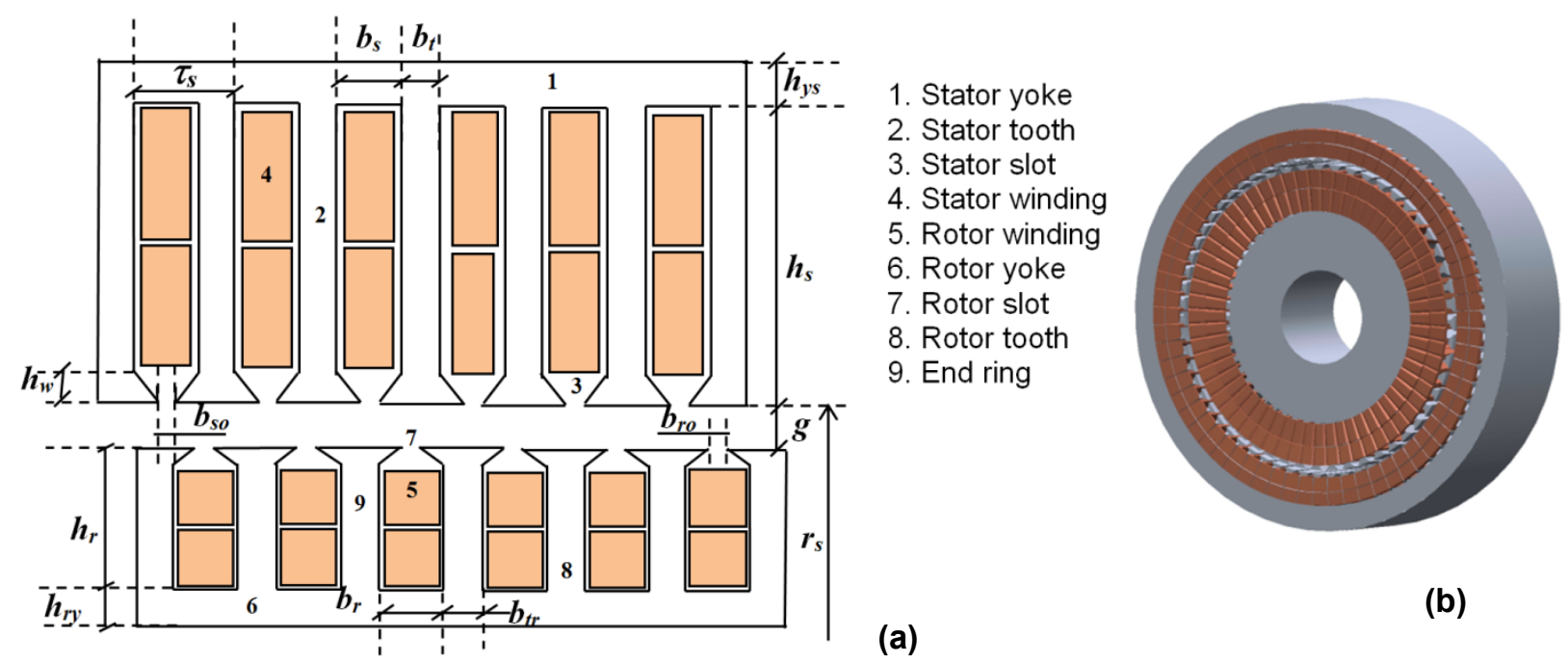

(a)

(b)

Figure 24. Basic design of a DFIG; design dimensions (a) and CAD illustration (b)

The analytical expressions for stator design are the same as the cage rotor machine discussed in Section 2.4. The number of pole pairs, $p$, were fixed at three. The dimensions of the rotor-slot geometry, rotor-slot pitch, and rotor-slot number are computed in the same manner as the cage rotor design. A magnetic wedge thickness of $h_{w}=5 \mathrm{~mm}$ was assumed for both stator and rotor slots. The air-gap length, $g$, is calculated using Eq. (111). The rated rotor slip, $S_{\text {Nmax }}$, was considered a design variable to allow for better optimization of the losses. The design equations 
for the rotor discussed here is consistent with the wound rotor design described in the generator handbook [33]. The rotor slot is semienclosed, with two-layer winding and number of rotor turns determined from the rotor-to-stator turns ratio, $K_{r s}$, which is calculated from the maximum operating slip as $K_{r s}=\frac{1}{\left|S_{N \max }\right|}$. The equivalent rotor field winding turns per phase considering a single current path is given by [33]

$$
N_{r}=\frac{K_{r s} k_{w 1} N_{s}}{k_{w 2}}
$$

with the winding factor for the stator and rotor, $k_{w 1}$ and $k_{w 2}$, calculated using the respective coil span to pole pitch ratios $\left(y_{s} / \tau_{p}=\beta_{s}=12 / 15\right.$ and $\left.y_{r} / \tau_{p}=\beta_{r}=10 / 12\right)$ in Eq. (27) and stator winding turns, $N_{s}$, from Eq. (106). The length of the field winding including end connection length, $l_{f r}$, is determined as

$$
L_{\text {cur }}=2 N_{r}\left(l_{f r}+l_{s}\right)
$$

where the end connection length, $l_{f r}$, on one machine side, for the rotor winding coils, is approximated using the end-connection geometry previously defined for SCIG stator winding in Figure 19 where stator parameters $h_{s}, \beta_{s}$, and $\tau_{s}$ are replaced with rotor parameters $h_{r}, \beta_{r}$, and $\tau_{r}$

$$
\begin{gathered}
l_{f r}=2\left(l_{1}+l_{1}^{\prime}\right)+\pi h_{r} \\
l_{f r}=2\left(0.015+\frac{\beta_{r} \tau_{r}}{\cos \alpha}\right)+\pi h_{r}
\end{gathered}
$$

The rotor slot height, $h_{r}$, is a design variable and rotor slot pitch, $\tau_{r}$, is calculated using Eq. (120). The rotor winding cross section and $A_{\text {cur }}$ is determined using

$$
A_{\text {cur }}=k_{\text {fillr }} p q_{2} \frac{b_{r}\left(h_{r}-h_{w}\right)}{N_{r}}
$$

The rotor winding resistance is computed using

$$
R_{r}=\frac{\rho_{c u} L_{c u r}}{A_{c u r}}
$$

Equations (112)-(114) are used to calculate stator leakage inductances. The magnetizing inductance, $L_{s m}$, is calculated using Eq. (115). The expressions for rotor leakage inductances are given by

$$
\begin{gathered}
L_{r s l}=\frac{\mu_{0}\left(2 n_{c 2}^{2}\right) Q_{r}}{m}\left(\frac{\left(h_{r}-h_{w}\right)}{3 b_{r}}+\frac{h_{w}}{b_{r o}}\right) \\
L_{r t l}=\frac{\mu_{0}\left(2 n_{c 2}^{2}\right) Q_{r}}{m}\left(\frac{5 g / b_{r 0}}{5+4 g / b_{r 0}}\right)
\end{gathered}
$$

The end-winding leakage inductance in the rotor is calculated using

$$
L_{r e l}=\frac{\mu_{0}\left(2 n_{c 2}^{2}\right) Q_{r}}{m}\left(l_{f r}-0.64 \beta_{r} \tau_{r}\right)
$$

The total inductance for the rotor and stator is determined as 


$$
L_{r, s}=L_{s m}+L_{r, s s e l}+L_{r, s s t l}+L_{r, s e l}
$$

The rotor inductance reduced to the stator is given by

$$
L_{r}^{\prime}=\frac{L_{r}}{K_{r s}^{2}}
$$

The equivalent rotor resistance reduced to the stator is calculated as

$$
R_{R}^{\prime}=R_{r} \frac{1}{K_{r s}^{2}}
$$

\subsubsection{Power Losses and Efficiency}

The equation for no-load voltage induced in the stator winding is computed in the same manner as Eq. (143). The fundamental component of no-load peak air-gap flux density is determined from rotor winding turns and magnetization current at no-load given by

$$
\hat{B}_{g 1}=\frac{3 \mu_{o} N_{r} \cdot I_{o} k_{w 2} \sqrt{2}}{\pi p K_{c} g\left(1+\mathrm{K}_{s}\right)}
$$

with rotor winding turns, $N_{r}$, determined from Eq. (169), no-load magnetization current, $I_{o}$, a design variable and rotor winding factor, $k_{w 2}$, calculated using Eq. (27). The carter factor, $K_{c}$, is determined using Eq. (117) and iron saturation factor, $K_{s}$ of 0.3 was assumed. The rotor active current is

$$
I_{R}=\frac{P_{\text {rated }}}{3 E_{p}\left(1-S_{N}\right)}
$$

The stator reactive current and phase currents are determined using Eq. (147) and (148). The copper losses in the stator and rotor are quantified using

$$
P_{c u}=m\left(I_{s}^{2} R_{s} K_{r}+I_{R}^{2} R_{R}^{\prime}\right)
$$

with a stator skin-effect correction coefficient assumed to be $K_{r}=1.2$. The specific iron losses $\left(P_{\mathrm{fe}}\right)$ in the stator and rotor are determined in the same manner as for the SCIG (Eq. [34] and $[150])$, using the Steinmetz formula. The magnetic loading in the stator and rotor teeth is determined using the same equations as the SCIG in (152) and (153).

The losses in the brushes and slip rings are approximated using [33]

$$
P_{b}=3 \cdot \Delta V \cdot I_{R}
$$

with a contact voltage drop of $\Delta \mathrm{V}$ limited to $<1$ by design. The efficiency of the generator is approximated using the same expression in Eq. (155) with the addition of brush losses from Eq. (184). 


\subsubsection{Generator Mass}

The generator active mass is computed using Eq. (161), where the main difference is in the copper mass, which is calculated as

$$
M_{c u}=\rho_{c u}\left(m L_{c u s} A_{c u s}+m L_{c u r} A_{c u r}\right)
$$

The mass of iron (electrical steel) is determined using the same equations as the SCIG (Eq. 157-160).

\section{Structural Mass}

Similar to the squirrel-cage induction machine discussed in Section 2.4, detailed structural design is not a part of the analytical models. An empirical estimate for structural mass was derived from the Upwind study [25] that relates generator active mass and inactive mass using

$$
\begin{gathered}
M_{\text {Structure-DFIG }}=0.0002 M_{\text {active }}^{2}+0.6457 M_{\text {active }}+645.24 \\
M_{\text {gen }}=M_{\text {act }}+M_{\text {Structure-DFIG }}
\end{gathered}
$$

\subsubsection{Design Optimization}

GeneratorSE uses the analytical models described earlier to determine the basic design geometry as well as performance parameters. The optimization process allows initialization of electromagnetic design variables and verifying performance parameters against constraints. A mathematical method searches for the optimal design, thereby satisfying one of the following objectives.

\subsubsection{Mass Optimization}

The objective function that seeks to find a lightweight design is given by

$$
\text { Mass }=M_{\text {act }}+M_{\text {Structure-DFIG }}
$$

This objective is achieved by also ensuring that the length and air-gap radius are sufficient to generate the required torque by using the principle of tangential stress: $\sigma$ (i.e., $T<2 \pi \sigma r_{s}^{2} l_{s}$ ). A value of $21.5 \mathrm{kPa}$ was assumed for the tangential stress.

\subsubsection{Cost and Efficiency Optimization}

Costs are minimized with an objective

$$
\text { Costs }=C_{C U} \cdot M_{C U}+C_{\text {steel,struc }} \cdot M_{\text {Structure-DFIG }}+C_{\text {steel,mag }} \cdot M_{\text {steel,mag }}
$$

The $C_{C U}, C_{\text {steel,struc, }}$ and $C_{\text {steel,mag }}$ are the specific costs of copper, structural steel, and electrical steel/iron used in the magnetic circuit as listed in Table 2.

\subsubsection{Optimization of Aspect Ratio}

Equation (167) also applies to optimize the design envelope of a DFIG. The aspect ratio for these machines is assumed to be in the same range as the SCIG.

\subsubsection{Decision Variables}

To optimize the generator design for the proposed objectives, we chose seven free parameters. The design inputs are consistent with SCIG (rated power, speed, efficiency of the gearbox and a target overall drivetrain efficiency). The other dimensions were calculated from the given parameters. 


\subsubsection{Magnetic Circuit}

Seven parameters of the generator, namely the air-gap radius $\left(r_{s}\right)$, stator length $\left(l_{s}\right)$, stator slot height $\left(h_{s}\right)$, rotor-slot height $\left(h_{r}\right)$, stator yoke flux density $\left(\hat{B}_{s y}\right)$, no-load magnetization current $\left(I_{o}\right)$. The rotor design is dependent on the maximum negative slip $\left(S_{N \max }\right)$ per power delivered [33], which in turn influences the rotor-stator winding turns ratio. $S_{N \max }$ is chosen a design variable to better optimize the winding design and losses. The value of rotor magnetization current is determined by the peak air-gap flux density required to generate the required terminal voltage. Detailed thermal modeling has not been included but will be in future work. Table 20 lists the main electromagnetic design and performance variables for the DFIG. For the purpose of optimal lamination, the magnetically required stator outer diameter was limited to be 1.37-1.4 times the air-gap diameter. Structural design has not been accounted for in the model, however, as a minimum the adequacy was confirmed by ensuring that the air-gap volume was sufficient to overcome the shear stress, $\sigma$.

Table 20. Electromagnetic Design and Performance Variables in the DFIG

\begin{tabular}{cccc}
\hline \hline Symbol & Design Variables & Symbol & Performance Variables \\
\hline \hline$r_{s}(\mathrm{~m})$ & Air-gap radius & $\widehat{B}_{g}$ & Peak air-gap flux density \\
$I_{s}(m)$ & Stator length & $\widehat{B}_{t s}$ & Peak stator-tooth flux density \\
$h_{s}(m)$ & Stator-slot height & $\widehat{B}_{r y}$ & Peak rotor-yoke flux density \\
$h_{r}(m)$ & Rotor-slot height & $\hat{B}_{r t}$ & Peak rotor-tooth flux density \\
$\hat{B}_{s y}(T)$ & Peak stator-yoke flux density & $E_{p}$ & Generator output voltage \\
$I_{o}(A)$ & No-load magnetization current & $A_{1}$ & Specific current loading \\
$S_{N \max }$ & Maximum slip & $J_{s}$ & Stator current density \\
& & $J_{f}$ & Rotor current density \\
& & $f$ & Frequency \\
& & $\eta$ & Efficiency
\end{tabular}


The key design constants and constraints imposed on the electromagnetic design and performance indices for the DFIG are listed in Table 21.

Table 21. Electromagnetic Design Constants and Constraints for the DFIG

\begin{tabular}{lll}
\hline Description & Symbol & Value \\
\hline \hline Slot wedge thickness & $h_{w}$ & $5 \mathrm{~mm}$ \\
\hline Stator-slot opening & $b_{s o}$ & $4 \mathrm{~mm}$ \\
\hline Rotor-slot opening & $b_{r o}$ & $4 \mathrm{~mm}$ \\
\hline Shear stress & $\sigma_{D F I G}$ & $21.5 \mathrm{kN} / \mathrm{m}^{2}$ \\
\hline Stator-slot fill factor & $k_{\text {sfill }}$ & 0.65 \\
\hline Rotor-slot fill factor & $k_{\text {fill }}$ & 0.55 \\
\hline Specific hysteresis losses & $P_{F e O h}$ & $4 \mathrm{~W} / \mathrm{kg}$ \\
\hline Specific eddy current losses & $P_{F e O e}$ & $1 \mathrm{~W} / \mathrm{kg}$ \\
\hline Copper resistivity & $\rho_{c u}$ & $2.52 \mathrm{e}-08 \Omega \mathrm{m}$ \\
\hline Stator Coil span/pole pitch & $y_{s} / \tau_{p}$ & $12 / 15$ \\
\hline $0.7 T \leq \hat{B}_{g} \leq 1.2 T$ & & $A_{1}<60 \mathrm{kA} / \mathrm{m}$ \\
\hline$\hat{B}_{r y}<2 T$ & & $J_{s} \leq 6 \mathrm{~A} / \mathrm{mm}^{2}$ \\
\hline$\hat{B}_{s t}<2 T$ & & $J_{r} \leq 6 \mathrm{~A} / \mathrm{mm}^{2}$ \\
\hline$\hat{B}_{r t}<2 T$ & & $\eta>\eta_{\text {target }}$ \\
\hline $500 \mathrm{~V}<E_{p}<5000 \mathrm{~V}$ & & $4 \leq h_{s} / b_{s} \leq 10$ \\
\hline $0.2 \leq K_{\text {rad }} \leq 1.5$ & & $2 \pi r_{s}^{2} l_{s} \sigma_{D F I G}<T$ \\
\hline $1.37 \leq D_{\text {out }} / D_{s} \leq 1.4$ & \\
\hline$-0.3 \leq S_{N \max } \leq-0.1$ & \\
\hline
\end{tabular}

\subsubsection{Optimization Assumptions, Results, and Validation}

The main assumptions for the SCIG are also valid for the design of a DFIG. A two-layer winding was assumed for the stator winding with five slots per pole per phase $\left(q_{l}=5\right)$. The rotor winding also assumes a two-layer arrangement with $q_{2}=4$. Appendix A10 presents the initial values and boundary conditions imposed for the generation of optimal DFIG dimensions. Results of costoptimized designs using the constrained minimization driver for turbines rated between 0.75 and $10 \mathrm{MW}$ are presented in Appendix A11. These designs also satisfy other design prerequisites including a target drivetrain efficiency $>93 \%$. The rated speed of the generator was assumed to be 1,200 rpm; hence, all machines were designed for a total pole count of six.

\subsubsection{Electromagnetic Design Validation}

To verify the electromagnetic design of the optimized DFIG, the finite-element model of the 5MW DFIG was created in FEMM4.2 using the MATLAB interface with dimensions provided in Appendix A11. The materials for the stator and rotor magnetic cores were retained as the SCIG. The stator and rotor windings were modeled in two layers using three-phase integer slot winding with five and four slots per pole per phase, respectively, with the winding pattern shown in Figure 25. The stranded coil conductors in the rotor were modeled with three circuits representing three phases injected with a no-load magnetization current of 40A. A magnetostatic simulation was carried out for the condition representing the no-load condition and the flux density contours were obtained as shown in Figure 26(b). 

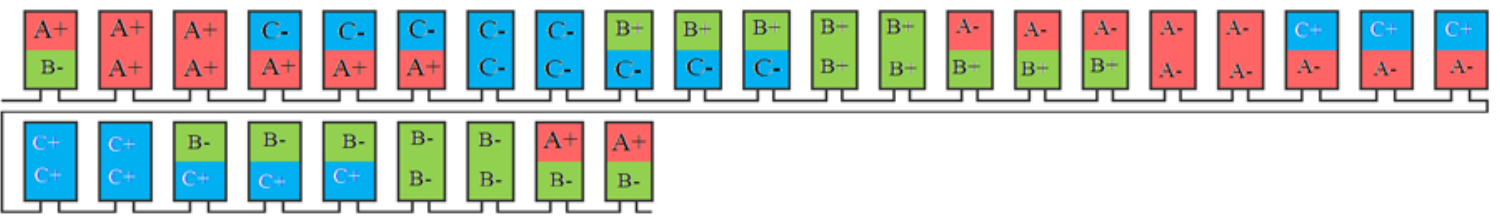

(a)

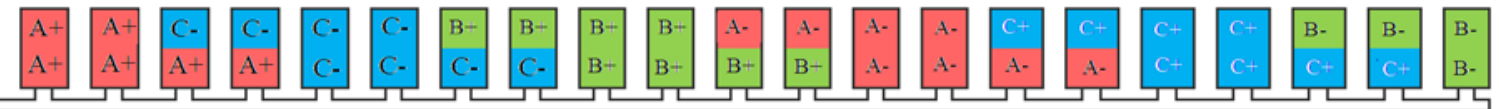

(b)

Figure 25. Stator winding layout in the DFIG reproduced from [26]: stator (a) and the rotor (b)

In Figure 26(c), the computed spatial distribution of air-gap flux density (using Eq. 168) is compared against results from FEA. No effort was made to model the effect of variation in airgap permeance caused by the slotting effect; the shape of flux density distribution correlates well with the analytical model. Table 22 compares the peak values of flux densities in the various parts of the machine predicted by FEA against GeneratorSE for the no-load condition. The results are between $100 \%$ and $110 \%$ of the FEA predictions.

Table 22. Comparison of Magnetic Loading in the DFIG (FEA vs. GeneratorSE)

\begin{tabular}{|l|c|c|c|}
\hline $\begin{array}{l}\text { Peak Value of Flux } \\
\text { Density } \\
\text { (Tesla) }\end{array}$ & GeneratorSE & FEA & $\Delta=\frac{X_{S E}-X_{F E A}}{X_{F E A}} \times 100$ \\
\hline Stator yoke & 1.59 & 1.44 & 10.42 \\
\hline Stator teeth & 1.33 & 1.32 & 0.76 \\
\hline Rotor yoke & 1.59 & 1.44 & 10.42 \\
\hline Rotor teeth & 1.67 & 1.52 & 9.87 \\
\hline
\end{tabular}




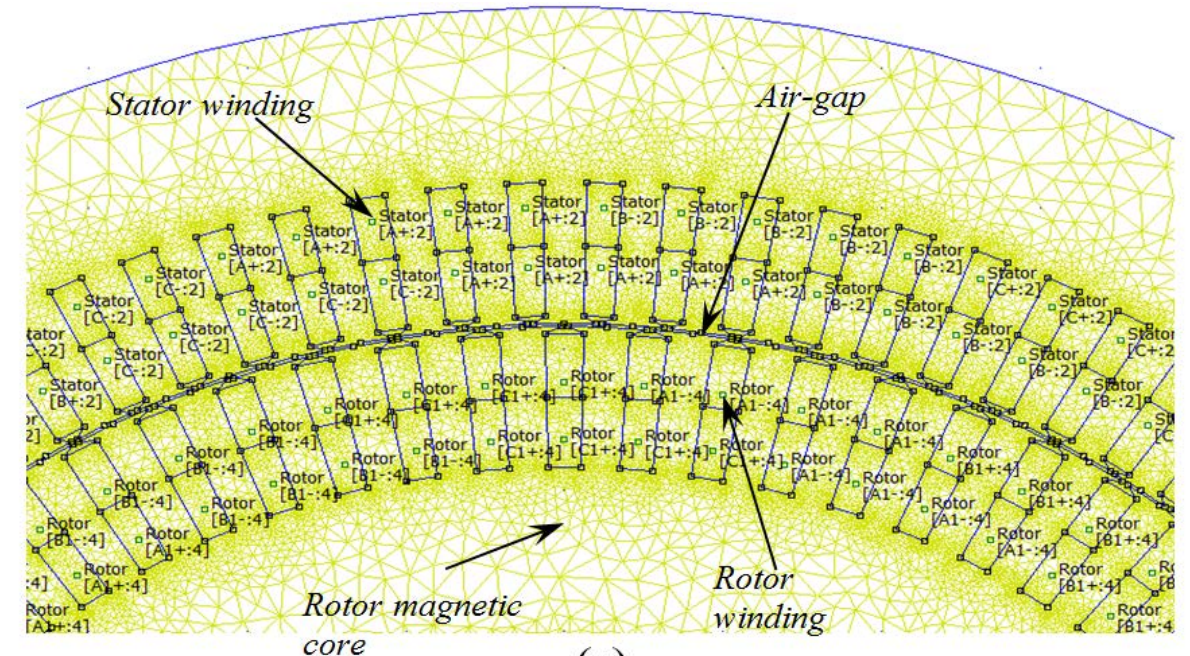

(a)

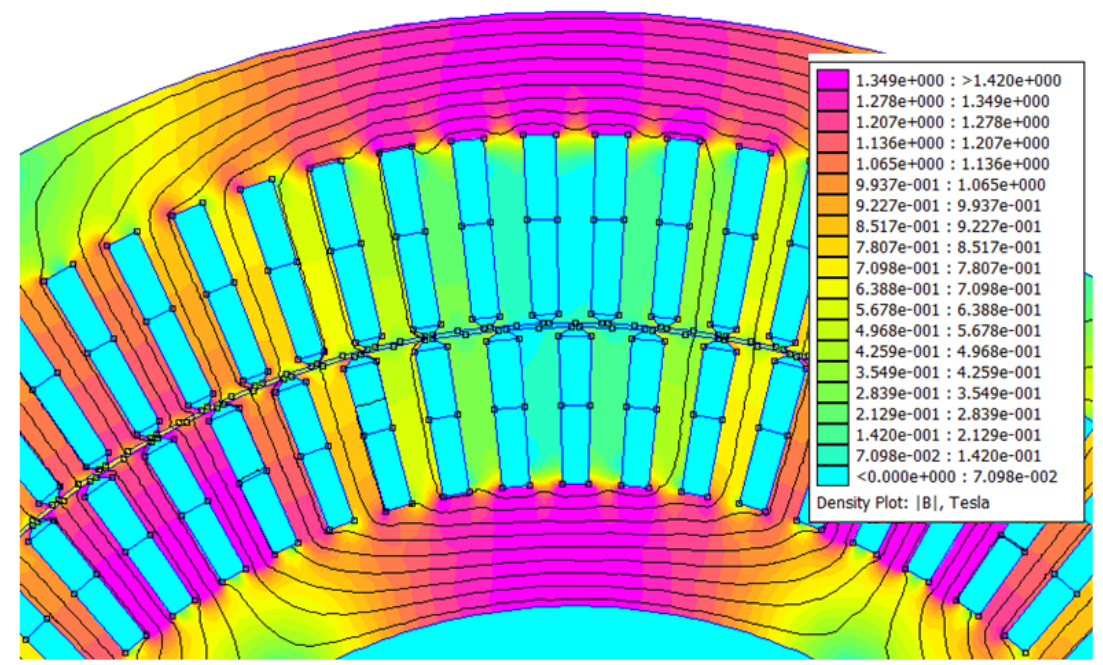

(b)

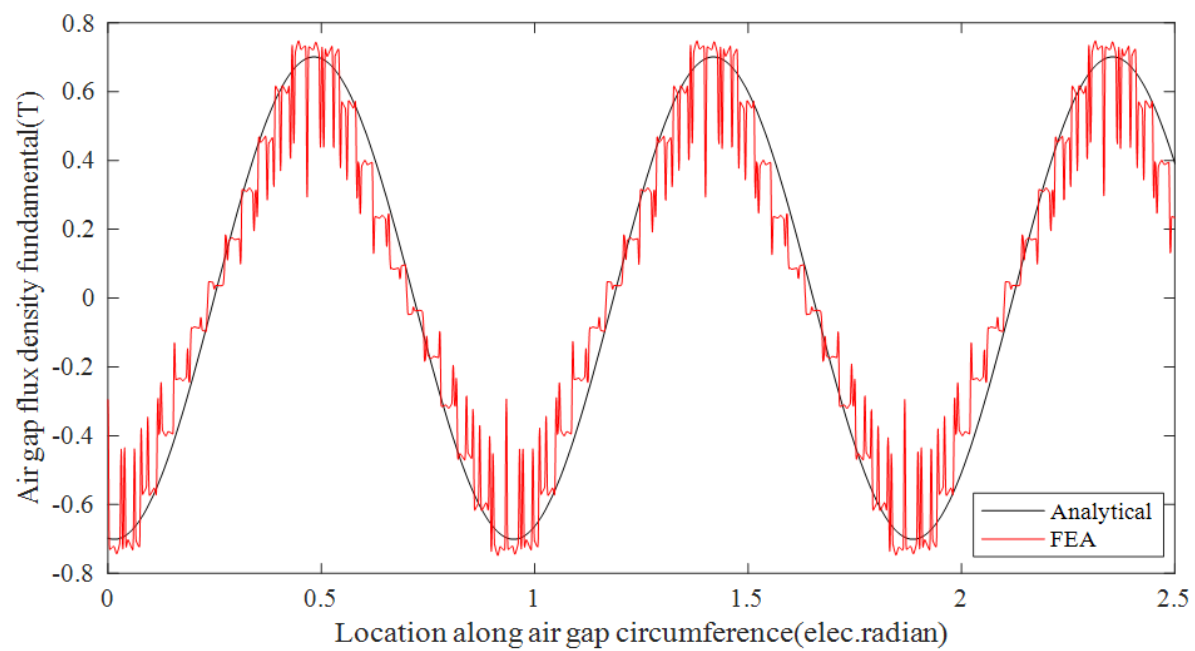

(c)

Figure 26. The 5-MW DFIG model using FEMM showing the finite-element mesh (a), the magnetic flux density contour (b), and a comparison of the air-gap flux density estimated using FEA and GeneratorSE (c) 


\subsection{GeneratorSE Mass Estimation: A Validation Exercise}

The masses estimated for PMSG for some conceptual designs, scaling law models, and existing commercial wind turbine generators [7], [14], [21], [25,35-43] are shown in Figure 27. In comparison, GeneratorSE provides two bands of weights that are possible with the type of support structure considered in the study that lie within the proximity of some of the commercial wind turbine designs rated below $4 \mathrm{MW}$. Note that the scaling law model proposed by [35] results in excessively massive designs beyond $4 \mathrm{MW}$, whereas the use of NREL's Cost and Scaling Model [7] presents designs that are substantially lighter beyond $4 \mathrm{MW}$. The mass estimates from GeneratorSE for the disc-type rotor design compare well against the estimates from the Upwind study reported in [25]. It is important to note that the maximum deflections in the air gap for all of the designs optimized by GeneratorSE were restricted to $10 \%$ of the air-gap diameter. A more stringent air-gap constraint is expected to increase the weight of the generator support structures. Validation of the model against turbines rated above $5 \mathrm{MW}$ was difficult because of the lack of data; hence estimates for some conceptual designs from previous studies and scaling law models are shown in [25, 35, 36] and [44-47]. Yet, a very large difference exists in the mass estimates, particularly at the 10-MW level. Note that although the results shown are for low-speed direct-drive designs, the approach for optimization and design are still valid for medium-speed and high-speed permanent-magnet synchronous machines. The torque specification for high-speed machines demands a smaller air-gap volume requirement. The main variables and constraints are consistent with the PMSG-DD design, but the output voltage requirement may be relaxed to $15 \mathrm{kV}$.

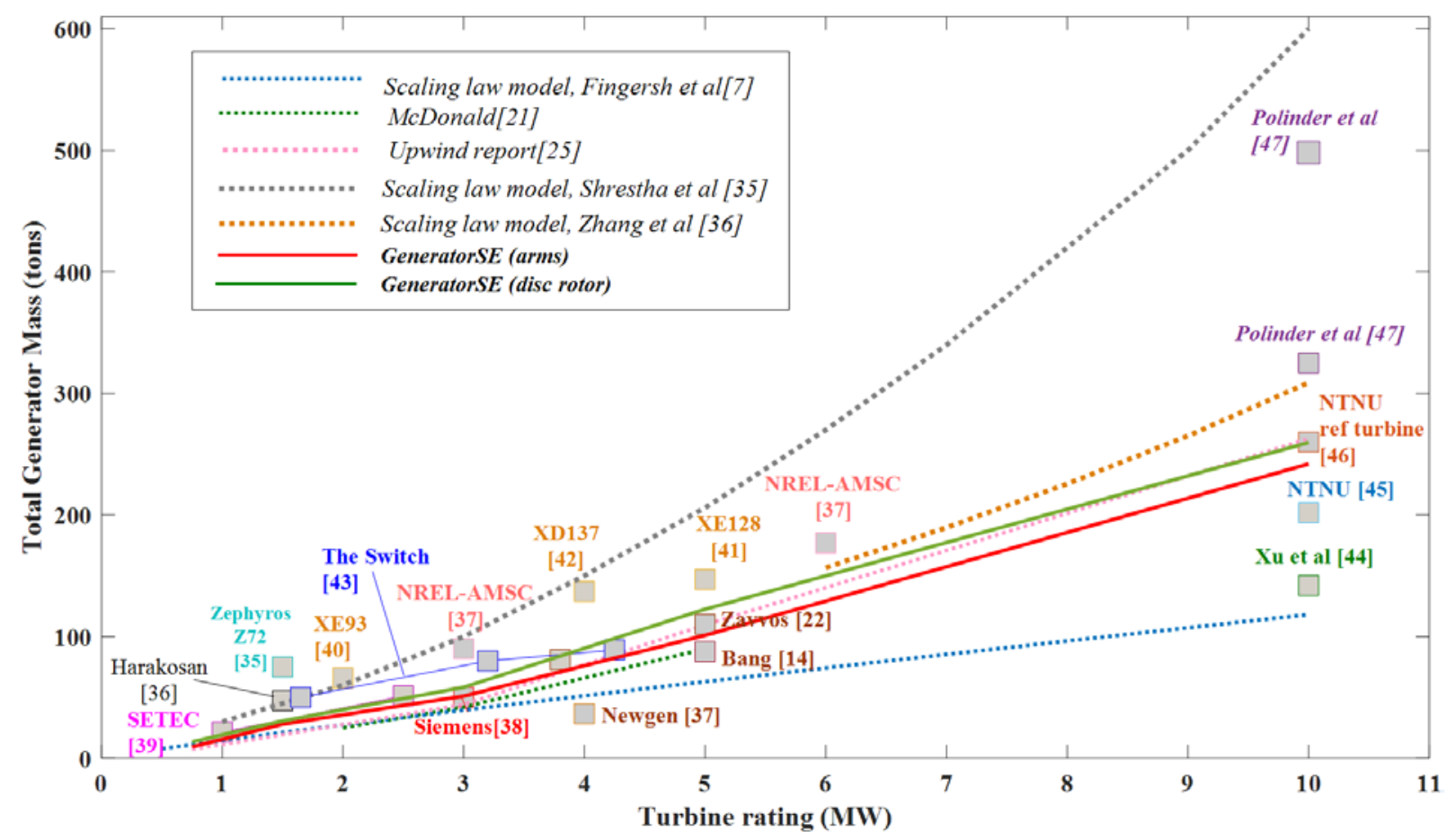

Figure 27. PMSG mass estimates for turbines rated between 0.75 and $10 \mathrm{MW}$; GeneratorSE vs. existing designs 
Figure 28 compares masses for EESG estimated by GeneratorSE to estimates from previous studies [25]. The masses estimated by [14] were based on the assumption of mass-to-torque ratio, $\mathrm{m} / \mathrm{T}=66.5 \mathrm{~kg} / \mathrm{kNm}$, based on an Enercon machine rated at 4.5 MW. It is evident that the scaling law model is no longer practical with excessively large masses predicted for turbines rated 5MW and above, thereby rendering such designs impractical. With fewer original equipment manufacturers, such as Enercon (Germany) and Emergya technologies, as proponents of this technology [48], data from commercial turbines have been scarce and only available for a few small turbine ratings [49-52].

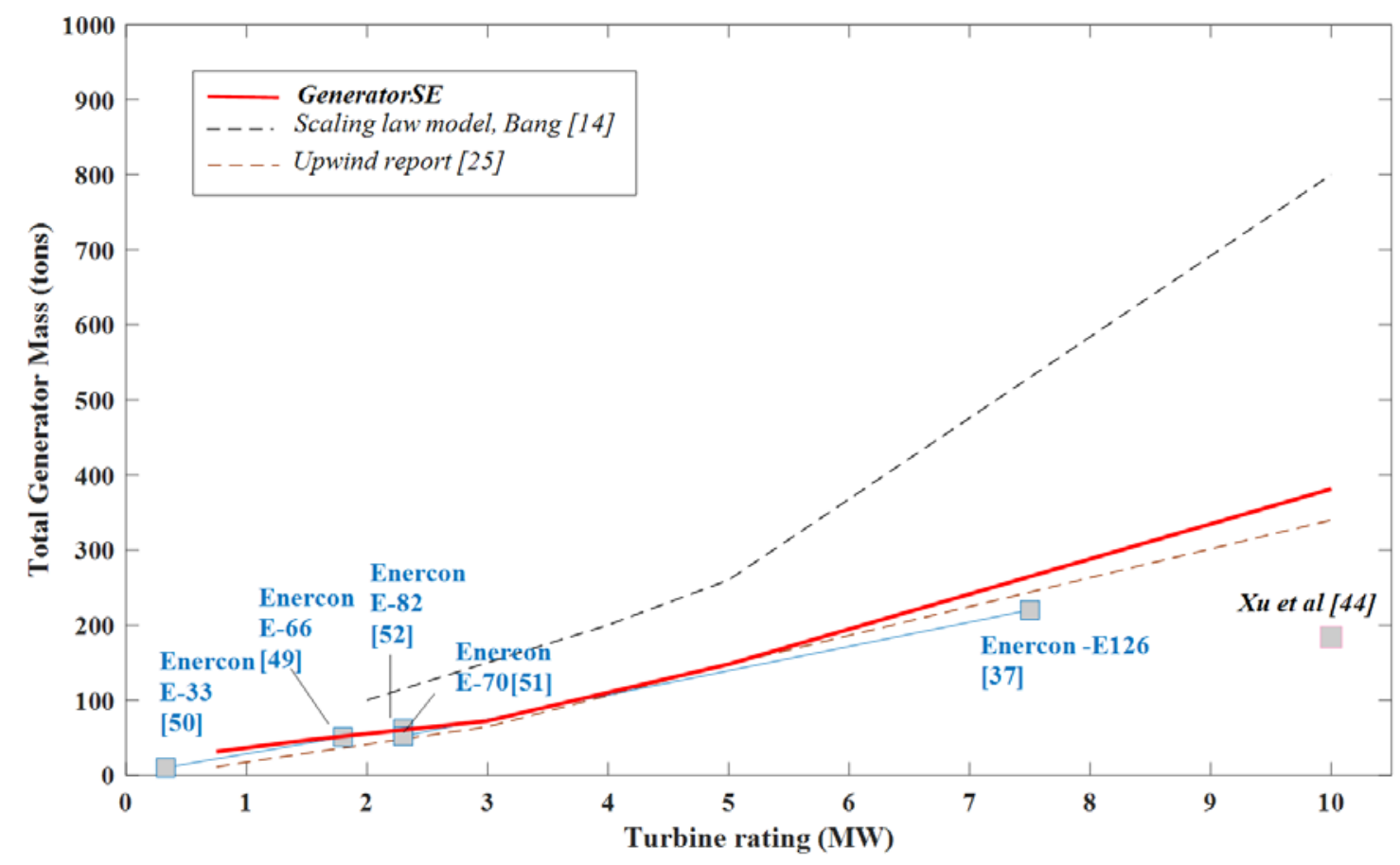

Figure 28. EESG mass estimates for turbines rated between 0.75 and $10 \mathrm{MW}$; GeneratorSE vs. existing designs

Figure 28 compares the weights estimated by GeneratorSE for SCIG against some commercial designs [53]. The scaling law model in [54] extrapolates from the motor data sheet at a similar rating and a Siemens 2.3-MW turbine. It is important to note that structural design has not been included in the optimization; the high-speed operation with a smaller air-gap diameter and tangential surface velocities less than 70 meters per second do not impose stringent requirements for structural design. However as a minimum, the machine mechanical strength is verified by its ability to withstand the tangential stress. The diameter of the machine was chosen in a way so that the stresses were not surpassed. Future work considering detailed designs for rotor and stator support structures( including casing and endplates to support bearings) and generator shaft will be modelled.

Figure 29 compares the weights estimated by GeneratorSE against the scaling law model and results from previous studies [7, 25] as well as few commercial wind turbine designs [53]. Note that the mass estimates for turbines rated above $5 \mathrm{MW}$ based on the scaling law model [7] are approximate with the validity in the range of $0.5-3 \mathrm{MW}$. 


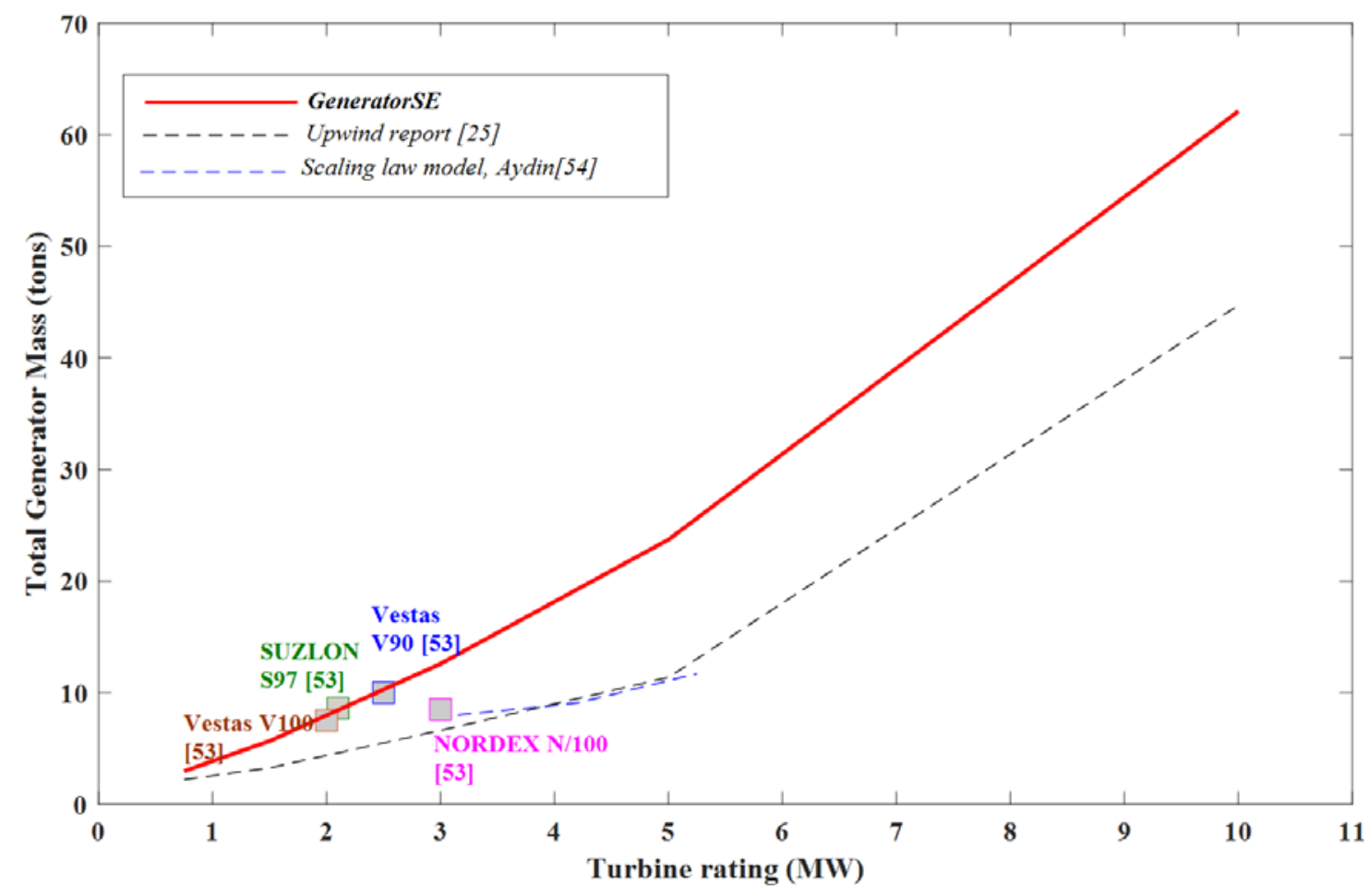

Figure 29. SCIG mass estimates for turbines rated between 0.75 and $10 \mathrm{MW}$; GeneratorSE vs. existing designs

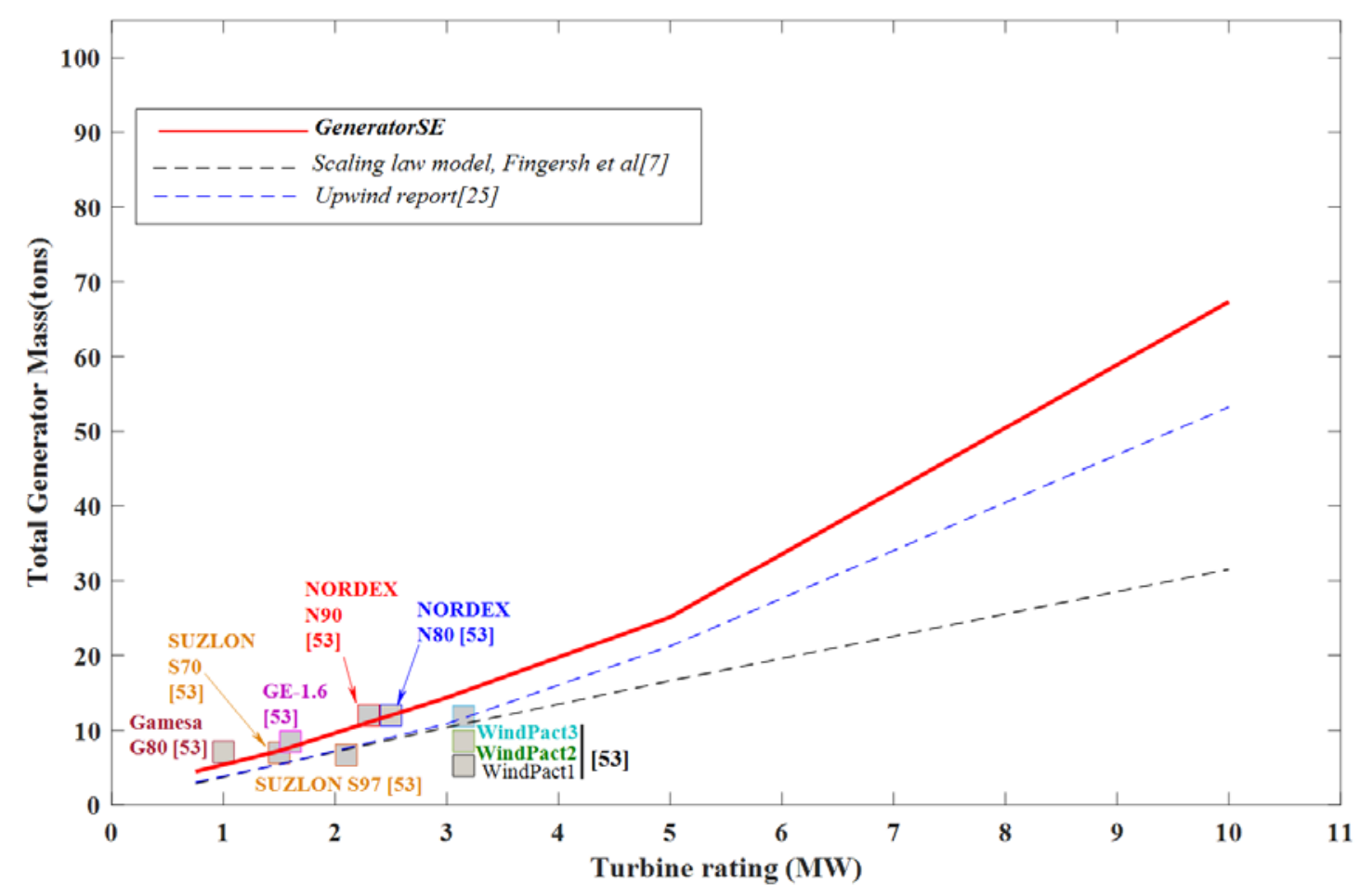

Figure 30. DFIG mass estimates for turbines rated between 0.75 and $10 \mathrm{MW}$; GeneratorSE vs. existing designs 


\section{Conclusions}

This report presented the analytical models used by the sizing tool GeneratorSE for the optimization of synchronous and asynchronous generators employed in variable-speed wind turbines. GeneratorSE provides the user with the opportunity to trade-off certain design dimensions both by a separate and simultaneous treatment of controverting objectives, such as economics, efficiency, and lightweight design. Preliminary design dimensions and performance parameters including estimated material costs to build four different generator types including direct-drive, low-speed synchronous generators and high-speed, gear-driven induction machines, are presented for five representative wind turbines rated between 0.75 and $10 \mathrm{MW}$. For the given torque and rated speed, the designs were optimized for the lowest costs while satisfying multiple requirements including output voltage and efficiency. The resulting estimates for masses were validated against estimates from previous studies and a few commercial designs.

The synchronous generator models are equipped to handle integrated structural and electromagnetic design optimization. Regarding the synchronous generators excited by permanent magnets, we presented analytical models for the radial flux topology with two support structure options. For structural optimization, the models for an electrically excited synchronous generator use an arm-type spider wheel arrangement. The structural stiffness was validated via static structural analysis in ANSYS. Detailed structural design is not part of the optimization for induction machines; however, the mechanical strength of the air-gap design was ensured by the machines' ability to withstand tangential stresses. An extension of the SCIG and DFIG modules to account for detailed structural design including generator shaft, stator casing and rotor support structures is under development [55]. Thermal design for all four generator types was accommodated by limiting the current densities to permissible limits and assuming an adequate cooling mechanism. However, the contribution of thermal design towards efficiency and impact on weight has not been studied. GeneratorSE provides information on various performance parameters including specific current loading, output frequency, and magnetic loading (peak flux densities) in various parts of the machine. The user has the opportunity to verify and validate the magnetic loading of optimized designs using a MATLAB interface to FEMM, an open-source finite-element suite of programs for solving low-frequency electromagnetic problems on twodimensional planar and axisymmetric domains.

The validation of mass estimates from GeneratorSE was helpful to identify and demonstrate the limitations of a few existing scaling law models. The advantage presented by GeneratorSE is the flexibility to examine the sensitivities to different specifications as well as newer and cheaper materials to build these machines, thus making it very relevant for studies investigating upscaling potentials. Also, the multiobjective optimization feature with the flexibility to model low, medium and high speed generators facilitates integration with DriveSE and NREL's Cost and Scaling Model allows users to conduct an integrated drivetrain design that is essential for system-wide cost optimization. The tool is useful to establish more realistic scaling laws for different generator models that are customized based on specific design requirements. 


\section{References}

1. K. Dykes, A. Ning, R. King, P. Graf, G. Scott, P. Veers, "Sensitivity Analysis of Wind Plant Performance to Key Turbine Design Parameters: A Systems Engineering Approach," (paper presented at AIAA, National Harbor, Maryland, January 13-17, 2014).

2. Cohen, J., Schweizer, T., Laxson, A., Butterfield, S., Schreck, S., Fingersh, L., Veers, P., Ashwill, T. 2008, Technology Improvement Opportunities for Low Wind Speed Turbines and Implications for Cost of Energy Reduction (Technical Report). NREL/TP-50041036, National Renewable Energy Laboratory, Golden, CO (US). http://www.nrel.gov/docs/fy08osti/41036.pdf.

3. "DriveSE and HubSE," accessed November 10, 2016, http://wisdem.github.io/DriveSE/.

4. D. Meeker, Finite Element Method Magnetics: Version 4.2-User's Manual, http://www.femm.info/wiki/Documentation/.

5. “Explore Engineering Simulation,” ANSYS, accessed May 2016, www.ansys.com.

6. “OpenMDAO,” accessed December 2016, http://openmdao.org/.

7. Fingersh, L., M. Hand, and A. Laxson. 2006. Wind Turbine Design Cost and Scaling Model (Technical Report). NREL/TP-500-40566, National Renewable Energy Laboratory, Golden, CO (US). http://www.nrel.gov/docs/fy07osti/40566.pdf.

8. NWTC Information Portal. 2015. "WISDEM." Last modified January 5. https://nwtc.nrel.gov/WISDEM.

9. Python programming language, accessed April 2017, https://www.python.org/

10. Bang, D., H. Polinder, G. Shrestha, J. A. Ferreira, "Review of Generator Systems for Direct-Drive Wind Turbines," (paper presented at European Wind Energy Conference, Brussels, Belgium, March 31-April 3, 2008).

11. I. Boldea, Electric Generators Handbook, Synchronous Generators (CRC Press, 2015).

12. A. Grauers, "Design of direct-driven permanent-magnet generators for wind turbines" (PhD diss, Chalmers Univ. Technol., Göteburg, Sweden, 1996).

13. H. Li, Z. Chen, and H. Polinder. 2006. Research report on models for numerical evaluation of variable speed different wind generator systems. UpWind deliverable No: D 1B2.b.2.

14. D. Bang. "Design of Transverse Flux Permanent Magnet Machines for Large DirectDrive Wind Turbines" (PhD diss, TU Delft, The Netherlands, 2010).

15. A. S. McDonald, M. A. Mueller. 2008. Development of Analytical Tools for Estimating Inactive Mass, University of Edinburgh, Scotland, UpWind report.

16. "Markets: Precious and Industrious Metals," Bloomberg Markets, accessed November 10, 2016, http://www.bloomberg.com/markets/commodities/futures/metals .

17. “Metal Pages,” An Argus Media Company, accessed November 10, 2016, https://www.metal-pages.com/. 
18. Imarc, "Neodymium-Iron-Boron Magnet Market - Industry Trends, Manufacturing Process, Plant Setup, Machinery, Raw Materials, Cost and Revenue," Imarc Group, 2016.

19. J. N. Stander, G. Venter, M. J. Kamper, "Review of direct-drive radial flux wind turbine generator mechanical design," Wind Energy 15 (2011): 459-472, doi:10.1002/we.484.

20. L. Sethuraman, Y. Xing, V. Venugopal, Z. Ghao, M. Mueller,T. Moan, “A 5MW directdrive generator for floating spar-buoy wind turbine: Drive-train dynamics," Proceedings of the Institution of Mechanical Engineers, Part C: Journal of Mechanical Engineering Science (2015), http://dx.doi.org/10.1177/0954406215623306.

21. A.S. McDonald, "Structural Analysis of Low Speed, High Torque Electrical Generators for Direct Drive Renewable Energy Converters" (PhD diss., University of Edinburgh, 2008).s

22. A. Zavvos, A. S. McDonald, M. A. Mueller, "Structural optimization tools for iron cored permanent magnet generators for large direct drive wind turbines" (PhD diss., University of Edinburgh, 2013).

23. A. S. McDonald, M. A. Mueller, and H. Polinder, "Structural mass in direct-drive permanent magnet electrical generators," IET Renewable Power Generation, 2 (2008), doi: 10.1049/iet-rpg:20070071.

24. J. Pyrhonen, T. Jokinen,V. Hrabovcova, "Design of Rotating Electrical Machines," J. Wiley (2009): 538. http://www.wiley.com/WileyCDA/WileyTitle/productCd0470740086.html.

25. H. Li, Z. Chen, H. Polinder, Research report on numerical evaluation of various variable speed wind generator systems, Upwind Deliverable No.: D 1B2.b.3, 2006.

26. "Electric motor winding calculator," EMETOR, accessed May 2016, https://www.emetor.com/edit/windings/.

27. H. Polinder, J. G. Slootweg. "Design optimization of a synchronous generator for a direct-drive wind turbine," (paper presented at the European Wind Energy Conference, Copenhagen, Denmark, July 2-6, 2001).

28. MorganAM\&T, "How to Select Carbon Brushes for Motors and Generators," accessed July 2016, http:/www.argointl.com/wp-content/uploads/2014/03/necpHow to Select_Brushes for_Motors_and_Generators2.pdf.

29. International Electrotechnical Commission, Standard IEC 136-Dimensions of brushes and brush holders for electrical machinery, Second Edition, 1986-06.

30. R. J. Zawoysky, K. C. Tornroos, GE Generator Rotor Design, Operational Issues, and Refurbishment Options, GE Power Systems. Accessed July 2016. https://powergen.gepower.com/content/dam/gepowerpgdp/global/en US/documents/technical/ger/ger-4212-ge-generator-rotor-designoperational-issues-refurb-options.pdf.

31. "Siemens Generators for Wind Turbines," accessed January 2017, https://www.industry.siemens.com/verticals/global/en/windturbine/Documents/generator.pdf 
32. I. Boldea, S. A. Nasar, The Induction Machine Handbook, (CRC Press, 2001) ISBN 9780849300042.

33. I. Boldea. Variable Speed Generators (The Electric Generators Handbook), (CRC Press, 2005), ISBN-13: 978-0849357152.

34. M. G. Simões, A. F. Farret, Modeling and Analysis with Induction Generators, (CRC Press, 2011) Third Edition.

35. G. Shrestha, H. Polinder, J. A. Ferreira, "Scaling Laws for Direct Drive Generators in Wind Turbines," (paper presented at the IEEE International Electric Machines and Drives Conference, Miami, Florida, May 3-6, 2009).

36. Z. Zhang, A. Chen, A. Matveev, R. Nilssen, A. Nysveen, "High-power Generators for Offshore Wind Turbines," Energy Procedia, 35 (2013): 52-61.

37. O. Keysan, "Superconducting Generators for Large Offshore Wind Turbines (PhD diss., University of Edinburgh, 2014).

38. H. Stiesdal. 2014. "Permanent Magnet Generators for Wind Turbines, Status and Outlook."

http://www.coilwindingexpo.com/berlin/\%20files/permanent_magnet_generators_for_wi nd turbines henrik_stiesdal.pdf

39. F. Fahrner. "The Wind-Turbine Concept behind Low-Cost and Advanced Technology for the Local Manufacturing in Tunisia."

https://tunesien.ahk.de/fileadmin/ahk tunesien/02 DE International/Energie Umwelt/ EEE2014/07 Herr Fritz Fahrner SETEC - The Wind-Turbine Concept behind LowCost and Advanced Technology for the Local Manufacturing.pdf.

40. DARWIND, Technical Data Sheet for XE93-2.0MW, http://www.xemcdarwind.com/media/02d2801f-cla0-49dd-9da2-2417b12667ac/826 37630/Downloads/Technical\%20datasheet/Datasheet\%20XE93-2.0MW.pdf?download $=$ true.

41. DARWIND, Technical Data Sheet for XE128-5.0MW, http://www.xemcdarwind.com/media/0c24eb85-e79f-4f56-adb2-88080164ce71/-202779 5193/Downloads/Technical\%20datasheet/Datasheet\%20XE128-5.0MW.pdf? download $=$ true

42. DARWIND, Technical Data Sheet for XD137-4.0MW, http://www.xemcdarwind.com/media/950e772a-a538-47b6-b373-70e32acac77d/139104 5275/Downloads/Technical\%20datasheet/Datasheet\%20XD137-4.0MW.pdf?download $=$ true

43. The Switch, Low-speed permanent magnet generators, PMG $1650-6300 \mathrm{~kW}$, data sheets, http://1r7x2o2d2jd315najr469ylc.wpengine.netdna-cdn.com/wpcontent/uploads/2013/10/Datasheet PMG1650-6300 EN final$5.0 \quad 12.11 .2016$ print.pdf.

44. Y. Xu, N. Maki, M. Izumi, "Performance Comparison of 10-MW Wind Turbine Generators With HTS, Copper, and PM Excitation," IEEE Transactions on Applied Superconductivity, 25, (2015): 6. http://ieeexplore.ieee.org/stamp/stamp.jsp?arnumber=7312921g127. 
45. H. E. Liseth and R. Nilssen, $10 \mathrm{MW}$ Reference Wind Turbine, Department of Electric Power Engineering, Norwegian University of Science and Technology, Trondheim, Norway, 2011.

46. E. B. Smith, "Design av nacelle fro en $10 \mathrm{MW}$ vindturbin," (MSc thesis, Norwegian University of Science and Technology, Trondheim, 2012).

47. H. Polinder, D. Bang, R. P. J. O. M. van Rooij, A. S. McDonald, M.A. Mueller, "10 MW Wind Turbine Direct-Drive Generator Design with Pitch or Active Speed Stall Control," (paper presented at IEEE International Electric Machines \& Drives Conference, Antalya, Turkey, May 3-5, 2007.

48. J. S. González and R. L. Arántegui, "Technological evolution of onshore wind turbinesa market-based analysis," Wind Energy 19 (2016): 2171-2187, doi: 10.1002/we.1974, 2016.

49. ENERCON, "E-66 data sheet," accessed May 2016, http://www.windtechnology.cz/stuff/Design.pdf.

50. Seren Energy, "Technical specification of Enercon E-33 Wind Turbine with 50m Hub Height," accessed July 2016, http://www.bing.com/search?q=Appendix $+\mathrm{A} \% 3 \mathrm{~A}+$ Technical + Specification + of + Enercon + E33 + Wind + Turbine + with $+50 \mathrm{~m}+\mathrm{Hub}+$ Height\&src $=$ IE$\underline{\text { SearchBox\&FORM }=\text { IENTTR\& conversationid }=\& \text { adlt }=\text { strict. }}$

51. ENERCON, "Confirmation for electrical performance of wind energy converter ENERCON E-70, configuration FT," accessed January 2017, http://www.gobiernodecanarias.org/industria/eolica/V LZ 045.pdf.

52. ENERCON, "Technical description; ENERCON Wind energy converter E-82 E4," accessed July 2016, http://awel.coop/wp-content/uploads/2015/11/06-01-10376616-2_E82-E4-2350_3000-kW_Technical-Description_eng.pdf.

53. Generator data, internal only, July 2016.

54. E. Aydin, "Determination of Best Drive Train Technology for Future Onshore Wind Turbines as a Function of the Output Power" (MS thesis, Eindhoven University of Technology, 2013).

55. C. R. Arthurs, L. Sethuraman, K. Dykes, L. Fingersh, Structural optimization of doubly fed induction generators using GeneratorSE, to be presented at the International Conference on Future Technologies for Wind Energy, October 24-26, 2017, Boulder, Colorado, USA. 


\section{Appendix A1}

Table A1. Constants and Parameters Used in Deflection Calculations for a Permanent-Magnet excited and Electrically Excited Synchronous Generator (Based on references [21,22])

\begin{tabular}{|c|c|}
\hline Spoked-Arm Structure & Disc-Arm Structure \\
\hline $\begin{array}{r}W_{r}=\frac{g \sin (\phi)}{n}(2 \rho l t \pi(R+0.5 t) \\
\left.+ \text { mass_ } P M^{2}\right)\end{array}$ & $W_{r}=0.5 \rho g \sin (\phi)\left(\left(l-t_{d}\right) h_{y r}\right)$ \\
\hline$w_{r}=\rho g \sin (\phi) a_{r} n_{r}, \phi=90^{\circ}$ & $w=\rho g \sin (\phi) t_{d}, \phi=90^{\circ}$ \\
\hline $\begin{array}{l}W_{i s}=0.5 \rho g \sin (\phi) l d^{2} \\
R_{s t}=r_{s}+h_{s}+0.5 h_{y s}\end{array}$ & $\begin{array}{l}W_{i s}=0.5 \rho g \sin (\phi) l d^{2} \\
R_{a}=R+0.5 h_{y r} ; R_{b}=R-0.5 h_{y r}\end{array}$ \\
\hline$w_{s}=g \sin (\phi) a_{s} \rho N_{s t}$ & $f=f_{d} \cdot t_{d}$ \\
\hline $\begin{array}{c}W_{i i s}=\frac{g \sin (\phi)}{N_{s t}}\left(\left(l h_{y s}\right) \pi\left(R_{s t}+0.5 h_{y s}\right) \rho\right. \\
\left.+M_{c u}+M_{\text {Fest }}\right)\end{array}$ & $=\frac{q R^{2}}{E\left(R_{a}-R\right)\left[\frac{R}{E\left(R^{2}-R_{o}^{2}\right)}\left[(1-v) R^{2}+(1+v) R_{o}^{2}\right]-t_{d}\left[\frac{1\left(C_{2} C_{a 2}-2 C_{3} C_{a 1}\right.}{4 D \lambda^{3} \cdot 2 C_{11}} F_{2}\left(x=\frac{l}{2}\right)-\frac{1\left(C_{3} C_{a 2}-C_{4} C_{a 1}\right)}{2 D \lambda^{3} \cdot 2 C_{11}} F_{1}\left(x=\frac{l}{2}\right)-\frac{1}{4 D \lambda^{3}} F_{a 4}\left(x=\frac{l}{2}\right)\right]\right]}$ \\
\hline$\theta=\frac{\pi}{n}$ & $M_{r b}=\frac{-w R_{b}^{2}}{C_{5}}\left[\frac{C_{6}}{2 R_{b} R_{o}}\left(R_{b}^{2}-R_{o}^{2}\right)-L_{14}\right]$ \\
\hline $\begin{array}{l}A_{r}=l t \\
A_{s}=l t_{s}\end{array}$ & $Q_{b}=\frac{w}{2 R_{o}}\left(R_{b}^{2}-R_{o}^{2}\right)$ \\
\hline$l_{i r}=R=r_{s}-g-h_{m}-0.5 t$ & $\lambda=\left(\frac{3\left(1-v^{2}\right)}{R_{a}^{2} h_{y r}^{2}}\right)^{1 / 4}$ \\
\hline $\begin{array}{c}l_{i i r}=R_{1}=R-0.5 h_{y r} \\
R_{1 s}=R_{s t}-0.5 h_{y s}\end{array}$ & $D_{r a}=\frac{E h_{y r}^{3}}{12\left(1-v^{2}\right)} \quad D_{a x}=\frac{E t_{d}^{3}}{12\left(1-v^{2}\right)}$ \\
\hline$l_{i s}, l_{i i s}, l_{i i i s}=R_{s t}-R_{o}$ & $\begin{array}{l}\text { Cylindrical shell functions } \\
F_{1}=\cosh (\lambda x) \cos (\lambda x) \\
F_{2}=\cosh (\lambda x) \sin (\lambda x)+\sinh (\lambda x) \cos (\lambda x) \\
F_{a 4}=\cosh (\lambda\langle x-a\rangle) \sin (\lambda\langle x-a\rangle)-\sinh (\lambda\langle x-a\rangle) \cos (\lambda\langle x- \\
a\rangle)\langle x-a\rangle=0 \text { if } x<a \\
\langle x-a\rangle=1 \text { if } x>a\end{array}$ \\
\hline$m_{r}=\frac{I_{r}}{\Delta D^{2}}$ & \multirow{7}{*}{ 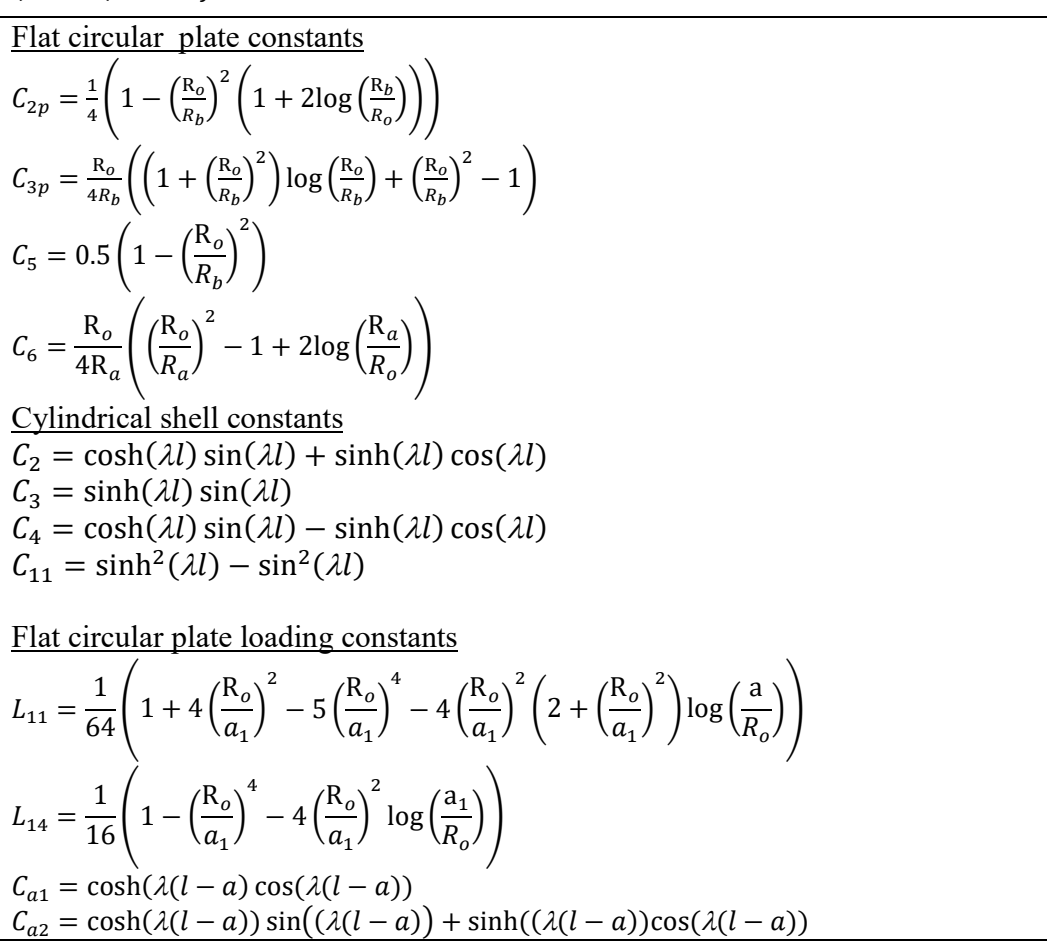 } \\
\hline$m_{s}=\frac{A_{r} R^{2}}{A_{s} R_{s t}^{2}}$ & \\
\hline$I_{r}=\frac{l t^{3}}{12}$ & \\
\hline$I_{s}=\frac{l t_{s}^{3}}{12}$ & \\
\hline $\begin{array}{c}\quad a=\left(b d-\left(b-2 t_{w}\right)\left(d-2 t_{w}\right)\right) \\
\text { With } a=a_{r}, b=b_{r}, d=d_{r} \text { and } t_{w}=t_{w r} \text { for rotor } \\
\text { and } a=a_{s}, b=b_{s t}, d=d_{s} \text { and } t_{w}=t_{w s} \text { for stator }\end{array}$ & \\
\hline$I_{\text {arm }, a x i}=\frac{\left(b d^{3}-\left(b-2 t_{w}\right)\left(d-2 t_{w}\right)^{3}\right.}{12}$ & \\
\hline$I_{\text {arm,tor }}=\frac{\left(d b^{3}-\left(d-2 t_{w}\right)\left(b-2 t_{w}\right)^{3}\right.}{12}$ & \\
\hline
\end{tabular}




\section{Appendix A2}

Table A2. Initial Values and Boundary Conditions Used for Generation of Spoked-Arm-Type Permanent Magnet Synchronous Generators

\begin{tabular}{|c|c|c|c|c|c|c|c|}
\hline $\begin{array}{c}\text { Turbine } \\
\text { Rating (MW) }\end{array}$ & $\mathbf{0 . 7 5}$ & $\mathbf{1 . 5}$ & $\mathbf{3}$ & $\mathbf{5}$ & $\mathbf{1 0}$ & $\begin{array}{l}\text { Lower } \\
\text { Limit }\end{array}$ & $\begin{array}{l}\text { Upper } \\
\text { Limit }\end{array}$ \\
\hline Variable & & & & & & & \\
\hline$r_{s}(\mathrm{~m})$ & 1.29 & 2 & 2.505 & 3.26 & 4.49 & 0.5 & 9 \\
\hline$I_{s}(\mathrm{~m})$ & 0.7 & 0.91 & 1.25 & 1.6 & 1.8 & 2.5 \\
\hline$h_{s}(\mathrm{~mm})$ & 45 & 55 & 52.5 & 70 & 80 & 40 & 100 \\
\hline$\tau_{p}(\mathrm{~mm})$ & 70 & 88 & 100 & 80 & 90 & 40 & 100 \\
\hline$h_{m}(\mathrm{~mm})$ & 7.2 & 31 & 14 & 9 & 7 & 5 & 100 \\
\hline$n_{s}$ & 5 & 5 & 5 & 5 & 5 & 5 & 5 \\
\hline$b_{s t}(\mathrm{~mm})$ & 220 & 340 & 450 & 480 & 650 & 100 & 1,500 \\
\hline$d_{s}(\mathrm{~mm})$ & 300 & 200 & 410 & 350 & 390 & 100 & 1,500 \\
\hline$t_{w s}(\mathrm{~mm})$ & 10 & 80 & 10 & 60 & 80 & 1 & 200 \\
\hline$n_{r}$ & 5 & 5 & 5 & 5 & 5 & 5 & 15 \\
\hline$b_{r}(\mathrm{~mm})$ & 190 & 345 & 450 & 530 & 650 & 100 & 1,500 \\
\hline$d_{r}(\mathrm{~mm})$ & 350 & 700 & 390 & 700 & 920 & 100 & 1,500 \\
\hline$t_{w r}(\mathrm{~mm})$ & 30 & 20 & 100 & 60 & 100 & 1 & 200 \\
\hline$h_{y r}(\mathrm{~mm})$ & 45 & 60 & 60 & 75 & 50 & 45 & 250 \\
\hline$h_{y s}(\mathrm{~mm})$ & 45 & 52 & 70 & 75 & 50 & 45 & 250 \\
\hline
\end{tabular}




\section{Appendix A3}

Table A3. Optimized Dimensions for spoked arm-Type Permanent Magnet Synchronous Generators

\begin{tabular}{|c|c|c|c|c|c|}
\hline $\begin{array}{l}\text { Turbine Rating (MW) } \\
\text { Variable }\end{array}$ & 0.75 & 1.5 & 3 & 5 & 10 \\
\hline \multicolumn{6}{|c|}{ Electromagnetic Design Dimensions } \\
\hline$r_{s}(\mathrm{~m})$ & 1.29 & 1.96 & 2.50 & 3.26 & 4.5 \\
\hline$I_{s}(\mathrm{~m})$ & 0.69 & 0.93 & 1.25 & 1.602 & 1.81 \\
\hline$h_{s}(\mathrm{~mm})$ & 44.91 & 58.32 & 60.28 & 59.69 & 60.35 \\
\hline$\tau_{p}(\mathrm{~mm})$ & 70.47 & 78.15 & 100 & 87.48 & 99.82 \\
\hline$N_{s}$ & 116 & 158 & 158 & 234 & 284 \\
\hline$S$ & 348 & 474 & 474 & 702 & 852 \\
\hline$P$ & 58 & 79 & 79 & 117 & 142 \\
\hline$h_{y s}(\mathrm{~mm})$ & 45.11 & 50.51 & 70.95 & 88.16 & 136.7 \\
\hline$h_{y r}(\mathrm{~mm})$ & 45.15 & 62.43 & 65.94 & 88.05 & 135.24 \\
\hline$b_{s}(\mathrm{~mm})$ & 10.48 & 11.73 & 14.95 & 13.14 & 14.94 \\
\hline$b_{t}(\mathrm{~mm})$ & 12.81 & 14.34 & 18.27 & 16.07 & 18.26 \\
\hline$b_{m}(\mathrm{~mm})$ & 49.33 & 54.7 & 70 & 61.24 & 69.87 \\
\hline$h_{m}(\mathrm{~mm})$ & 6.33 & 5.00 & 7.75 & 10.03 & 17.87 \\
\hline \multicolumn{6}{|c|}{ Structural Dimensions } \\
\hline$n_{s}$ & 5 & 5 & 5 & 5 & 5 \\
\hline$b_{s t}(\mathrm{~mm})$ & 219.28 & 337.28 & 446.6 & 482 & 649.8 \\
\hline$d_{s}(\mathrm{~mm})$ & 300.03 & 218.53 & 410.2 & 350.70 & 395.31 \\
\hline$t_{w s}(\mathrm{~mm})$ & 10.93 & 59.76 & 16.95 & 61.62 & 94.23 \\
\hline$n_{r}$ & 5 & 5 & 5 & 5 & 5 \\
\hline$b_{r}(\mathrm{~mm})$ & 190.13 & 341.21 & 446.6 & 529.6 & 649.8 \\
\hline$d_{r}(\mathrm{~mm})$ & 350.15 & 701.57 & 402.6 & 700.26 & 920.67 \\
\hline$t_{w r}(\mathrm{~mm})$ & 31.08 & 25.23 & 112.97 & 61.51 & 102.09 \\
\hline \multicolumn{6}{|c|}{ Performance Variables } \\
\hline$\hat{B}_{g}(\mathrm{~T})$ & 0.938 & 0.73 & 0.802 & 0.801 & 0.88 \\
\hline$\hat{\hat{B}}_{s y}(\mathrm{~T})$ & 0.57 & 0.44 & 0.44 & 0.31 & 0.252 \\
\hline$\hat{\hat{B}}_{r y}(\mathrm{~T})$ & 0.51 & 0.32 & 0.427 & 0.28 & 0.229 \\
\hline$\hat{\hat{B}}_{s t}(\mathrm{~T})$ & 1.70 & 1.33 & 1.46 & 1.45 & 1.61 \\
\hline $\begin{array}{l}\text { No-load Output Voltage } \\
(\mathrm{V})\end{array}$ & 500.02 & 753.07 & $1,092.25$ & $1,949.06$ & $3,383.03$ \\
\hline $\begin{array}{c}\text { Generator Phase Current } \\
\text { (A) }\end{array}$ & 560.24 & 729.72 & 996.96 & 876.52 & 996.06 \\
\hline$J_{s}\left(A / \mathrm{mm}^{2}\right)$ & 4.11 & 3.58 & 3.71 & 3.75 & 3.705 \\
\hline $\begin{array}{l}\text { Generator Output } \\
\text { Frequency }(\mathrm{Hz})\end{array}$ & 27.64 & 26.99 & 21.06 & 23.59 & 23.66 \\
\hline Efficiency $(\%)$ & 93.04 & 93.00 & 93.33 & 93.01 & 94.33 \\
\hline$A_{1}(k A / m)$ & 48.09 & 55.96 & 60 & 60 & 60 \\
\hline
\end{tabular}




\begin{tabular}{|c|c|c|c|c|c|}
\hline $\begin{array}{c}\text { Turbine Rating (MW) } \\
\text { Variable }\end{array}$ & $\mathbf{0 . 7 5}$ & $\mathbf{1 . 5}$ & $\mathbf{3}$ & $\mathbf{5}$ & $\mathbf{1 0}$ \\
\hline \multicolumn{6}{|c|}{ Optimized Variables } \\
\hline Iron Mass (ton) & 6.09 & 15.09 & 30.17 & 58.99 & 134.66 \\
\hline Magnet Mass (ton) & 0.22 & 0.34 & 0.91 & 1.89 & 5.28 \\
\hline Copper Mass (ton) & 0.83 & 2.13 & 3.74 & 5.7 & 9.04 \\
\hline Mass of Arms (ton) & 2.22 & 10.33 & 16.23 & 34.45 & 92.97 \\
\hline Total Mass (ton) & 9.37 & 27.92 & 51.06 & 101.05 & 241.97 \\
\hline $\begin{array}{c}\text { Total Material Cost } \\
(\$ 1.000)\end{array}$ & 29.69 & 56.93 & 130.07 & 257.61 & 667.59 \\
\hline
\end{tabular}




\section{Appendix A4}

Table A4. Initial Values and Boundary Conditions Used for Generation of Disc-Arm-Type Permanent Magnet Synchronous Generators

\begin{tabular}{|c|c|c|c|c|c|c|c|}
\hline $\begin{array}{c}\text { Turbine Rating } \\
\text { (MW) }\end{array}$ & $\mathbf{0 . 7 5}$ & $\mathbf{1 . 5}$ & $\mathbf{3}$ & $\mathbf{5}$ & $\mathbf{1 0}$ & $\begin{array}{c}\text { Lower } \\
\text { Limit } \\
\text { Variable }\end{array}$ & $\begin{array}{c}\text { Upper } \\
\text { Limit }\end{array}$ \\
\hline$r_{s}(\mathrm{~m})$ & 1.3 & 2 & 2.43 & 3.49 & 4.3 & 0.9 & 6. \\
\hline$l_{s}(\mathrm{~m})$ & 0.7 & 0.81 & 1.3 & 1.5 & 2.2 & 0.2 & 5 \\
\hline$h_{s}(\mathrm{~mm})$ & 40 & 40 & 45 & 60 & 60 & 30 & 70 \\
\hline$\tau_{p}(\mathrm{~mm})$ & 70 & 70 & 60 & 70 & 80 & 40 & 100 \\
\hline$h_{\text {yr }}(\mathrm{mm})$ & 45 & 45 & 50 & 55 & 65 & 45 & 250 \\
\hline$h_{y s}(\mathrm{~mm})$ & 45 & 50 & 80 & 85 & 108 & 45 & 250 \\
\hline$h_{m}(\mathrm{~mm})$ & 8 & 15 & 15 & 10.5 & 14 & 5 & 100 \\
\hline$n_{s}$ & 5 & 5 & 5 & 5 & 5 & 5 & 15 \\
\hline$b_{s t}(\mathrm{~mm})$ & 210 & 340 & 340 & 460 & 579 & 80 & 1,500 \\
\hline$d_{s}(\mathrm{~mm})$ & 170 & 200 & 220 & 350 & 410 & 100 & 1,500 \\
\hline$t_{w s}(\mathrm{~mm})$ & 30 & 50 & 100 & 150 & 190 & 1 & 200 \\
\hline$t_{d}(\mathrm{~mm})$ & 100 & 100 & 100 & 105 & 160 & 100 & 500 \\
\hline
\end{tabular}




\section{Appendix A5}

Table A5. Optimized Dimensions for Disc-Arm-Type Permanent Magnet Synchronous Generators

\begin{tabular}{|c|c|c|c|c|c|}
\hline $\begin{array}{l}\text { Turbine Rating (MW) } \\
\text { Variable }\end{array}$ & 0.75 & 1.5 & 3 & 5 & 10 \\
\hline \multicolumn{6}{|c|}{ Electromagnetic Design Dimensions } \\
\hline$r_{s}(\mathrm{~m})$ & 1.3 & 1.99 & 2.43 & 3.49 & 4.31 \\
\hline$I_{s}(\mathrm{~m})$ & 0.69 & 0.81 & 1.29 & 1.51 & 2.2 \\
\hline$h_{s}(\mathrm{~mm})$ & 44.5 & 62.84 & 59.98 & 60.3 & 53.49 \\
\hline$\tau_{p}(\mathrm{~mm})$ & 70.58 & 69.91 & 64.57 & 75.41 & 83.74 \\
\hline$N_{s}$ & 116 & 180 & 236 & 292 & 324 \\
\hline$S$ & 348 & 540 & 708 & 876 & 972 \\
\hline$p$ & 58 & 90 & 118 & 146 & 162 \\
\hline$\overline{h_{y r}(\mathrm{~mm})}$ & 47.4 & 45 & 50.57 & 54.5 & 66.25 \\
\hline$h_{y s}(\mathrm{~mm})$ & 50.86 & 47.7 & 78.98 & 84.24 & 109.24 \\
\hline$b_{s}(\mathrm{~mm})$ & 10.57 & 10.46 & 9.72 & 11.28 & 12.5 \\
\hline$b_{t}(\mathrm{~mm})$ & 12.91 & 12.78 & 11.88 & 13.78 & 15.33 \\
\hline$b_{m}(\mathrm{~mm})$ & 49.4 & 48.94 & 45.2 & 52.79 & 58.62 \\
\hline$h_{m}(\mathrm{~mm})$ & 6.20 & 5.32 & 7.82 & 9.01 & 13.89 \\
\hline \multicolumn{6}{|c|}{ Structural Dimensions } \\
\hline$n_{s}$ & 5 & 5 & 5 & 5 & 5 \\
\hline$b_{s t}(\mathrm{~mm})$ & 209.34 & 337.65 & 348.36 & 463.8 & 579.7 \\
\hline$d_{s}(\mathrm{~mm})$ & 171.17 & 205.02 & 224.8 & 350.32 & 450.06 \\
\hline$t_{w s}(\mathrm{~mm})$ & 33.67 & 59.17 & 100.27 & 147.2 & 189.51 \\
\hline$t_{d}(\mathrm{~mm})$ & 100.0 & 100.0 & 100.0 & 100.00 & 158.46 \\
\hline \multicolumn{6}{|c|}{ Performance Variables } \\
\hline$\widehat{B}_{g}(\mathrm{~T})$ & 0.93 & 0.748 & 0.81 & 0.74 & 0.81 \\
\hline$\hat{\hat{B}}_{s y}(\mathrm{~T})$ & 0.50 & 0.43 & 0.26 & 0.26 & 0.24 \\
\hline$\hat{B}_{r y}(\mathrm{~T})$ & 0.48 & 0.41 & 0.364 & 0.36 & 0.36 \\
\hline$\hat{B}_{s t}(\mathrm{~T})$ & 1.69 & 1.36 & 1.47 & 1.35 & 1.48 \\
\hline $\mathrm{L} / \mathrm{D}$ & 0.27 & 0.20 & 0.26 & 0.21 & 0.25 \\
\hline $\mathrm{h}_{\mathrm{s}} / \mathrm{b}_{\mathrm{s}}$ & 4.21 & 6.0 & 6.17 & 5.35 & 4.26 \\
\hline$J_{s}\left(\mathrm{~A} / \mathrm{mm}^{2}\right)$ & 4.12 & 3.54 & 3.73 & 3.7 & 4.23 \\
\hline$A_{l}(\mathrm{kA} / \mathrm{m})$ & 47.70 & 59.99 & 60.0 & 59.99 & 60 \\
\hline $\begin{array}{c}\text { Generator Output Voltage } \\
\text { (V) }\end{array}$ & 500 & 779.5 & $1,576.0$ & $2,248.7$ & $4,008.15$ \\
\hline $\begin{array}{c}\text { Generator Phase Current } \\
\text { (A) }\end{array}$ & 560.3 & 697.43 & 648.0 & 751.8 & 836.29 \\
\hline $\begin{array}{l}\text { Generator Output } \\
\text { Frequency }(\mathrm{Hz})\end{array}$ & 27.6 & 30.75 & 31.47 & 29.44 & 27 \\
\hline Efficiency (\%) & 93.03 & 93.19 & 93.01 & 93.0 & 93.0 \\
\hline \multicolumn{6}{|c|}{ Optimized Parameters } \\
\hline Iron Mass (ton) & 6.57 & 11.86 & 27.69 & 48.7 & 102.2 \\
\hline
\end{tabular}




\begin{tabular}{|c|c|c|c|c|c|}
\hline $\begin{array}{c}\text { Turbine Rating (MW) } \\
\text { Variable }\end{array}$ & $\mathbf{0 . 7 5}$ & $\mathbf{1 . 5}$ & $\mathbf{3}$ & $\mathbf{5}$ & $\mathbf{1 0}$ \\
\hline Magnet Mass (ton) & 0.22 & 0.33 & 0.88 & 1.7 & 4.62 \\
\hline Copper Mass (ton) & 0.82 & 2.06 & 3.40 & 5.72 & 8.67 \\
\hline Disc and arm Mass (ton) & 5.82 & 16.37 & 26.32 & 66.45 & 144.13 \\
\hline $\begin{array}{c}\text { Total Mass (ton) } \\
\begin{array}{c}\text { Total Material Cost } \\
(\$ 1,000)\end{array}\end{array}$ & 13.44 & 30.63 & 58.3 & 122.56 & 259.63 \\
\hline
\end{tabular}




\section{Appendix A6}

Table A6. Initial Values and Boundary Conditions Used for Generation of the Designs for Electrically Excited Synchronous Generators

\begin{tabular}{|c|c|c|c|c|c|c|c|}
\hline $\begin{array}{c}\text { Turbine Rating } \\
(\mathbf{M W})\end{array}$ & $\mathbf{0 . 7 5}$ & $\mathbf{1 . 5}$ & $\mathbf{3}$ & $\mathbf{5}$ & $\mathbf{1 0}$ & $\begin{array}{c}\text { Lower } \\
\text { Limit } \\
\begin{array}{c}\text { Design } \\
\text { Variable }\end{array}\end{array}$ & $\begin{array}{c}\text { Upper } \\
\text { Limit }\end{array}$ \\
\hline$r_{s}(\mathrm{~m})$ & 1.5 & 2.1 & 2.55 & 3.2 & 4.65 & 0.5 & 9 \\
\hline$I_{s}(\mathrm{~m})$ & 0.7 & 1 & 1 & 1.4 & 2 & 0.5 & 2.5 \\
\hline$h_{s}(\mathrm{~mm})$ & 80 & 130 & 60 & 60 & 125 & 60 & 150 \\
\hline$\tau_{p}(\mathrm{~mm})$ & 100 & 110 & 140 & 170 & 180 & 40 & 200 \\
\hline$N_{f}$ & 250 & 117 & 82 & 100 & 110 & 10 & 300 \\
\hline$I_{f}(A)$ & 15 & 30 & 59 & 69 & 78 & 1 & 500 \\
\hline$h_{y s}(\mathrm{~mm})$ & 10 & 45 & 82 & 130 & 155 & 10 & 250 \\
\hline$h_{y r}(\mathrm{~mm})$ & 10 & 45 & 72 & 120 & 150 & 10 & 250 \\
\hline$n_{s}$ & 5 & 5 & 5 & 5 & 5 & 5 & 15 \\
\hline$b_{s t}(\mathrm{~mm})$ & 170 & 310 & 325 & 470 & 630 & 100 & 1,500 \\
\hline$d_{s}(\mathrm{~mm})$ & 360 & 190 & 250 & 400 & 490 & 100 & 1,500 \\
\hline$t_{w s}(\mathrm{~mm})$ & 50 & 100 & 100 & 70 & 200 & 1 & 200 \\
\hline$n_{r}$ & 5 & 5 & 5 & 5 & 5 & 5 & 15 \\
\hline$b_{r}(\mathrm{~mm})$ & 200 & 330 & 380 & 480 & 630 & 100 & 1,500 \\
\hline$d_{r}(\mathrm{~mm})$ & 420 & 310 & 340 & 510 & 940 & 100 & 1,500 \\
\hline$t_{w r}(\mathrm{~mm})$ & 50 & 100 & 100 & 140 & 200 & 1 & 200 \\
\hline & & & & & & & \\
\hline
\end{tabular}




\section{Appendix A7}

Table A7. Optimized Designs for Electrically Excited Synchronous Generators

\begin{tabular}{|c|c|c|c|c|c|}
\hline $\begin{array}{l}\text { Turbine Rating } \\
\text { Variable }\end{array}$ & 0.75 & 1.5 & 3 & 5 & 10 \\
\hline$r_{s}(\mathrm{~m})$ & 1.63 & 2.23 & 2.59 & 3.408 & 4.65 \\
\hline$I_{s}(\mathrm{~m})$ & 0.779 & 1.02 & 1.13 & 1.52 & 2 \\
\hline$h_{s}(\mathrm{~mm})$ & 61.5 & 67 & 88.6 & 60.68 & 71.96 \\
\hline$\tau_{p}(\mathrm{~mm})$ & 160.18 & 158.3 & 132.32 & 200 & 182.3 \\
\hline$h_{y s}(m m)$ & 103.8 & 49.02 & 90.89 & 139.3 & 153.15 \\
\hline$h_{y r}(\mathrm{~mm})$ & 47.34 & 53.4 & 82.32 & 131.36 & 153.19 \\
\hline$N_{f}$ & 250 & 117 & 82 & 100 & 105 \\
\hline$I_{f}(\mathrm{~A})$ & 15 & 29.9 & 58.9 & 68.95 & 78 \\
\hline \multicolumn{6}{|c|}{ Electromagnetic Design Dimensions } \\
\hline$p$ & 32 & 44 & 61 & 54 & 80 \\
\hline$S$ & 384 & 528 & 732 & 648 & 960 \\
\hline$N_{s}$ & 128 & 176 & 244 & 216 & 320 \\
\hline$b_{t}(\mathrm{~mm})$ & 14.67 & 14.62 & 12.22 & 18.17 & 16.76 \\
\hline$b_{s}(\mathrm{~mm})$ & 12 & 11.97 & 10.0 & 14.87 & 13.72 \\
\hline$h_{p c}(\mathrm{~mm})$ & 96.11 & 94.98 & 79.39 & 120 & 108.43 \\
\hline$b_{p c}(\mathrm{~mm})$ & 64.07 & 63.32 & 52.92 & 80 & 72.95 \\
\hline$h_{p}(\mathrm{~mm})$ & 112.13 & 110.8 & 92.62 & 140 & 127.67 \\
\hline$b_{p}(\mathrm{~mm})$ & 112.13 & 110.8 & 92.62 & 140 & 127.67 \\
\hline \multicolumn{6}{|c|}{ Structural Design Dimensions } \\
\hline$n_{s}$ & 5 & 5 & 5 & 5 & 5 \\
\hline$b_{s t}(\mathrm{~mm})$ & 196.18 & 317.13 & 354.54 & 537.7 & 626.7 \\
\hline$d_{s}(\mathrm{~mm})$ & 386.49 & 213.44 & 262.27 & 442.25 & 492.07 \\
\hline$t_{w s}(\mathrm{~mm})$ & 77.98 & 96.29 & 102.7 & 42.02 & 195.8 \\
\hline$n_{r}$ & 5 & 5 & 5 & 5 & 5 \\
\hline$b_{r}(\mathrm{~mm})$ & 200.98 & 337.8 & 406.7 & 520.75 & 630.06 \\
\hline$d_{r}(\mathrm{~mm})$ & 440.51 & 336.6 & 349.9 & 615.32 & 946.97 \\
\hline$t_{w r}(\mathrm{~mm})$ & 82.59 & 105.3 & 106.9 & 87.62 & 199.91 \\
\hline \multicolumn{6}{|c|}{ Performance Variables } \\
\hline $\mathrm{L} / \mathrm{D}$ & 0.238 & 0.23 & 0.216 & 0.22 & 0.215 \\
\hline $\mathrm{h}_{\mathrm{s}} / \mathrm{b}_{\mathrm{s}}$ & 5.12 & 5.64 & 8.61 & 4.08 & 5.24 \\
\hline$\hat{B}_{g}(\mathrm{~T})$ & 0.751 & 0.703 & 0.84 & 1.02 & 0.928 \\
\hline$\hat{\hat{B}}_{s y}(\mathrm{~T})$ & 0.37 & 0.72 & 0.44 & 0.468 & 0.358 \\
\hline$\hat{\hat{B}}_{r y}(\mathrm{~T})$ & 0.97 & 0.8 & 0.61 & 0.606 & 0.46 \\
\hline$\hat{\hat{B}}_{s t}(\mathrm{~T})$ & 1.28 & 1.203 & 1.64 & 1.75 & 1.58 \\
\hline$\hat{\hat{B}}_{p c}(\mathrm{~T})$ & 1.44 & 1.35 & 1.91 & 1.99 & 1.94 \\
\hline$J_{s}\left(\mathrm{~A} / \mathrm{mm}^{2}\right)$ & 2.34 & 2.57 & 2.49 & 3.21 & 2.88 \\
\hline$J_{f}\left(\mathrm{~A} / \mathrm{mm}^{2}\right)$ & 1.32 & 1.19 & 2.31 & 1.49 & 2.04 \\
\hline
\end{tabular}




\begin{tabular}{|c|c|c|c|c|c|}
\hline $\begin{array}{c}\text { Turbine Rating } \\
\text { (MW) }\end{array}$ & $\mathbf{0 . 7 5}$ & $\mathbf{1 . 5}$ & $\mathbf{3}$ & $\mathbf{5}$ & $\mathbf{1 0}$ \\
\hline $\begin{array}{c}\text { Variable } \\
A_{l}(\mathrm{kA} / \mathrm{m})\end{array}$ & 38.76 & 46.93 & 59.32 & 52.44 & 56.51 \\
\hline$E_{p}(\mathrm{~V})$ & 499.99 & 831.71 & $1,559.05$ & $1,990.6$ & $3,979.4$ \\
\hline$I_{s}(\mathrm{~A})$ & 517.21 & 624.08 & 659.45 & 866.6 & 861.56 \\
\hline$f(\mathrm{~Hz})$ & 15.25 & 15.03 & 16.26 & 10.89 & 13.33 \\
\hline Efficiency $(\%)$ & 93.01 & 93.00 & 93.04 & 93.0 & 93.00 \\
\hline Mass of Iron (tons) & 14.89 & 20.98 & 37.29 & 91.22 & 179.97 \\
\hline Copper Mass (tons) & 4.69 & 8.43 & 10.44 & 20.85 & 36.46 \\
\hline Mass of Arms (tons) & 11.9 & 17.2 & 24.66 & 35.8 & 165.05 \\
\hline $\begin{array}{c}\text { Total Mass (tons) } \\
\text { Total Material Cost } \\
(\$ 1,000)\end{array}$ & 31.49 & 46.62 & 72.4 & 147.8 & 381.46 \\
\hline & 36.71 & 60.67 & 83.07 & 168.5 & 357.19 \\
\hline
\end{tabular}




\section{Appendix A8}

Table A8. Initial Values and Boundary Conditions Used for Generation of the Designs for SquirrelCage Induction Generators

\begin{tabular}{|c|c|c|c|c|c|c|c|}
\hline $\begin{array}{c}\text { Turbine Rating } \\
\text { (MW) }\end{array}$ & $\mathbf{0 . 7 5}$ & $\mathbf{1 . 5}$ & $\mathbf{3}$ & $\mathbf{5}$ & $\mathbf{1 0}$ & $\begin{array}{c}\text { Lower } \\
\text { Limit }\end{array}$ & $\begin{array}{c}\text { Upper } \\
\text { Limit }\end{array}$ \\
\hline$r_{s}(\mathrm{~m})$ & 0.3 & 0.5 & 0.41 & 0.55 & 0.6 & 0.2 & 1 \\
\hline$I_{s}(\mathrm{~m})$ & 0.51 & 0.5 & 1.09 & 1.3 & 1.8 & 0.25 & 2 \\
\hline$h_{s}(\mathrm{~mm})$ & 40 & 100 & 70 & 90 & 100 & 40 & 100 \\
\hline$h_{r}(\mathrm{~mm})$ & 50 & 50 & 50 & 50 & 50 & 40 & 100 \\
\hline$\hat{B}_{s y}(T)$ & 1.3 & 1.5 & 1.5 & 1.4 & 1.3 & 1 & 2 \\
\hline$l_{o}(\mathrm{~A})$ & 80 & 80 & 120 & 140 & 160 & 5 & 200 \\
\hline
\end{tabular}




\section{Appendix A9}

Table A9. Optimized Designs for Squirrel-Cage Induction Generators

\begin{tabular}{|c|c|c|c|c|c|}
\hline $\begin{array}{l}\text { Turbine Rating } \\
\text { Variable }\end{array}$ & 0.75 & 1.5 & 3 & 5 & 10 \\
\hline \multicolumn{6}{|c|}{ Design Variables } \\
\hline$r_{s}(\mathrm{~m})$ & 0.32 & 0.37 & 0.39 & 0.48 & 0.58 \\
\hline$l_{s}(\mathrm{~m})$ & 0.42 & 0.628 & 1.18 & 1.274 & 1.74 \\
\hline$h_{s}(\mathrm{~mm})$ & 40 & 73.26 & 82.09 & 98.33 & 100 \\
\hline$h_{r}(\mathrm{~mm})$ & 40 & 40 & 40 & 40 & 40 \\
\hline$\hat{\hat{B}}_{s y}(\mathrm{~T})$ & 1.35 & 1.49 & 1.99 & 1.86 & 1.480 \\
\hline$I_{0}(A)$ & 79.99 & 80 & 119.98 & 139.9 & 159.99 \\
\hline \multicolumn{6}{|c|}{ Magnetic Circuit } \\
\hline$S$ & 108 & 108 & 108 & 108 & 108 \\
\hline$N_{s}$ & 36 & 36 & 36 & 36 & 36 \\
\hline$R$ & 72 & 72 & 72 & 72 & 72 \\
\hline$N_{\text {bars }}$ & 72 & 72 & 72 & 72 & 72 \\
\hline$b_{s}(\mathrm{~mm})$ & 8.6 & 9.8 & 10.31 & 12.68 & 15.22 \\
\hline$b_{t}(\mathrm{~mm})$ & 10.51 & 11.98 & 12.60 & 15.5 & 18.61 \\
\hline$p$ & 3 & 3 & 3 & 3 & 3 \\
\hline$\tau_{p}(\mathrm{~mm})$ & 344.19 & 392.09 & 412.5 & 507.56 & 609.0 \\
\hline$h_{y r}=h_{y s}(\mathrm{~mm})$ & 77.24 & 64.61 & 61.3 & 80.43 & 111.13 \\
\hline$b_{r}(\mathrm{~mm})$ & 12.86 & 14.64 & 15.4 & 18.94 & 22.73 \\
\hline$b_{t r}(\mathrm{~mm})$ & 15.72 & 17.9 & 18.81 & 23.16 & 27.78 \\
\hline Krad & 0.64 & 0.84 & 1.49 & 1.31 & 1.497 \\
\hline$D_{\text {out }} / D_{s}$ & 1.37 & 1.38 & 1.37 & 1.38 & 1.37 \\
\hline$h_{s} / b_{s}$ & 4.64 & 7.47 & 7.96 & 7.74 & 6.56 \\
\hline$h_{r} / b_{r}$ & 3.11 & 2.73 & 2.59 & 2.11 & 1.759 \\
\hline \multicolumn{6}{|c|}{ Performance Variables } \\
\hline$\hat{\hat{B}}_{g 0}(\mathrm{~T})$ & 0.957 & 0.77 & 0.93 & 0.926 & 0.848 \\
\hline$\hat{\hat{B}}_{g 1}(\mathrm{~T})$ & 0.887 & 0.72 & 0.87 & 0.866 & 0.794 \\
\hline$\hat{\hat{B}}_{r y}(\mathrm{~T})$ & 1.357 & 1.49 & 1.99 & 1.86 & 1.48 \\
\hline$\widehat{B}_{s t}(\mathrm{~T})$ & 1.74 & 1.406 & 1.69 & 1.68 & 1.54 \\
\hline$\hat{B}_{r t}(\mathrm{~T})$ & 1.98 & 1.57 & 1.89 & 1.83 & 1.65 \\
\hline$J_{s}\left(\mathrm{~A} / \mathrm{mm}^{2}\right)$ & 3.23 & 1.83 & 1.75 & 1.57 & 1.70 \\
\hline$J_{r}\left(\mathrm{~A} / \mathrm{mm}^{2}\right)$ & 0.405 & 0.453 & 0.468 & 0.52 & 0.58 \\
\hline$A_{1}(\mathrm{kA} / \mathrm{m})$ & 20.4 & 22.58 & 24.42 & 26.45 & 29.07 \\
\hline
\end{tabular}




\begin{tabular}{|c|c|c|c|c|c|}
\hline $\begin{array}{l}\text { Turbine Rating } \\
\text { (MW) }\end{array}$ & 0.75 & 1.5 & 3 & 5 & 10 \\
\hline$S_{N}$ & -0.002 & -0.002 & -0.002 & -0.002 & -0.002 \\
\hline $\begin{array}{c}\text { Generator Output } \\
\text { Voltage }(\mathrm{V})\end{array}$ & 716.86 & 985.28 & $2,368.8$ & $3,114.78$ & $4,684.2$ \\
\hline Stator Current (A) & 195.05 & 245.99 & 279.76 & 373.0 & 491.89 \\
\hline $\begin{array}{c}\text { Output Frequency } \\
(\mathrm{Hz})\end{array}$ & 60 & 60 & 60 & 60 & 60 \\
\hline $\begin{array}{c}\text { Generator } \\
\text { Efficiency }(\%) \\
\end{array}$ & 98.54 & 98.69 & 98.41 & 98.49 & 98.72 \\
\hline $\begin{array}{l}\text { Overall drivetrain } \\
\text { Efficiency (\%) }\end{array}$ & 94.10 & 94.25 & 93.98 & 94.06 & 94.27 \\
\hline Iron Mass (tons) & 1.33 & 2.3 & 4.55 & 7.61 & 15.55 \\
\hline Cu Mass (tons) & 0.19 & 0.397 & 0.72 & 1.06 & 1.69 \\
\hline $\begin{array}{l}\text { Structural Mass } \\
\text { (tons) }\end{array}$ & 1.44 & 2.98 & 7.32 & 15.05 & 44.87 \\
\hline Total Mass (tons) & 2.97 & 5.67 & 12.59 & 23.72 & 62.11 \\
\hline $\begin{array}{c}\text { Total Material Cost } \\
(\$ 1,000)\end{array}$ & 2.37 & 4.67 & 9.65 & 16.86 & 39.27 \\
\hline
\end{tabular}




\section{Appendix A10}

Table A10. Initial Values and Boundary Conditions Used for Generation of the Designs for DoublyFed Induction Generators

\begin{tabular}{|c|c|c|c|c|c|c|c|}
\hline $\begin{array}{c}\text { Turbine Rating } \\
\text { (MW) }\end{array}$ & $\mathbf{0 . 7 5}$ & $\mathbf{1 . 5}$ & $\mathbf{3}$ & $\mathbf{5}$ & $\mathbf{1 0}$ & $\begin{array}{c}\text { Lower } \\
\text { Limit }\end{array}$ & $\begin{array}{c}\text { Upper } \\
\text { Limit }\end{array}$ \\
\hline$r_{s}(\mathrm{~m})$ & 0.3 & 0.43 & 0.55 & 0.61 & 0.8 & 0.2 & 1 \\
\hline$I_{s}(\mathrm{~m})$ & 0.5 & 0.65 & 0.58 & 0.49 & 0.66 & 0.4 & 2 \\
\hline$h_{s}(\mathrm{~mm})$ & 100 & 75 & 100 & 80 & 100 & 45 & 100 \\
\hline$h_{r}(\mathrm{~mm})$ & 100 & 85 & 100 & 100 & 100 & 45 & 100 \\
\hline$\hat{B}_{s y}(T)$ & 1.3 & 1.3 & 1.6 & 1.3 & 1.5 & 1 & 2 \\
\hline$I_{0}(\mathrm{~A})$ & 22 & 25 & 33 & 40 & 60 & 5 & 100 \\
\hline$S_{N \max }$ & -0.15 & -0.2 & -0.2 & -0.2 & -0.2 & -0.3 & -0.1 \\
\hline
\end{tabular}




\section{Appendix A11}

Table A11. Optimized Designs for Doubly-Fed Induction Generators

\begin{tabular}{|c|c|c|c|c|c|}
\hline $\begin{array}{l}\text { Turbine Rating } \\
\text { Variable }\end{array}$ & 0.75 & 1.5 & 3 & 5 & 10 \\
\hline \multicolumn{6}{|c|}{ Design Variables } \\
\hline$r_{s}(\mathrm{~m})$ & 0.373 & 0.375 & 0.54 & 0.49 & 0.67 \\
\hline$I_{s}(\mathrm{~m})$ & 0.41 & 0.61 & 0.565 & 1.06 & 1.002 \\
\hline$h_{s}(\mathrm{~mm})$ & 69.15 & 62.85 & 100 & 100 & 100 \\
\hline$h_{r}(\mathrm{~mm})$ & 79.2 & 99.85 & 100 & 99.87 & 94.29 \\
\hline$\tau_{p}(\mathrm{~mm})$ & 390.71 & 394.87 & 569.05 & 516.44 & 708.35 \\
\hline$\hat{\hat{B}}_{s y}(\mathrm{~T})$ & 1.31 & 1.31 & 1.60 & 1.59 & 1.33 \\
\hline$S_{\text {Nmax }}$ & -0.3 & -0.268 & -0.256 & -0.3 & -0.3 \\
\hline$I_{0}(A)$ & 21.93 & 25 & 33 & 40 & 60 \\
\hline \multicolumn{6}{|c|}{ Magnetic Circuit } \\
\hline$S$ & 90 & 90 & 90 & 90 & 90 \\
\hline$N_{s}$ & 30 & 30 & 30 & 30 & 30 \\
\hline$Q_{R}$ & 72 & 72 & 72 & 72 & 72 \\
\hline$N_{r}$ & 98 & 110 & 115 & 98 & 98 \\
\hline$b_{s}(\mathrm{~mm})$ & 11.72 & 11.84 & 17.07 & 15.49 & 21.25 \\
\hline$b_{t}(\mathrm{~mm})$ & 14.32 & 14.47 & 20.86 & 18.93 & 25.97 \\
\hline$p$ & 3 & 3 & 3 & 3 & 3 \\
\hline$h_{y r}=h_{y s}(\mathrm{~mm})$ & 68.92 & 71.6 & 93.99 & 75.55 & 149.104 \\
\hline$b_{r}(\mathrm{~mm})$ & 14.6 & 14.74 & 21.26 & 19.28 & 26.45 \\
\hline$b_{t r}(\mathrm{~mm})$ & 17.85 & 18.02 & 25.99 & 23.56 & 32.33 \\
\hline$K_{\text {rad }}$ & 0.55 & 0.815 & 0.52 & 1.076 & 0.74 \\
\hline$D_{\text {out }} / D_{s}$ & 1.38 & 1.369 & 1.36 & 1.37 & 1.37 \\
\hline$h_{s} / b_{s}$ & 5.9 & 5.3 & 5.85 & 6.45 & 4.70 \\
\hline$h_{r} / b_{r}$ & 5.42 & 6.76 & 4.70 & 5.17 & 3.56 \\
\hline \multicolumn{6}{|c|}{ Performance Variables } \\
\hline$\hat{\hat{B}}_{g 0}(\mathrm{~T})$ & 0.72 & 0.75 & 0.83 & 0.73 & 0.88 \\
\hline$\hat{\hat{B}}_{g 1}(\mathrm{~T})$ & 0.66 & 0.69 & 0.767 & 0.682 & 0.816 \\
\hline$\hat{B}_{r y}(\mathrm{~T})$ & 1.31 & 1.32 & 1.60 & 1.59 & 1.33 \\
\hline$\widehat{B}_{s t}(\mathrm{~T})$ & 1.32 & 1.36 & 1.51 & 1.33 & 1.60 \\
\hline$\widehat{B}_{r t}(\mathrm{~T})$ & 1.67 & 1.86 & 1.86 & 1.67 & 1.86 \\
\hline$J_{s}\left(\mathrm{~A} / \mathrm{mm}^{2}\right)$ & 2.60 & 3.73 & 2.17 & 2.55 & 2.41 \\
\hline$J_{r}\left(\mathrm{~A} / \mathrm{mm}^{2}\right)$ & 5.26 & 6 & 5.99 & 5.99 & 6 \\
\hline
\end{tabular}




\begin{tabular}{|c|c|c|c|c|c|}
\hline $\begin{array}{l}\text { Turbine Rating } \\
\text { (MW) }\end{array}$ & 0.75 & 1.5 & 3 & 5 & 10 \\
\hline$A_{1}(\mathrm{kA} / \mathrm{m})$ & 30.05 & 38.9 & 37.25 & 43.62 & 41.29 \\
\hline$I_{m a g} / I_{s}$ & 0.146 & 0.145 & 0.147 & 0.138 & 0.16 \\
\hline $\begin{array}{c}\text { Generator Output } \\
\text { Voltage }(\mathrm{V})\end{array}$ & 500.00 & 782.52 & $1,145.15$ & $1,734.26$ & $2,685.9$ \\
\hline Stator Current (A) & 391.41 & 512.14 & 706.73 & 750.95 & 975.07 \\
\hline $\begin{array}{c}\text { Output Frequency } \\
(\mathrm{Hz})\end{array}$ & 60 & 60 & 60 & 60 & 60 \\
\hline $\begin{array}{c}\text { Generator } \\
\text { Efficiency }(\%)\end{array}$ & 97.93 & 98.18 & 98.32 & 98.33 & 98.58 \\
\hline $\begin{array}{l}\text { Overall drivetrain } \\
\text { Efficiency (\%) }\end{array}$ & 93.53 & 93.76 & 93.9 & 93.91 & 94.14 \\
\hline Iron Mass (tons) & 1.61 & 2.43 & 4.42 & 6.59 & 13.32 \\
\hline Cu Mass (tons) & 0.28 & 0.51 & 0.71 & 1.09 & 1.28 \\
\hline $\begin{array}{l}\text { Structural Mass } \\
\text { (tons) }\end{array}$ & 2.59 & 4.29 & 9.25 & 17.46 & 52.74 \\
\hline Total Mass (tons) & 4.49 & 7.24 & 14.39 & 25.15 & 67.34 \\
\hline $\begin{array}{c}\text { Total Material Cost } \\
(\$ 1,000)\end{array}$ & 3.57 & 5.96 & 10.52 & 17.67 & 39.98 \\
\hline
\end{tabular}

